LUCIANO OGIBOSKI

EXTENSÃO DE CICLO DE VIDA DE UMA SUBESTAÇÃO ISOLADA A GÁS SF $_{6}$ POR MEIO DE UM SISTEMA DE MONITORAMENTO DE TEMPO REAL 
LUCIANO OGIBOSKI

\section{EXTENSÃO DE CICLO DE VIDA DE UMA SUBESTAÇÃO ISOLADA A GÁS SF 6 POR MEIO DE UM SISTEMA DE MONITORAMENTO DE TEMPO REAL}

Tese apresentada à Escola Politécnica da Universidade de São Paulo para obtenção do título de Doutor em Ciências.

Área de concentração: Sistemas de Potência

Orientador:

Prof. Dr. José Antonio Jardini

São Paulo

2013 
Este exemplar foi revisado e corrigido em relação à versão original, sob responsabilidade única do autor e com a anuência de seu orientador.

São Paulo, 18 de março de 2013.

Assinatura do autor

Assinatura do orientador

FICHA CATALOGRÁFICA

Ogiboski, Luciano

Extensão de ciclo de vida de uma subestação isolada a gás SF6 por meio de um sistema de monitoramento de tempo real $I$

L. Ogiboski. -- São Paulo, 2013.

$88 \mathrm{p}$.

Tese (Doutorado) - Escola Politécnica da Universidade de São Paulo. Departamento de Engenharia de Energia e Automação Elétricas.

1. Distribuição de energia elétrica 2. Subestações elétricas I. Universidade de São Paulo. Escola Politécnica. Departamento de Engenharia de Energia e Automação Elétricas II. t. 
DEDICATÓRIA

Aos que foram companheiros verdadeiros nos caminhos da vida 


\section{AGRADECIMENTOS}

Meu agradecimento principal é ao meu orientador, prof. José Antonio Jardini pela oportunidade de realizar um dos grandes sonhos e objetivos de minha vida. Os meus agradecimentos a ele vão além, pois aprendi muitos dos meus valores observando a sua conduta pessoal e profissional. Sem dúvida alguma é uma pessoa por quem tenho uma admiração muito grande.

Meu segundo agradecimento não poderia ser para outra pessoa senão o prof. Luiz Carlos Magrini, que participou ativamente deste trabalho. Porém a minha gratidão vai muito além da sua contribuição ao trabalho, sou grato pelos ensinamentos ao longo de todos os anos que trabalhamos juntos. Acredito que parte considerável do meu crescimento profissional e acadêmico se deve a ele. Os seus valores e o seu comprometimento com o trabalho não são apenas exemplos a seguir ou merecedores de respeito, já foram incorporados a minha formação pessoal.

Aos meus pais Nilson e Adelia, que sempre me indicaram os bons caminhos e me deram suporte para ser quem eu sou. Obrigado pelo constante incentivo e orgulho.

Ao meu irmão Nilson, que sempre esteve ao meu lado e sempre me apoiou com todo o seu empenho. Pra mim é um exemplo de pessoa e merece gratidão dobrada. Sua seriedade é admirável ao mesmo tempo em que seu senso de humor é contagiante.

Ao meu irmão mais novo Vitor. Que sempre foi companheiro e que muitas vezes lutou pelo meu bem estar. Espero continuar sempre sendo referência, como ele mesmo comentou. Agradeço também ao restante da família, meu querido sobrinho Lucas e minha cunhada Carol.

Ao meu companheiro mais próximo, Nestor, que apesar de não ser humano sempre trouxe uma alegria sem tamanho. 
Ao meu grande amigo de toda a vida, Antonio Carlos Leal, que sempre foi leal em sua amizade e sempre foi amigo de verdade, seja para dar força nas dificuldades ou pra tomar cerveja nas conquistas. Minha profunda gratidão, meu amigo. Incluo neste agradecimento a sua esposa, Luciana Detoni, que sempre foi amiga na mesma proporção.

À Alex Lopes, sem dúvida o meu amigo "paulistano" mais antigo. Agradeço a convivência pelos longos anos, desde que cheguei a São Paulo.

Aos queridos colegas de trabalho, e amigos, Ferdinando Crispino, Paula Kayano, Thales Sousa, Gerson Sakay, Patricia Albertini, Patricia Silveira, Elizandra Bernardes, Mauricio Jardini, Ronaldo Casolari, Mario Masuda, Fabiana Toledo Silva, Sidnei Nicoli, Ricardo Leon, Diogo Alves e Milana dos Santos. Sou muito grato pela convivência diária muito agradável.

Agradeço á Eletropaulo, que financiou o projeto de pesquisa. Em especial a Carlos Ossamu, Anderson Cunha e José de Souza Dias.

À José Guilherme de Itaipu, que colaborou muito partilhando a sua experiência e conhecimento do tema desta pesquisa.

À Aneel que, por meio do seu programa de pesquisa e desenvolvimento, permitiu que o projeto de pesquisa que resultou nesta tese pudesse ser desenvolvido.

À todos os demais, que colaboraram de forma direta ou indireta, mas que não puderam ser citados nominalmente.

Finalmente, agradeço a todas as pessoas que amo e que me amam, pois também colaboraram e fizeram parte desta etapa de minha vida. 
EPÍGRAFE

"Torna-te aquilo que és"

Friedrich Nietzsche 


\section{RESUMO}

Subestações blindadas são utilizadas por empresas de energia há mais de 50 anos. Muitas destas subestações estão em operação até os dias de hoje, sem qualquer modificação em seu projeto original, e ainda assim continuam operando sem apresentar problemas ou indícios de fadiga. Isto pode ser atribuído a sua qualidade construtiva em conjunto com o material isolante utilizado por este tipo de equipamento, o Hexafluoreto de Enxofre $\left(\mathrm{SF}_{6}\right)$. Este gás possui todas as características desejáveis para manter adequadas as propriedades dielétricas da subestação, além de ser inerte e extremamente estável. O tempo de vida nominal de uma subestação blindada pode ser de 30 a 50 anos, dependendo de suas características ou recomendação do fabricante. A proximidade, ou até a ultrapassagem, do final do tempo de vida gera preocupação às empresas detentoras destes equipamentos antigos no que diz respeito a operação da subestação com segurança. Outro aspecto importante está relacionado a vazamentos de gás na atmosfera, pois o $\mathrm{SF}_{6}$ está entre os elementos mais danosos para o efeito estufa. Por estas razões este trabalho apresenta o desenvolvimento de um sistema para monitoramento de vazamentos e também de parâmetros indicativos do gás $\mathrm{SF}_{6}$ em uma subestação blindada antiga. O objetivo principal foi de desenvolver um sistema com dados históricos para se realizar estudos a respeito do comportamento do gás. A subestação utilizada neste trabalho não possuía nenhum sistema de monitoramento online. Assim, foi desenvolvido um sistema de tempo real para coletar dados de densidade do gás e de ponto de orvalho nos compartimentos da subestação. $O$ sistema de coleta de dados foi instalado em três bays de uma subestação. Foram instalados sensores para medir estas duas grandezas, e também, módulos de aquisição de dados de baixo custo que se comunicam por meio de protocolos padrão e abertos. A partir do sistema instalado, no longo prazo, se espera a redução de vazamentos de gás com a possibilidade de inspeções online. Pode ser atribuído como resultado do trabalho a redução de custos, pois os dados históricos com indicativos favoráveis permitem estender o tempo entre manutenções preventivas. Como resultado complementar deste trabalho, o monitoramento de perdas de gás se torna mais eficiente e rápido, colaborando, assim com as expectativas ambientais atuais.

Palavras-chave: Sistemas de Potência. Monitoramento de Subestação. Subestação Isolada a Gás. $\mathrm{SF}_{6}$. 


\begin{abstract}
Gas Insulated Substations (GIS) are used by energy companies for over 50 years. Many early substations have been in operation until the present day, without any modification in its original design, and still are operating without problems or indications of fatigue. This can be attributed to its constructive quality along with the insulating material used for this type of equipment, the gas sulfur hexafluoride $\left(\mathrm{SF}_{6}\right)$. This gas has all the desirable features for maintaining the dielectric of the substation as well as being inert and extremely stable. The nominal lifetime of a GIS substation can be 30 to 50 years, depending on their characteristics or manufacturer's recommendation. The proximity, or even exceeding, the lifetime generates concern to companies holding these old equipment as regards the operation of the substation safely. Another important aspect is related to gas leakages into the atmosphere because $\mathrm{SF}_{6}$ is among the most damaging elements to the greenhouse effect. Therefore, this work presents the development of a system for monitoring leakage and also indicative parameters of $\mathrm{SF}_{6}$ gas at an old GIS. The main objective was to develop a system with historical data to conduct studies about the behavior of the gas. The substation used for this work had no online monitoring system. Thus, it was developed a real-time system for collecting data of gas density and dew point in the compartments of the substation. The data collection system was installed in three bays of the substation. Sensors were installed to measure these two quantities, and also low cost data acquisition modules which communicate via standard and open protocols. In long term, with the system, there should be a reduction of gas leakages with the possibility of online inspections of the gas. May be assigned as a result the reduction of costs, since the historical data with good indicative allows extending the time for preventative maintenance. As additional result of this work, it is expected that the monitoring of leakage become more efficient and faster, thus contributing to the current environmental expectations.
\end{abstract}

Keywords: Power Systems. Substation Monitoring. Gas Insulated Substation. $\mathrm{SF}_{6}$. 


\section{LISTA DE ILUSTRAÇÕES}

Figura 1: Molécula de SF6 24

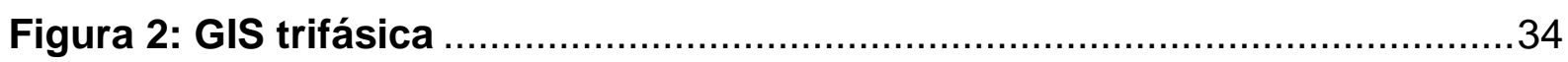

Figura 3: Subestação Paula Souza (AES Eletropaulo) ............................... 40

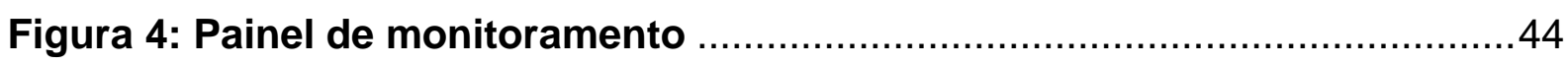

Figura 5: Arquitetura completa do sistema de monitoramento ......................52

Figura 6: Arquitetura do sistema de monitoramento (instalado) .....................53

Figura 7: Arquitetura de aquisição de dados..........................................55

Figura 8: Sensores instalados (barra 2) ................................................ 57

Figura 9: Sensores instalados (ponto central do bay) ..............................58

Figura 10: Sensores instalados (disjuntor) ......................................... 58

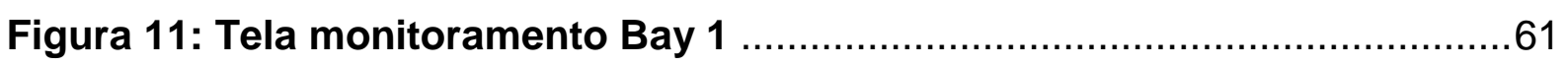

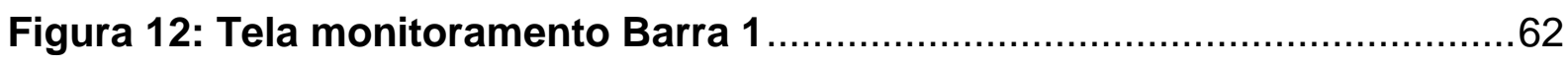

Figura 13: Tela monitoramento de vazamentos ..................................... 63

Figura 14: Tela para criação de gráficos Bay 1 .......................................64

Figura 15: Tela para gráficos de massa (vazamentos) ..............................65

Figura 16: Dados de ponto de orvalho Barra 2 (média horária) ......................68

Figura 17: Dados de ponto de orvalho Barra 2 (desvio padrão) ......................68

Figura 18: Dados de ponto de orvalho Bay 1 - Sensor 1 (média horária)...........69

Figura 19: Dados de ponto de orvalho Bay 1 - Sensor 1 (desvio padrão) ..........69

Figura 20: Dados de ponto de orvalho bay 2 - sensor 1 (média horária)..........70

Figura 21: Dados de ponto de orvalho bay 2 - sensor 1 (desvio padrão) ..........70

Figura 22: Dados de ponto de orvalho bay 3 - sensor 1 (média horária)..........71

Figura 23: Dados de ponto de orvalho bay 3 - sensor 1 (desvio padrão).........71

Figura 24: Dados de ponto de orvalho barra 2 (média de 24h) ......................72

Figura 25: Dados de ponto de orvalho barra 2 (desvio padrão) ......................73

Figura 26: Dados de densidade barra 1 (média horária) .................................75

Figura 27: Dados de densidade barra 1 (desvio padrão) ..............................75

Figura 28: Dados de densidade bay 1 - sensor 2 (média horária)...................76

Figura 29: Dados de densidade bay 1 - sensor 2 (desvio padrão) ....................76

Figura 30: Dados de densidade bay 2 - sensor 2 (média horária)...................77 
Figura 31: Dados de densidade bay 2 - sensor 2 (desvio padrão) .77

Figura 32: Dados de densidade bay 3 - sensor 2 (média horária).......................78

Figura 33: Dados de densidade bay 3 - sensor 2 (desvio padrão) ……..............78

Figura 34: Dados de densidade barra 2 (média de 24h) …….......................... 79

Figura 35: Dados de densidade barra 2 (desvio padrão) ….............................. 80 


\section{LISTA DE ABREVIATURAS E SIGLAS}

AES

Grupo controlador de empresas de energia, incluindo a ELETROPAULO

CIGRÉ Council on Large Electric Systems

$\mathrm{CO}_{2}$ Representação Química do Dióxido de Carbono, ou gás carbônico

COM Component Object Model

DCOM Distributed Component Object Model

EE Enterprice Edition, relativo a versão do Java

ETD Estação Transformadora de Distribuição

GIS Gas Insulated Substation

GWF Global Warming Factor

$\mathrm{H}_{2} \mathrm{O} \quad$ Representação Química da Água

IEEE Institute of Electrical and Electronic Engineers

JSP Java Server Pages

JVM Java Virtual Machine

MODBUS Protocolo de Comunicação de Dados

OLE Object Linking and Embedding

OPC OLE for Process Control

PES Power \& Energy Society

$\mathrm{SF}_{4} \quad$ Representação Química do Tetrafluoreto de Enxofre

$\mathrm{SF}_{6} \quad$ Representação Química do Hexafluoreto de Enxofre

$\mathrm{SO}_{2} \mathrm{~F}_{2} \quad$ Representação Química do Fluoreto de Sulfurila

$\mathrm{SOF}_{2} \quad$ Representação Química do Fluoreto de Tionilo 
$\mathrm{SOF}_{4}$

Representação Química do Tetrafluoreto de Tionilo

TCP/IP

Transmission Control Protocol/Internet Protocol

UHF

Ultra High Frequency

VHF

Very High Frequency 


\section{SUMÁRIO}

1 PREÂMBULO

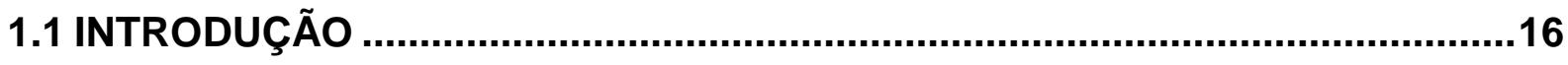

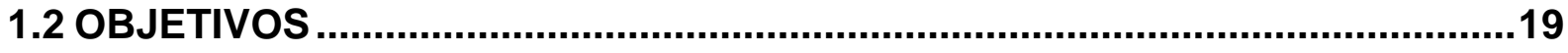

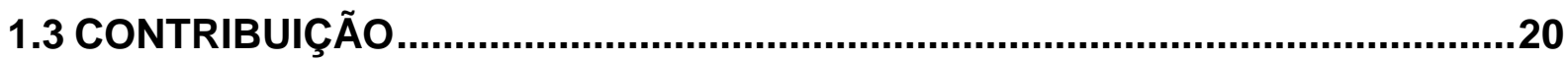

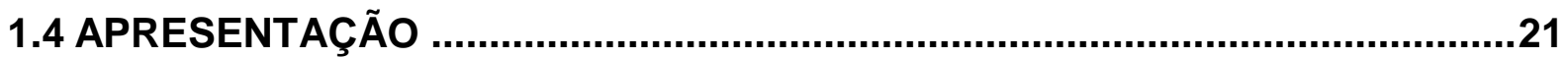

$\underline{2}$ REVISÃO DE LITERATURA

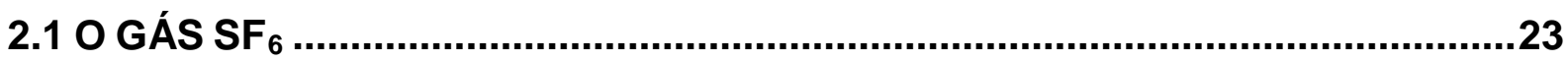

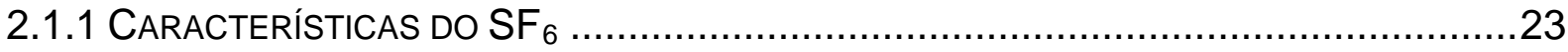

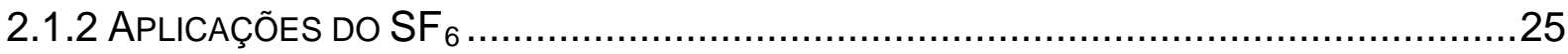

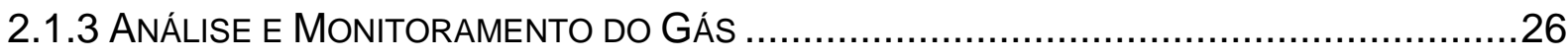

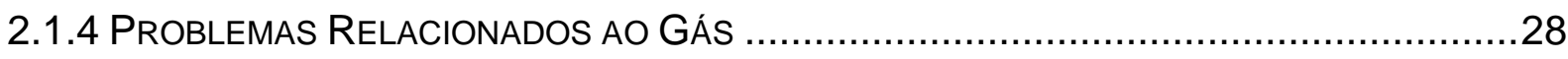

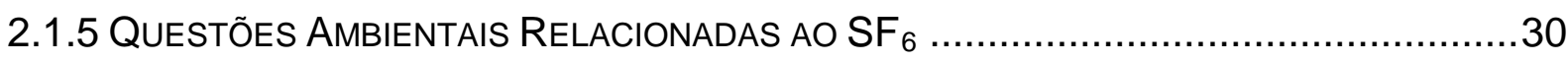

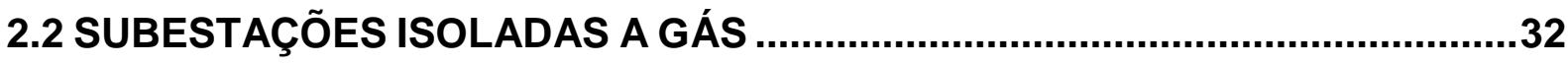

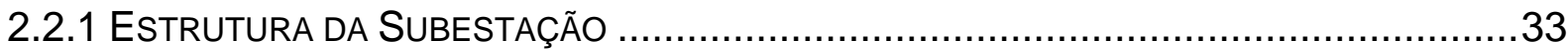

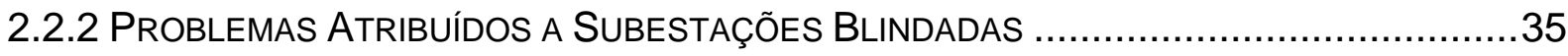

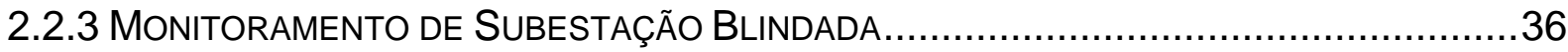

2.2.4 CARACTERÍ́sticas da Subestação Paula Souza (Eletropaulo) ........................38

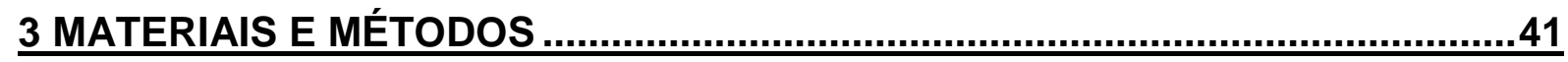

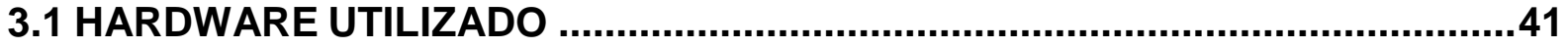

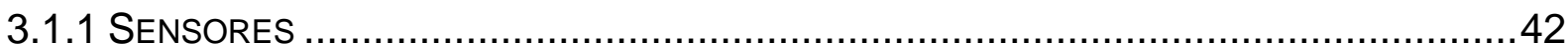

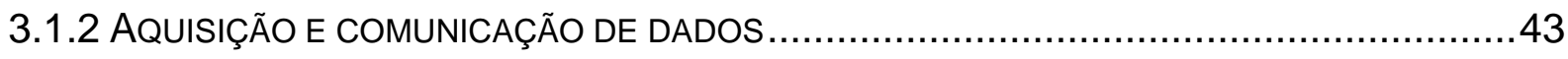

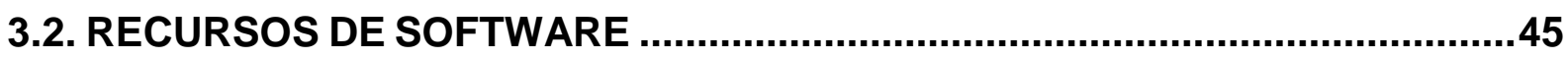

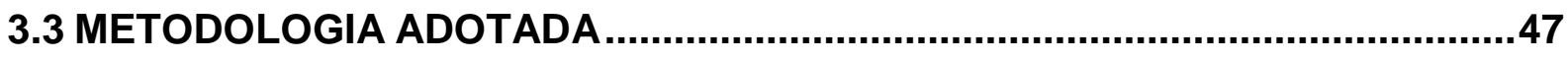

4 RESULTADOS 
4.1 REQUISITOS DO SISTEMA DE MONITORAMENTO .....................................50

4.2. ARQUITETURA DO SISTEMA DE MONITORAMENTO ..................................51

4.3 ARQUITETURA DE SOFTWARE DO SISTEMA DE MONITORAMENTO..........54

4.4 ADAPTAÇÕES PARA CONEXÃO DOS SENSORES.......................................55

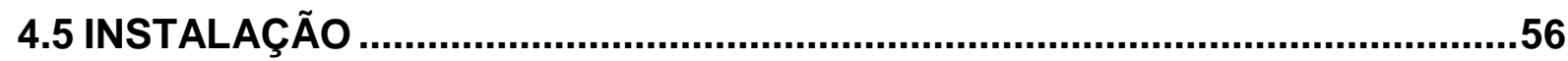

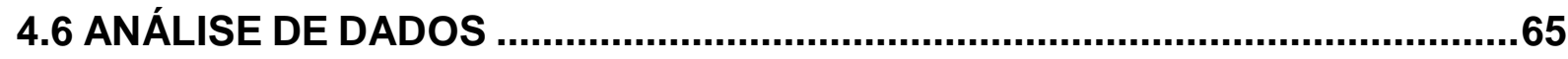

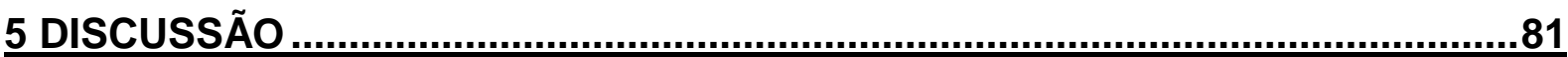

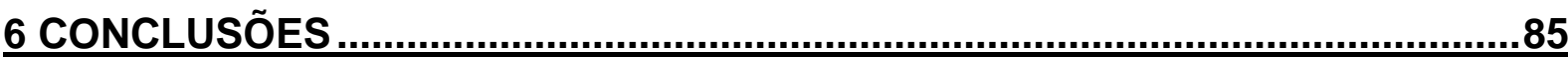

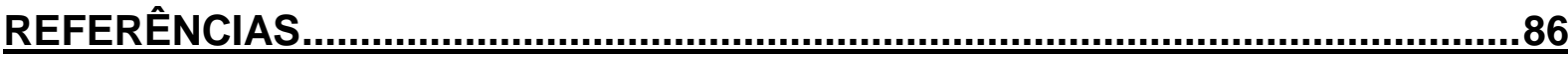




\section{PREÂMBULO}

\subsection{INTRODUÇÃO}

$\mathrm{SF}_{6}$ (Hexafluoreto de Enxofre) é um gás que possui excelentes propriedades para ser usado como isolante elétrico, além de características adicionais como, ser inerte, atóxico, ter alta capacidade dielétrica, alta capacidade de resfriamento, ser não inflamável, estável ao aquecimento e ter capacidade de auto regeneração $(P$. O'CONNELL et al., 2002). Com o início da utilização do $\mathrm{SF}_{6}$ pela indústria de energia, foi possível desenvolver equipamentos de alta capacidade e alto desempenho, além de possibilitar a criação de equipamentos com outras características importantes, como, o tamanho reduzido, menor peso e maior segurança operacional. Atualmente, o uso de subestações isoladas a gás $\mathrm{SF}_{6}$ (GISGas Insulated Substation) no sistema elétrico de potência é importante, principalmente, porque elas podem ser construídas em espaços físicos até 90\% menores do que o necessário para uma mesma subestação convencional. Isto foi possível apenas com a introdução e desenvolvimento do $\mathrm{SF}_{6}$ como isolante elétrico (Bolin e Koch, 2008). Além das características citadas acima, no setor elétrico, o $\mathrm{SF}_{6}$ também é usado como meio de refrigeração para transformador e extintor de arcos elétricos de seccionadoras de média e alta tensão (Etter e Koch, 2008).

A baixa necessidade de manutenção preventiva é uma das vantagens também atribuída à utilização de GIS ("IEEE guide for gas-insulated substations.", 1994). Entretanto, quando há necessidade de alguma intervenção, seja preventiva ou devido a falhas, a manutenção é complexa, de custo elevado e consome bastante tempo. Por isso, é necessário que a qualidade e a quantidade de $\mathrm{SF}_{6}$ sejam mantidas ou inspecionadas adequadamente durante o tempo de vida do equipamento para garantir que os seus níveis sempre estejam dentro dos padrões especificados para a operacionalidade apropriada da GIS. 
Por um longo período as pesquisas relacionadas a monitoramento de subestações isoladas a $\mathrm{SF}_{6}$ foram escassas e de pouco interesse do meio acadêmico. Durante os estudos de estado da arte, foi observado certo volume de publicações nos períodos iniciais da instalação e utilização desta tecnologia e um crescimento substancial de pesquisas nos últimos 10 anos. Isso pode ser explicado parcialmente pelo alto desempenho obtido com gás e estabilidade da tecnologia envolvida no desenvolvimento de subestações.

O estado atual da tecnologia e exigências governamentais abrem campo para o desenvolvimento de novos estudos, principalmente, com temas ambientais relacionados à prevenção de vazamentos de gás e também estratégias de manutenção para instalações GIS antigas, muitas delas com décadas de operação.

Existem pelo menos duas questões atualmente que demandam estudos mais detalhados e que são abordados neste trabalho. A primeira delas está relacionada ao ciclo de vida das subestações mais antigas, principalmente as primeiras instalações, dos anos 1970. Estas subestações, quase que em sua totalidade, se encontram operando perfeitamente, mas com sua vida útil nominal já ultrapassada (40 a 50 anos, dependendo do fabricante). O segundo elemento de pesquisa está relacionado com as questões ambientais em que o SF 6 está inserido. Sendo ele um dos gases mais largamente utilizado como dielétrico, também é objeto de divergências a respeito do seu uso, devido ao seu alto potencial nocivo para o efeito estufa.

A subestação utilizada como base para os estudos e desenvolvimentos deste trabalho está próxima do final do seu tempo de vida nominal. Portanto, este foi o principal fator motivador para o desenvolvimento do trabalho. A proposta foi criar subsídios informativos para poder observar o estado do gás e da subestação. Devido à estabilidade do equipamento e baixo índice de falha, a expectativa é que no longo prazo os dados informativos possam sustentar a sua operação segura além do seu ciclo de vida nominal. Desta forma, foi desenvolvido um sistema de 
aquisição de dados para coletar informações de dois parâmetros, que se consideram importantes, para auxiliar na observação das condições operativas da subestação. Os parâmetros são:

- Ponto de orvalho, que indica a temperatura na qual o vapor de água, contido nos compartimentos, se condensa e passa para o estado liquido;

- Densidade, parâmetro indicativo para se saber a massa de gás nos compartimentos.

Portanto, considerando as questões expostas, este trabalho se justifica, e pretende colaborar para esta área de pesquisa, com um sistema de monitoramento contínuo do gás $\mathrm{SF}_{6}$ em subestações antigas visando fornecer dados históricos e em tempo real para possibilitar a determinação de novas estratégias de manutenção e conservação.

Após o desenvolvimento e instalação do sistema de monitoramento, esperase que algumas melhorias na manutenção possam ser atingidas e também alguns ganhos ambientais possam ser atribuídos ao sistema. Pode-se citar:

- Possibilitar a identificação ou percepção de vazamentos de gás com maior rapidez;

- Diminuir as emissões de $\mathrm{SF}_{6}$ para a atmosfera;

- Possibilitar o estabelecimento de prazos mais adequados para a realização de manutenções preventivas;

- Possibilitar o estabelecimento de prazos mais adequados para realização de inspeções da qualidade do gás com equipamentos externos;

- Possibilitar a determinação de comportamentos sazonais do gás na subestação através do sistema de monitoramento;

- Determinar as condições operativas da subestação baseado na avaliação das condições do gás. 


\subsection{OBJETIVOS}

O objetivo principal deste trabalho é:

- Fornecer subsídios para se observar o estado e o comportamento do gás de uma subestação blindada, a partir de dados obtidos de um sistema de monitoramento de tempo real, visando o acompanhamento seguro de seu ciclo de vida.

Para obtenção dos dados foi desenvolvido um sistema para monitorar a massa de gás (verificação de perdas) e um parâmetro de qualidade (contaminação por umidade) do gás $\mathrm{SF}_{6}$ em uma subestação blindada. Desta forma têm-se também como objetivos:

- Criar uma metodologia para coleta e tratamento de dados para permitir melhor avaliação das condições operativas, além de fornecer informações necessárias para se estudar novos critérios de manutenção;

- Desenvolver um sistema de tempo real que auxilie a realização de inspeções das condições operativas e verificação de quantidade de gás nos compartimentos;

- Instalar o sistema em uma subestação isolada a $\mathrm{SF}_{6}$ de forma a avaliar a sua estabilidade e capacidade de fornecer informações. 


\subsection{CONTRIBUIÇÃO}

A principal contribuição deste trabalho está na proposição de uma abordagem diferenciada das soluções comerciais ou propostas acadêmicas para monitoramento de subestações isoladas a $\mathrm{SF}_{6}$. Pode-se destacar a utilização de equipamentos e recursos de baixo custo. As soluções comerciais para monitorar parâmetros de uma subestação demandam um investimento financeiro muito grande e para o caso de subestações antigas pode haver limitações de algumas funções.

Foi instalado um protótipo do sistema de monitoramento proposto em três bays de uma subestação blindada. Este equipamento no qual o sistema foi instalado trata-se de um dos primeiros projetos desta tecnologia, onde existem pressões diferentes para os vários compartimentos do bay. Desta forma, há que se considerar esta característica, principalmente, para o monitoramento de vazamentos, uma vez que durante a operação dos equipamentos há movimentações de gás entre os compartimentos internos do bay, sem que isso represente um vazamento. O sistema apresentado neste trabalho considera estes elementos característicos da subestação e também representa um dos elementos diferenciais desta solução em relação aos que estão disponíveis comercialmente.

O sistema faz o armazenamento de dados históricos dos sensores. A coleta cíclica dos dados, por longos períodos, permitirá que sejam feitas análises comportamentais do gás. Uma vez que, devido principalmente à estabilidade da tecnologia e também do gás, se sabe pouco sobre este comportamento. A análise detalhada e refinada dos dados irá proporcionar um melhor entendimento do $\mathrm{SF}_{6}$. Neste contexto é apresentada a especificação e o desenvolvimento do um sistema de monitoramento em tempo real para uma subestação blindada da AES Eletropaulo. Os dados históricos fornecidos pelo sistema servem de subsídios para se fazer a análise do comportamento do gás da subestação por períodos longos, que podem ser semestrais, anuais ou por períodos maiores. Além disso, os dados em tempo real servem de base para se supervisionar o nível de confiabilidade da 
subestação no exato momento da observação. O sistema facilita a percepção de vazamentos de gás e torna a sua localização mais rápida. A verificação online de parâmetros de ponto de orvalho, em conjunto com o controle de quantidade de gás possibilita o acompanhamento mais seguro do ciclo de vida e operação da subestação.

Adicionalmente, como produtos acadêmicos, este trabalho resultou em duas publicações em congressos internacionais e uma publicação em congresso de abrangência nacional. Os trabalhos publicados e os respectivos eventos são listados abaixo:

- "Development and Installation of a Data Acquisition and Monitoring System to Gas Insulated Substation", apresentado no evento: 13th International Conference on Optimization of Electrical and Electronic Equipment, 2012 (Ogiboski et al., 2012);

- $\quad$ "Real Time System to Monitor SF6 Leakage and Quality of Gas in GIS Substation", apresentado no evento: PowerTech, 2011(Ogiboski et al., 2011);

- "Sistema de Monitoramento de Tempo Real para Prevenção de Vazamentos e Qualidade do SF6 em uma Subestação Isolada a Gás", apresentado no evento: IV CITENEL - Congresso de Inovação Tecnológica em Energia Elétrica, 2011(Ogiboski et al., 2011).

\subsection{APRESENTAÇÃO}

A organização deste trabalho apresenta nos seus capítulos subsequentes os detalhes relativos ao desenvolvimento e resultados. O capítulo 2 apresenta os estudos de estado da arte que estão relacionados com os temas desta pesquisa. 
Apresentam as características e aplicações do gás $\mathrm{SF}_{6}$ no setor elétrico. Além disso, são abordados os temas relacionados a questões ambientais onde este gás está inserido. Serão abordadas também as subestações isoladas a gás, ou subestações blindadas, que foram o ambiente onde o sistema desenvolvido foi instalado. Apesar deste tipo de subestação ter a mesma função da uma tradicional, ela possui características diferenciadas que são abordadas no texto. Além disso, são apresentados também os aspectos de monitoramento, considerando os seus problemas e falhas.

O capítulo 3 apresenta os materiais e métodos utilizados no desenvolvimento do trabalho. São abordados os detalhes de hardware, como sensores e equipamentos para aquisição de dados, além de detalhes sobre os recursos de software utilizados para o desenvolvimento da aplicação de aquisição, armazenamento e apresentação de dados.

Os resultados com a instalação do sistema na subestação são tratados pelo capítulo 4, enquanto a discussão e conclusões são tratados, respectivamente, pelos capítulos 5 e 6 . 


\section{REVISÃO DE LITERATURA}

\subsection{GÁS $\mathrm{SF}_{6}$}

Neste capítulo são apresentados conceitos básicos relacionados gás $\mathrm{SF}_{6} \mathrm{e}$ seu uso como dielétrico no setor elétrico. Além disso, serão apresentadas as aplicações mais utilizadas que fazem uso do gás, como equipamentos diversos que necessitam de um isolante gasoso. Desde o conhecimento das características nocivas do $\mathrm{SF}_{6}$ ao meio ambiente este tema se tornou bastante importante e relevante, portanto esses aspectos também serão apresentados e discutidos neste capítulo.

\subsubsection{Características do $\mathrm{SF}_{6}$}

O gás $\mathrm{SF}_{6}$ (hexafluoreto de enxofre) é um gás sintético e desde o início de 1960 passou a ser utilizados pela indústria de equipamentos elétricos de alta tensão como dielétrico. Ele é quimicamente formado por seis moléculas de flúor e uma molécula de enxofre, conforme representação na figura 1. 


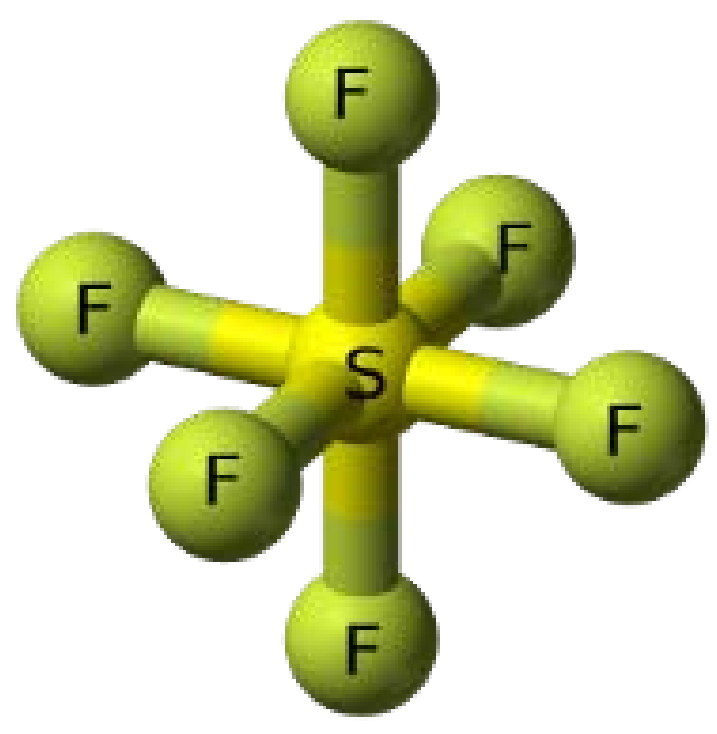

Figura 1: Molécula de SF6

Esta sua formulação proporciona uma série de características desejáveis em um dielétrico além de outras que o tornam muito interessante para ser utilizado em equipamentos elétricos. $\mathrm{O}_{\mathrm{SF}}$ é quimica e termicamente estável, inerte, possui excelente isolação elétrica, não oferece toxicidade, não é inflamável e ainda é auto regenerável (recomposição das moléculas).

Foram estudadas aplicações de outros gases para serem utilizados como dielétrico, mas apesar de alguns apresentarem capacidades até melhores para algumas características necessárias, nenhum apresenta o conjunto de vantagens do SF $_{6}$ ("IEEE Guide for Sulphur Hexaflouride (SF6) Gas Handling for High-Voltage (over 1000 Vac) Equipment", 2012). Alternativas tecnológicas sem SF6 não são livres de potenciais impactos ambientais além de oferecerem menor eficiência operacional, maiores custos e maiores riscos para segurança do equipamento (Biasse, Otegui e Tilwitz-von Keiser, 2010). Desta forma, tecnicamente, a sua adoção exclusiva como dielétrico gasoso pela indústria de equipamentos elétricos é facilmente justificável. 
Fisicamente o gás pode ser caracterizado como sendo sem odor, sem sabor, não tóxico, não corrosivo e não inflamável. Em temperatura ambiente o SF 6 é cinco vezes mais pesado que o ar, com uma densidade de 6,139 g/L. Fundamentalmente não oferece perigo ao ser humano. Entretanto, instalações totalmente fechadas não são recomendadas, pois o fato de ser mais pesado que o ar o torna capaz de expulsar o oxigênio do ambiente, podendo assim oferecer risco de asfixia ao ser humano caso haja vazamento de gás ("IEEE Guide for Sulphur Hexaflouride (SF6) Gas Handling for High-Voltage (over 1000 Vac) Equipment”, 2012). As características elétricas do gás são as principais responsáveis pela sua adoção na indústria de equipamentos elétricos de potência. Além de ser altamente eletronegativo, possui uma combinação de alta rigidez dielétrica com alta capacidade de interrupção térmica (ETTER e KOCH, 2008).

A tecnologia desenvolvida a partir do $\mathrm{SF}_{6}$ como dielétrico se tornou dominante na indústria, pois possibilitou o desenvolvimento de equipamentos altamente robustos, confiáveis e extremamente compactos (Biasse, Otegui e Tilwitzvon Keiser, 2010).

\subsubsection{Aplicações do $\mathrm{SF}_{6}$}

A partir do surgimento e conhecimento de suas características, o $\mathrm{SF}_{6}$ permitiu o desenvolvimento de equipamentos elétricos de alta capacidade e desempenho, além de mais compactos, leves e seguros (MCDONALD, 2007). Destacam-se dentre os equipamentos elétricos que foram desenvolvidos em função do $\mathrm{SF}_{6}$ os disjuntores $\mathrm{e}$ as subestações blindadas. Alguns produtos são extremamente compactos, ocupando apenas $10 \%$ do espaço físico se comparado aos seus equivalentes convencionais (P. O'CONNELL et al., 2002) (BOLIN e KOCH, 2008). Aplicações específicas, na área de potência, incluem a utilização do gás 
como isolante em subestações, como isolante e meio de resfriamento em transformadores e como meio isolante e extintor de arco elétrico em disjuntores e chaves para aplicações de alta e média tensão (ETTER e $\mathrm{KOCH}, 2008$ ). O SF mesmo que em menor escala, ainda é utilizado em outras áreas, como: metalurgia, eletrônica, equipamentos científicos, cirurgia ocular e aplicações militares ("IEEE Guide for Sulphur Hexaflouride (SF6) Gas Handling for High-Voltage (over 1000 Vac) Equipment", 2012).

As subestações blindadas são as aplicações de maior porte que utilizam a tecnologia em torno do $\mathrm{SF}_{6}$, além de serem as que demandam a maior volume de gás. São equipamentos desenvolvidos, principalmente, para atender a demanda de instalações bastante específicas que dispõem de pouco espaço físico e necessitam de altas taxas de disponibilidade ou segurança

\subsubsection{Análise e Monitoramento do Gás}

Os estudos relativos ao monitoramento de condições de gás $\mathrm{SF}_{6}$ para isolamento de equipamentos e de monitoramento de vazamentos de gás não demonstram um método único para a solução do problema de inspeção de volume e qualidade, uma vez que são necessários vários métodos para se ter resultados mais eficientes. Para determinação da qualidade do gás há necessidade de se definir de forma mais efetiva quais são os parâmetros ou grandezas que realmente devem ser monitoradas para indicativos de qualidade. Várias formas de monitorar a qualidade do gás são apresentadas na literatura científica visando a manutenção preditiva de subestações GIS. As principais linhas de análise consideradas para a elaboração deste trabalho foram: 
- Métodos para diagnosticar a situação do gás $\mathrm{SF}_{6}$ através da definição de parâmetros e verificação de partículas existentes em uma subestação blindada. A partir dos métodos devem-se estudar os tipos de informações necessárias para estabelecer critérios preditivos para manutenção da subestação;

- Sistema de monitoramento para determinação de indicativos de qualidade do gás em uma subestação GIS.

Os estudos iniciais de definição metodológica demonstraram que havia a necessidade de considerar os possíveis dispositivos em duas categorias: os equipamentos para análise externa do gás e os equipamentos para monitoramento dos compartimentos internos.

O $\mathrm{SF}_{6}$ no estado gasoso e com $100 \%$ de pureza possui algumas propriedades físico-químicas como condutibilidade térmica e velocidade de propagação do som, características que podem ser verificadas através de instrumentos portáteis. Contaminações por gases derivados causam alterações nestas propriedades. A partir da determinação dos contaminantes mais comuns, pode ser feita uma associação entre a presença destes contaminantes e a sua dispersão medida em relação ao $\mathrm{SF}_{6}$ puro.

Quando identificadas alterações do teor de pureza do $\mathrm{SF}_{6}$ devem-se realizar ensaios complementares para caracterizar os contaminantes e adoção do procedimento de recuperação do $\mathrm{SF}_{6}$, como também, se necessário, a intervenção no equipamento.

Quando há suspeita de vazamentos de gás é necessário utilizar um equipamento para detecção do local onde pode haver vazamento. Devido às características do gás, na maioria das vezes, não é possível identificar o local exato do vazamento sem equipamento adequado. Nestes casos um detector de 
vazamentos pode ser utilizado para identificar o local exato e a partir de sua confirmação se possam tomar providências para a minimização e eliminação do problema.

Tanto para o caso de medição para verificar a qualidade do gás quanto para identificação de vazamentos existem produtos comerciais para efetuar estes procedimentos. Entretanto, eles não são adequados para realizar monitoramentos constantes, pois dependem de intervenção humana para obter os dados necessários. No caso de verificação da qualidade do gás, estes equipamentos necessitam de amostras para realizar as leituras das condições do gás e este procedimento deve ser feito com a menor frequência possível, pois sempre causa pequenas emissões. Já os equipamentos para localização de vazamentos, chamados de sniffers, são apenas adequados para verificação de locais específicos onde há suspeita de vazamentos e não são adequados para inspeções gerais. Desta forma, tanto os equipamentos ou as soluções apresentadas na literatura ou no mercado não são adequados para aplicação de uma solução como proposta nos objetivos deste trabalho, ou seja, supervisão em tempo real. Portanto, a direção adotada foi no sentido de desenvolver um sistema de monitoramento para coleta automática de dados.

\subsubsection{Problemas Relacionados ao Gás}

Mesmo considerando a estabilidade do gás $\mathrm{SF}_{6}$ o CIGRÉ (INTERNATIONAL COUNCIL ON LARGE ELECTRIC SYSTEMS (CIGRE), 1997) publicou estatísticas que mostraram que $67 \%$ de todas as falhas das GIS são atribuídas às variações na composição do gás de seus compartimentos ao longo do tempo. Estas variações estão relacionadas a duas naturezas principais, a decomposição do gás e ou a sua contaminação. Devido a operação dos equipamentos dentro dos compartimentos, 
ou devido a outros elementos, como descargas parciais, uma pequena porção de $\mathrm{SF}_{6}$ se decompõe em um subproduto, o $\mathrm{SF}_{4}$. Além disso, a presença de água ou umidade nos compartimentos interfere no equilíbrio químico do gás e provoca reações que geram novos subprodutos, como $\mathrm{SOF}_{4}, \mathrm{SOF}_{2}, \mathrm{SO}_{2} \mathrm{~F}_{2}$, além de outras variações a partir destas novas composições (Yuanyuan et al., 2011). A segunda origem de elementos que influenciam nas características do gás são os contaminantes não gasosos. Devido também a sua operação normal podem ser desprendidas partículas metálicas da própria blindagem ou de outros equipamentos internos (Kumar, Amarnath e Singh, 2008). Além disso, procedimentos de manutenção ou preenchimento de gás podem introduzir outros tipos de contaminantes nos compartimentos ("IEEE guide for gas-insulated substations.", 1994).

$\mathrm{O} \mathrm{SF}_{6}$ mantém plenamente as suas características apenas quando a sua composição está próxima da pureza. O gás com 100\% de pureza é composto apenas com moléculas de $\mathrm{SF}_{6}$, sem a existência de outras moléculas decompostas e sem contaminação por outros elementos. Qualquer modificação na sua condição de pureza desencadeia um processo de degeneração das suas características, que pode, mesmo que lentamente, causar problemas de diversas consequências. Há que se considerar, ainda, que a quantidade de gás no equipamento é outro fator importante que influencia o dielétrico. Considerando, ainda apenas tecnicamente, os vazamentos de gás podem comprometer a operacionalidade dos equipamentos. Portanto, é necessário utilizar técnicas e procedimentos para garantir a qualidade e quantidade do gás nos equipamentos. Mantendo estes dois parâmetros podem-se evitar falhas e a perda da confiabilidade operacional da subestação. 


\subsubsection{Questões Ambientais Relacionadas ao $\mathrm{SF}_{6}$}

$\mathrm{O} \mathrm{SF}_{6}$ foi tratado como a solução ideal para ser utilizado como dielétrico gasoso, pois as suas características técnicas atendiam a praticamente todas as necessidades operacionais e de segurança. Entretanto o gás se mostrou extremamente danoso ao meio ambiente e nos dias atuais há uma preocupação muito grande quanto ao seu uso e formas de manipulação. Isso tem motivado muitas discussões governamentais e acadêmicas a respeito da sua utilização e manutenção além de estimular uma grande quantidade de estudos neste tema.

Quando se trata de questões ambientais associadas ao $\mathrm{SF}_{6}$ existem muitas divergências relativas ao seu uso pela indústria elétrica. O $\mathrm{SF}_{6}$ é considerado um gás de efeito estufa, e a partir da instituição do protocolo de Quioto, que objetiva a redução de emissões desses gases (Pittock, 2009), foram desencadeados estudos, criadas políticas e formuladas exigências a respeito do uso deste gás em equipamentos elétricos. O seu potencial de danos para o meio ambiente é muito alto, pois se estima que o seu ciclo de vida natural esteja entre 800 e 3200 anos (Jabiri e Sharafi, 2010). Além disso, o seu fator de aquecimento global (GWF Global Warming Potential) é 23.900. Este é um fator para se calcular ou determinar qual o potencial que um gás de efeito estufa contribui para o aquecimento global, trata-se de um método para comparar os danos causados por outros gases em relação de danos do $\mathrm{CO}_{2}$ (dióxido de carbono). O fator tem como base o $\mathrm{CO}_{2}$ (dióxido de carbono) que foi definido como fator 1, portanto o $\mathrm{SF}_{6}$ é dezenas de milhares de vezes mais danoso para o aquecimento global que $0 \mathrm{CO}_{2}$ (Christophorou, Olthoff e Brunt, Van, 1997).

Com resultado das discussões ambientais a respeito do uso do $\mathrm{SF}_{6}$ no setor elétrico, o CIGRÉ publicou em 2010 um guia com recomendações para testes de hermeticidade e também métodos para medições de vazamentos em equipamentos isolados a $\mathrm{SF}_{6}$ (INTERNATIONAL COUNCIL ON LARGE ELECTRIC SYSTEMS (CIGRE), 2010). A maioria dos métodos citados são não invasivos, podendo ser de 
ordem quantitativa ou qualitativa. O principal objetivo deste guia de referência é apresentar opções e diretivas para manutenção e prevenção de perdas de gás. A IEEE PES também publicou recentemente um guia para manipulação de $\mathrm{SF}_{6}$ em equipamentos elétricos de alta tensão, que tem por objetivo a redução de emissões de gás através de boas práticas de manipulação e manutenção ("IEEE Guide for Sulphur Hexaflouride (SF6) Gas Handling for High-Voltage (over 1000 Vac) Equipment", 2012). Entretanto, estas soluções são baseadas em verificações periódicas por equipes que utilizam dispositivos para esta finalidade, diferente da proposta deste trabalho, que é oferecer a possibilidade de inspeção automática por software de computador através de monitoramento on-line.

As novas políticas de manipulação do $\mathrm{SF}_{6}$ motivaram também diversas pesquisas para tentar melhorar as políticas de manutenção do gás, principalmente relacionado a controle de vazamentos. Um método de detecção automática de vazamentos através de imagens foi proposto por (Zhengzheng et al., 2010). De acordo com os autores, é possível detectar vazamentos de gás através do processamento de imagens e reconhecimento de padrões. Detecção de vazamentos também pode ser feita com uso de espectrometria fotoacústica. (Xu et al., 2009) publicou um trabalho demonstrando o seu estudo experimental para detectar a presença de $\mathrm{SF}_{6}$ considerando as suas características fotoacústicas. Outros métodos mais tradicionais também são alvo de pesquisas atuais, como Graber, que sugere o monitoramento de vazamentos através de sensores de temperatura e densidade (Graber, 2011). Estudos adicionais sobre o SF 6 e redução de emissões também estão em evidência. (Jabiri e Sharafi, 2010) apresentam um estudo geral sobre as possibilidades de redução de emissões através de técnicas de controle, políticas de manutenção e alternativas preventivas. 


\subsection{SUBESTAÇÕES ISOLADAS A GÁS}

Uma subestação é um conjunto de equipamentos elétricos, geralmente, de um sistema de potência que são utilizados para manobras, transformação ou compensação de reativos. Além disso, são importantes para direcionar o fluxo de energia por diversos caminhos. Também funciona como dispositivo para a proteção do sistema que ao detectar faltas, possibilita, por exemplo, o isolamento de trechos de uma linha.

As subestações podem ser classificadas de várias formas, entretanto, devido ao tema de pesquisa deste trabalho, elas serão classificadas em função de seu meio isolante. Portanto, as subestações podem ser classificadas como: isoladas a ar e isoladas a gás.

Subestações isoladas a ar são as aplicações mais comuns. Neste tipo de projeto, os equipamentos e condutores são isolados pela distância, ou seja, são dispostos a uma distância segura de forma a não causar curto-circuito. Este tipo de subestação é largamente utilizado por ser o projeto de melhor custo benefício. Por outro lado, demanda um espaço físico grande para acomodar todos os equipamentos. Este modelo de instalação está sujeito a condições atmosféricas e climáticas desfavoráveis que reduzem a eficácia do isolamento e também necessita de manutenção e inspeção frequente.

As subestações isoladas a gás possuem as mesmas funcionalidades e tipos de equipamentos de subestações tradicionais. Elas foram desenvolvidas entre o final da década de 1960 e começo da década de 1970. O que as diferencia são, principalmente, o meio isolante e a sua aplicação. Em uma subestação isolada a gás, o seu meio isolante é geralmente o $\mathrm{SF}_{6}$. A principal aplicação deste tipo de projeto é permitir instalações em ambiente com pouco espaço disponível e crítico com relação à segurança, como por exemplo, no centro de uma grande cidade; e algumas instalações podem ser subterrâneas. Como este modelo de subestação, 
quase sempre é instalado em local abrigado, ela não é sujeita a condições climáticas, portanto, demanda pouca manutenção, ou muito menos se comparada com uma subestação tradicional (McDonald, 2007). Mesmo considerando que uma subestação blindada é idêntica, em funcionalidade, a uma subestação tradicional, existem diversas particularidades construtivas ou operacionais que as diferem.

\subsubsection{Estrutura da Subestação}

O projeto e a construção de uma subestação isolada a gás consideram a utilização de equipamentos de mesmas funcionalidades que uma subestação tradicional. Isto inclui equipamentos de mesma capacidade, como: disjuntores, transformadores, seccionadores, barramentos de interconexão, pára-raios e conexões para o restante do sistema elétrico. Um conjunto de equipamentos, ou de forma individual, é dividido em módulos que representam compartimentos internos onde são preenchidos com gás e isolados dos demais módulos por peças isoladoras. Os isoladores são feitos com epóxi fundido com pequenos furos, portanto essa configuração permite a isolação entre os módulos da subestação e também pode permitir a passagem de gás entre alguns compartimentos ou sub compartimentos. As construções mais comuns são de sistemas trifásicos montados em compartimentos únicos. Atualmente, os materiais mais utilizados para se criar os compartimentos são alumínio ou aço. A pressão interna para o gás é determinada pelo fabricante do equipamento e geralmente são acoplados medidores de pressão com o objetivo de permitir observações das variações na quantidade de gás. A figura 2 (McDonald, 2007), apresenta uma visão genérica de um compartimento trifásico de uma subestação isolada a gás. 
1- Disjuntor

2- Seccionadora (isolador)

3 - Chave Aterramento

4 - Transformador Corrente

5 - Transformador Tensão

6 - Câmara de Vedação Final do Cabo

7 - Barreira de Gás

8 - Suporte Isolador

9 - Barramento Principal

10- Barramento Reserva

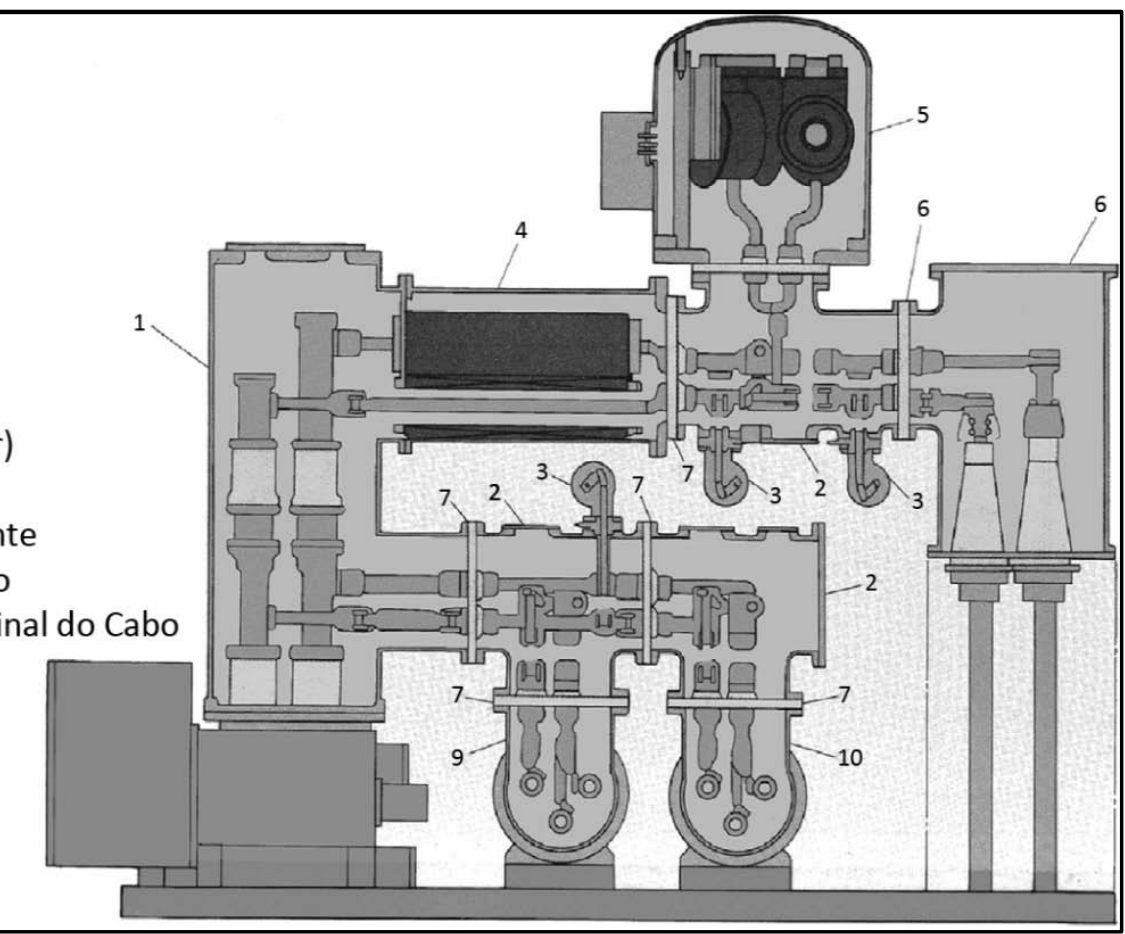

Figura 2: GIS trifásica

Os projetos deste tipo de subestação consideram a robustez uma das características mais importantes. Desta forma, existe uma preocupação muito grande com a disponibilidade e também com o seu tempo de vida. As subestações como um todo, ou suas partes e equipamentos, são projetadas para ter baixa manutenção, altíssima disponibilidade, além de terem um tempo de vida longo (40 a 50 anos). Para que essas características possam ser atingidas, alguns detalhes sobre a blindagem da subestação devem ser considerados. A vedação é um dos elementos mais importantes na construção de uma subestação blindada. Isso garante o seu dielétrico e também garante que não haja interferências entre o meio externo e interno, ou vice-versa. A garantia de vedação é feita principalmente com a fabricação de peças de encaixe ideal e utilização de anéis de obstrução (do inglês, o-ring) para vedar completamente. Além disso, na construção dos elementos, são aplicadas pinturas internas nas paredes dos módulos e também utilizados lubrificantes nas partes mecânicas para que o desprendimento de partículas seja o 
mínimo possível. Estas características de robustez e qualidade são confirmadas através de publicações que relatam a baixa ocorrência de problemas e também a alta operacionalidade do equipamento ao longo de décadas. Desta forma, a inspeção interna de uma subestação blindada não é recomendada e as políticas de manutenção também não consideram este tipo de inspeção (Hase, 2007).

A tecnologia empregada na construção de subestações GIS evoluiu ao longo dos anos e se tornou mais eficiente e mais confiável. Os compartimentos foram otimizados e necessitam de menos gás para manter o isolamento. O tempo de manutenção também foi estendido, ou seja, atualmente há menor necessidade de verificações e intervenções nos equipamentos. Pode-se destacar também a inclusão de estrutura construtiva para conexão de instrumentos de medição ou sensores já integrados ao produto. Além disso, os fabricantes oferecem sistemas de monitoramento e outros acessórios complementares. De maneira geral, os projetos atuais são mais seguros.

\subsubsection{Problemas Atribuídos a Subestações Blindadas}

Uma das grandes vantagens atribuída as GIS é a baixa necessidade de manutenções preventivas, por outro lado, quando necessária alguma intervenção, seja preventiva ou em decorrência de falhas internas, as manutenções são complexas, demoradas e dispendiosas. Desta forma, é necessário que a qualidade e a quantidade do gás $\mathrm{SF}_{6}$ sejam inspecionadas adequadamente durante todo o período de operação do equipamento para assegurar a conformidade com os seus respectivos parâmetros de referência.

A maioria dos problemas ou faltas citados na literatura, atribuídas às GIS, estão relacionadas com o seu dielétrico, ou seja, referem-se diretamente ao gás e 
suas políticas de manutenção e controle. $\mathrm{O} \mathrm{SF}_{6}$ em quantidade insuficiente ou com suas características comprometidas são as maiores causas de problemas. Desta forma, os vazamentos de gás, a ocorrência de descargas parciais e a formação de arcos elétricos internos são considerados os principais elementos degradantes do dielétrico da subestação.

Mesmo considerando a confiabilidade da tecnologia envolvida, as falhas em GIS também estão relacionadas a variações na composição do SF 6 (INTERNATIONAL COUNCIL ON LARGE ELECTRIC SYSTEMS (CIGRE), 1997). A presença de partículas ou outros fatores contaminantes, como umidade, resultantes de sua operação, bem como vazamentos de gás da GIS são fatores críticos para o funcionamento da subestação, uma vez que podem causar falhas que comprometem a operacionalidade do equipamento. A presença de arco elétrico em um ambiente com $\mathrm{SF}_{6}$ faz com que o gás seja decomposto em alguns subprodutos reagentes e algumas vezes produtos tóxicos (Tsai, 2007). Todas as reações e subprodutos gerados afetam o material dentro dos compartimentos e também contribuem para a redução da capacidade de isolamento do gás. Isso conduz a uma diminuição gradativa da confiabilidade operacional da GIS.

\subsubsection{Monitoramento de Subestação Blindada}

O monitoramento da subestação é uma funcionalidade considerada fundamental para que a sua confiabilidade seja mantida e que eventuais problemas possam ser percebidos com antecedência ao seu acontecimento. Atualmente existem algumas frentes de pesquisa nesta área que propõem formas de monitoramento das condições da subestação e também do SF $_{6}$. 
A criação de métodos e técnicas para inspecionar o estado operacional da subestação e principalmente o gás está em evidência há algum tempo, como (Hillers e Beierl, 1995) que sugere o monitoramento do $\mathrm{SF}_{6}$ na GIS como elemento obrigatório. O monitoramento de descargas parciais, monitoramento de vazamentos, e monitoramento da qualidade do gás estão entre os temas de pesquisa mais importantes. Dentro destas áreas de pesquisa é possível observar a inserção de várias técnicas matemáticas, computacionais e da engenharia de diversos ramos como forma de colaborar com a melhoria das práticas de uso e manutenção de GIS.

Um sistema de monitoramento dos compartimentos com gás $\mathrm{SF}_{6}$ se torna importante, pois se pode armazenar um histórico de anomalias e evoluções do gás na subestação. $\mathrm{O} \mathrm{SF}_{6}$ é um gás que se regenera, portanto algumas anomalias podem não ser detectadas apenas com a verificação do estado atual do gás utilizando os equipamentos para medições rotineiras. Portanto, um sistema de monitoramento em tempo real e armazenamento de históricos pode servir de base para análises em situações particulares de operação da subestação.

Atualmente existem diversas técnicas para monitoramento e instrumentos de ensaio para verificação de características do gás e do dielétrico, podendo-se citar os seguintes controles recomendados pelos fabricantes:

- Densidade;

- Teor de umidade.

Outras opções de controle oferecidas no mercado de instrumentos, inclusive algumas não convencionais, incluem:

- Densidade on-line por sensores eletro-eletrônicos;

- Teor de pureza (porcentagem do $\mathrm{SF}_{6}$ em relação a contaminantes); 
- Teor de $\mathrm{SO}_{2}$;

- Índice de mobilidade iônica;

- Teor de umidade (por sensores não ponto de orvalho);

- Descargas parciais por sensores acústicos;

- Descargas parciais por ondas VHF;

- Descargas parciais por ondas UHF.

Apesar de haver várias soluções comerciais para monitoramento das condições do gás e também de verificação de vazamentos, os produtos comerciais não são suficientemente eficientes, alguns demandam verificação manual e outros deles não se adaptam a subestações antigas. Desta forma, o desenvolvimento proposto neste trabalho seguiu uma linha de trabalho diferenciada, o monitoramento de perdas de gás por meio de sensores de densidade e o monitoramento de um elemento de qualidade do gás por meio do ponto de orvalho utilizando sensores instalados nos compartimentos de uma subestação GIS antiga.

\subsubsection{Características da Subestação Paula Souza (Eletropaulo)}

O sistema desenvolvido neste trabalho foi projetado e construído para ser instalado na estação transformadora de distribuição (ETD) Paula Souza da AES Eletropaulo. Esta estação está localizada no centro da cidade de São Paulo, próximo ao Mercado Municipal, e atende praticamente toda esta região. Foi identificada a necessidade de uma subestação blindada, principalmente, por ocupar pouco espaço em uma região de alta densidade populacional. Além disso, a segurança contra falhas elétricas e incidentes na região foram fatores que também 
levaram à escolha deste tipo de projeto de subestação. Ela foi instalada em meados da década de 70.

Paula Souza é formada por quinze bays e duas barras que operam em 88 kV. Estima-se que na subestação toda existam aproximadamente $1280 \mathrm{~kg}$ de gás $\mathrm{SF}_{6}$ distribuídos pelos diversos compartimentos. A quantidade de gás é um valor estimado em função da inserção inicial, pois não há equipamentos para se medir a quantidade atualmente. Os equipamentos da subestação (em cada bay) estão abrigados em compartimentos, onde há uma distinção entre a pressão do gás em dois compartimentos principais. Os disjuntores operam a uma pressão de aproximadamente 15 bar, enquanto os outros equipamentos operam em uma pressão bem menor, aproximadamente 3 bar. Durante a operação dos disjuntores o gás é transvasado do compartimento de maior pressão para outro de menor pressão e após esta operação a pressão alta deve ser equalizada novamente. Para o procedimento de transferência de gás de um compartimento para outro há um sistema com compressores, que entram em operação quando há necessidade. A subestação pode ser observada na figura 3. 


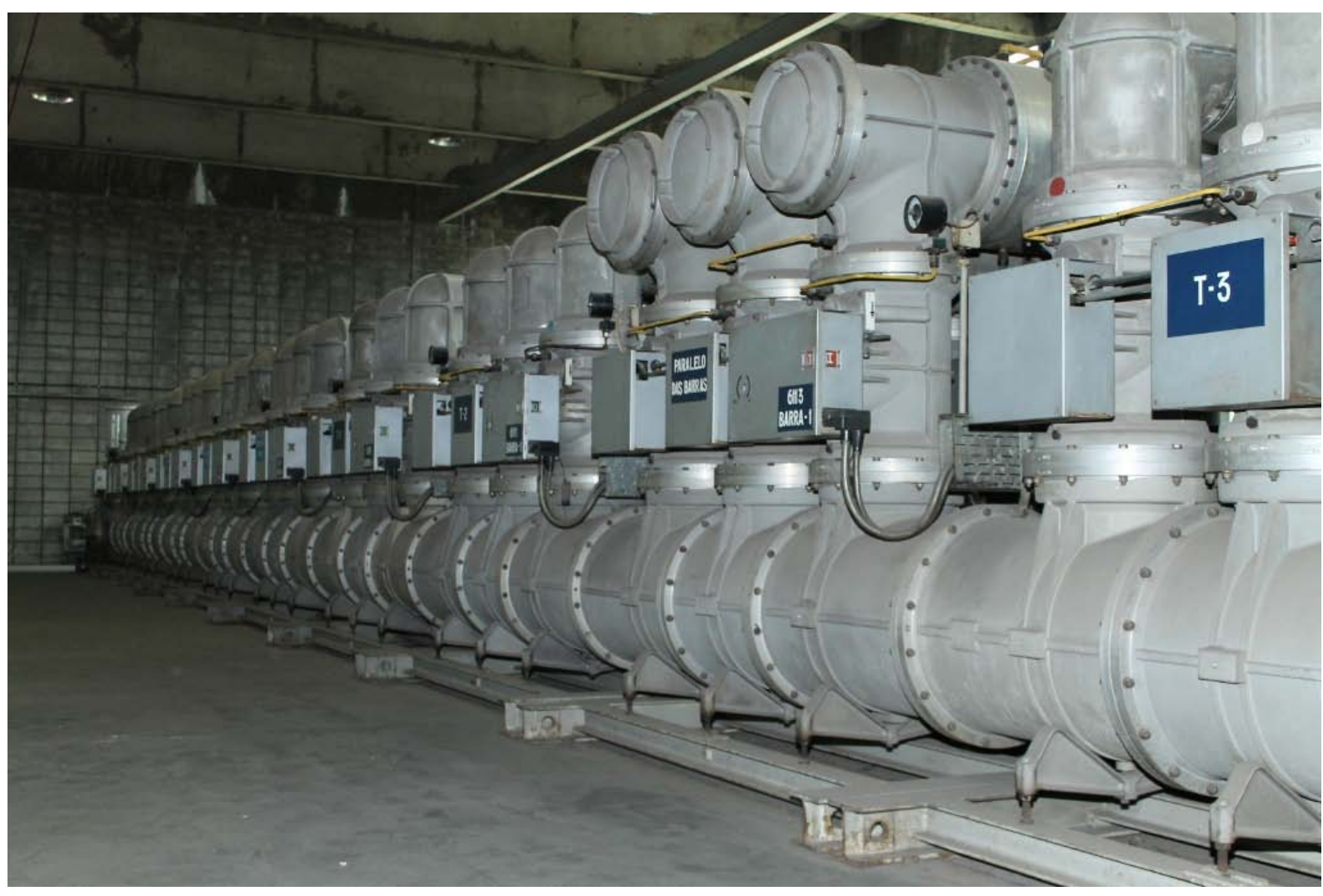

Figura 3: Subestação Paula Souza (AES Eletropaulo)

Esta subestação está se aproximando do fim de sua vida útil nominal. Esta questão gera diversas incertezas a respeito da sua confiabilidade. Desde a sua instalação, foram poucos incidentes relatados, todos de gravidade baixa, sem comprometimento de sua operacionalidade. Isso confirma a sua estabilidade, entretanto não se tem conhecimento a respeito da evolução e dos efeitos do tempo sobre o equipamento. Além disso, não se tem parâmetros históricos sobre o gás e o seu comportamento sazonal ou no longo prazo. Estes fatores foram motivadores para o desenvolvimento deste trabalho, pois o sistema desenvolvido permitirá que sejam feitas análises de comportamentos a partir de dados históricos. Desta forma, espera-se que a confiabilidade seja melhorada e que o seu ciclo de operação ao longo dos próximos anos possa ser acompanhado com mais segurança. 


\section{MATERIAIS E MÉTODOS}

$\mathrm{Na}$ área de engenharia elétrica e também na área de tecnologia da informação existem atualmente inúmeras tecnologias e soluções tanto de hardware quanto de software. Isso permite que possam ser propostas e discutidas idéias diversas e diferenciadas para a problemática exposta neste trabalho. Neste capítulo serão apresentados os materiais e recursos utilizados, bem como a descrição da metodologia usada para a construção do sistema remoto de aquisição de dados em tempo real e monitoramento proposto.

\subsection{HARDWARE UTILIZADO}

Para a estrutura de aquisição, comunicação e armazenamento de dados alguns recursos de hardware foram necessários para a criação da estrutura proposta. Um dos objetivos foi criar um sistema de aquisição de baixo custo, portanto os equipamentos escolhidos, sempre que possível, foram favorecidos por esta característica.

O hardware usado na solução inclui um micro computador, com características industriais, dedicado para o sistema. Esta máquina é usada como servidor central para o processo de aquisição e armazenamento de dados. Há também um painel de monitoramento construído para o acondicionamento dos módulos de aquisição de dados e módulos de comunicação com o servidor. As leituras dos parâmetros monitorados são feitas por dois tipos de sensores instalados diretamente nos compartimentos da subestação. Os detalhes dos equipamentos são apresentados nos itens subsequentes. 


\subsubsection{Sensores}

De forma a atender os objetivos do trabalho, foram utilizados dois tipos de sensores para leitura das grandezas a serem monitoradas, o ponto de orvalho e a densidade do gás $\mathrm{SF}_{6}$. As características de conexão destes transdutores foram determinadas em função do tipo de conector existente na subestação e de forma que pudessem ser instalados fisicamente. Entretanto, os sensores não oferecem interface para conexão direta, desta forma foram desenvolvidos conectores específicos para os sensores.

O sensor de densidade de gás utilizado foi o modelo GD-10 do fabricante Wika®. Este sensor determina a densidade do gás $\mathrm{SF}_{6}$ através de um sistema eletrônico com equações que levam em consideração as variações de temperatura e pressão no compartimento em que foi instalado. Os valores de densidade são fornecidos através de sinais proporcionais a correntes de 4-20mA.

O sensor de ponto de orvalho utilizado foi o modelo FA 415 do fabricante CS Instruments ${ }^{\circledR}$. Este sensor faz medições de ponto de orvalho a temperaturas entre $80^{\circ} \mathrm{C}$ e $20^{\circ} \mathrm{C}$ em compartimento de até 15 bar. Os valores são fornecidos através de sinais proporcionais a correntes de 4-20mA.

Os sensores são os equipamentos de maior custo do projeto. Optou-se por utilizar unidades de alta precisão e robustez, pois se espera a observação de variações pequenas e sutis, desta forma estes são os tipos de sensores mais adequados a essas exatidões. 


\subsubsection{Aquisição e comunicação de dados}

Para leitura dos dados dos sensores foram necessários módulos de aquisição de dados. Esses módulos têm a função de fazer leituras de sinais analógicos de 4-20mA ou sinais digitais e os converter em valores de engenharia. Foram utilizados dois tipos de módulos distintos para sinais analógicos e digitais. Estes módulos fazem aquisições constantes e disponibilizam os dados mais atuais para serem lidos. Os dados convertidos ficam disponíveis para serem lidos por meio do protocolo MODBUS/TCP (MODBUS over Ethernet).

Os módulos analógicos utilizados são do modelo ET-7017 do fabricante ICP $D A S \circledR$. As suas características principais incluem precisão de 16 bits para os dados em 10 canais de entradas analógicas diferenciais. Eles podem fazer aquisições de dados a partir de sinais 4-20mA e disponibilizar os dados através do protocolo MODBUS/TCP.

Os módulos digitais utilizados são do modelo ET-7051 do fabricante ICP $D A S \circledR$. Esse equipamento possui 16 canais, com isolação, de entradas digitais para leitura de contatos secos. Os dados lidos também são disponibilizados por meio do protocolo MODBUS/TCP.

Além disso, foi construído um painel concentrador para fornecer o suporte necessário para os equipamentos instalados. Ele tem também a função de fornecer a alimentação, além de incluir elementos de proteção para os diferentes equipamentos. A figura 4 apresenta o painel, onde podem ser observados os módulos de aquisição e comunicação, bem como os elementos de proteção e alimentação dos sensores.

Para comunicação de dados entre o painel de aquisição e o servidor foi utilizado um concentrador de rede ethernet do tipo switch. Este equipamento possui interfaces para cabos de rede, utilizados para conectar os módulos e também possui uma interface para fibra ótica, utilizada para comunicação com o servidor. Esta 
conexão com fibra ótica se faz necessária dada a distância entre o painel e o servidor, além de evitar interferências eletromagnéticas. O painel inclui também os seguintes componentes: fonte de alimentação, disjuntor 4A, isoladores 4-20mA, acopladores óticos e protetor de surto.

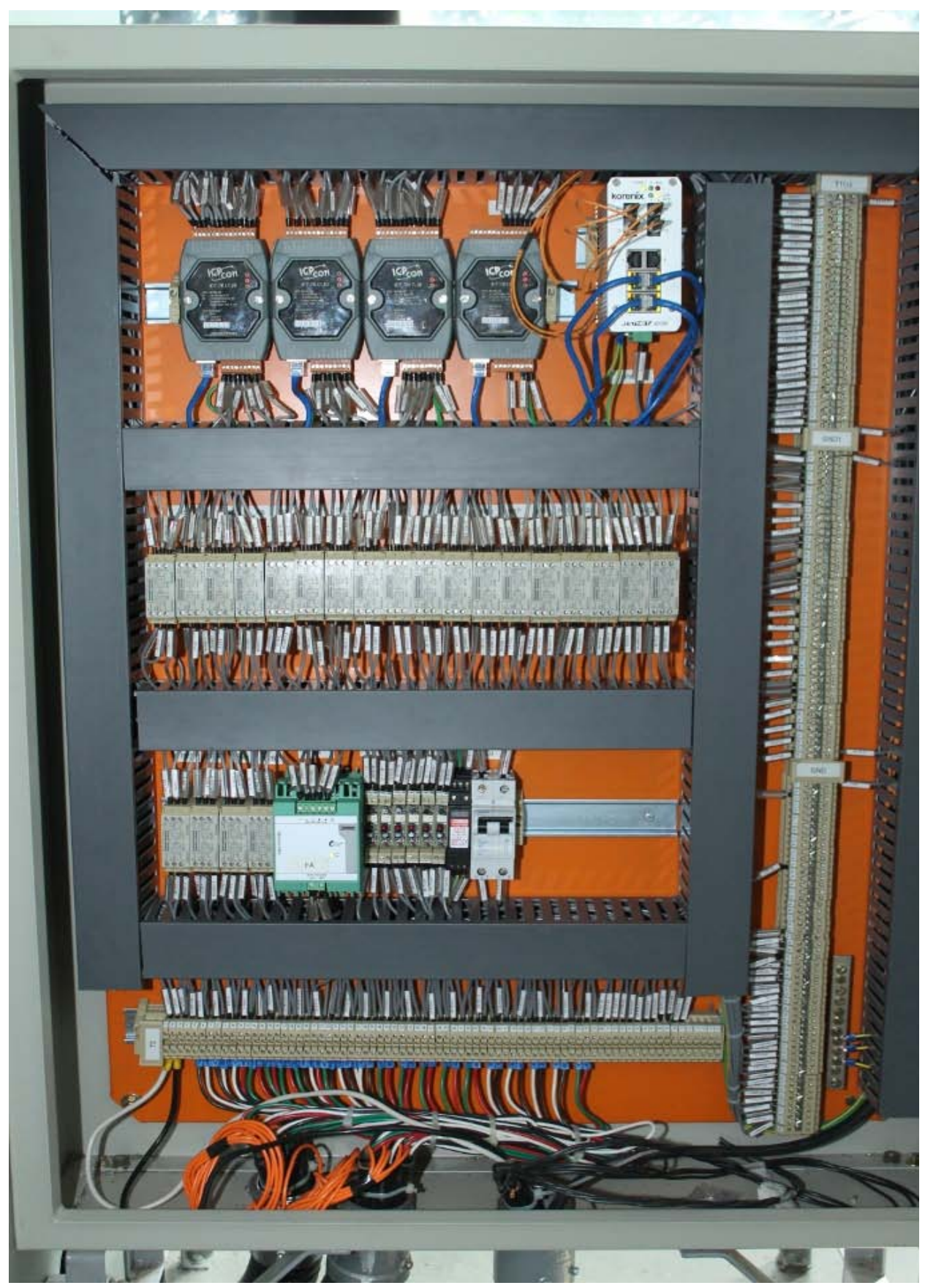

Figura 4: Painel de monitoramento 


\subsection{RECURSOS DE SOFTWARE}

Os recursos de software para o projeto podem ser categorizados de duas formas: os que foram adquiridos ou utilizados e os que foram desenvolvidos especificamente para este trabalho. Entre os softwares que foram utilizados ou adquiridos, estão incluídos: o sistema operacional Windows 7, o banco de dados Oracle, o servidor OPC, a ferramenta de desenvolvimento Eclipse, além dos softwares que compõem a tecnologia Java utilizada. Os softwares desenvolvidos incluem a interface de coleta dos dados do servidor $O P C$, que faz gravação dos dados na base de dados, e a interface de usuário para manipulação e visualização dos dados. A apresentação de alguns dos recursos e a sua justificativa de utilização são detalhadas abaixo, enquanto os softwares desenvolvidos são detalhados no capítulo seguinte.

Como solução para armazenamento de dados foi utilizada a versão gratuita Database $11 \mathrm{~g}$ Express Edition, do desenvolvedor Oracle® (Greenwald, Stackowiak e Stern, 2007). Esta versão possui limitações em relação à versão comercial, mas atende as necessidades do projeto e não foi necessária a compra de licença. A versão gratuita oferece até $4 \mathrm{~Gb}$ de dados. Apesar do sistema de aquisição receber e armazenar um volume grande de dados a expectativa é que ao longo de anos este limite do banco não seja atingido. Por outro lado, uma versão sem limitação ou até mesmo outro banco de dados poderá ser utilizado futuramente.

Para a aquisição de dados foi utilizado o padrão OPC (OLE for Process Control). A sua especificação foi desenvolvida em 1996 com o objetivo de padronizar a automação e comunicação de dados de uma planta industrial, permitindo a interoperabilidade entre equipamentos de diferentes fabricantes. A sua especificação está baseada nas tecnologias de objetos OLE, COM e DCOM desenvolvida pela Microsoft $\circledast$. A partir do padrão especificado foram desenvolvidas diversas soluções e produtos por fabricantes de software. As versões mais comuns comercializadas são os chamados servidores $O P C$, que são sistemas com função de 
fazer aquisições de dados a partir de diversos protocolos (chamados de drivers) e disponibilizar os dados unicamente no padrão OPC (Mahnke, Leitner e Damm, 2009). Para a solução desenvolvida neste trabalho foi utilizado o servidor OPCKEPServerEX v5 com driver para dispositivos MODBUS do desenvolvedor de software Kepware ${ }^{\circledR}$.

A tecnologia ou plataforma Java foi escolhida para servir de base para a interface de usuário desenvolvida. Optou-se por esta tecnologia por oferecer um suporte ferramental muito grande, permitindo que sejam desenvolvidas funções complexas e também pela possibilidade de ser agregada a plataforma Web. As principais vantagens da plataforma Web são a compatibilidade com qualquer sistema e também familiaridade da interface por praticamente qualquer usuário de sistemas computacionais. A plataforma Java foi criada pela Sun Microsistems e recentemente comprada pela Oracle. A plataforma engloba a linguagem de programação Java e também outros elementos para o suporte das aplicações, como as máquinas virtuais java (java virtual machine, do inglês ou jvm) que são o ambiente no qual os programas são executados. Existem as chamadas tecnologias Java, que são pacotes de funções e ferramentas para desenvolvimento de aplicações específicas. Para o desenvolvimento deste projeto foi utilizada a tecnologia Java EE (Java Enterprise Edition), que é a edição direcionada para desenvolvimento de aplicações para Web. Para o desenvolvimento da aplicação foi utilizada a ferramenta de desenvolvimento de software Eclipse. Esta ferramenta faz parte de um projeto open source (código livre) e é desenvolvida e mantida por uma fundação sem fins lucrativos, a Eclipse Foundation. O Eclipse pode ser definido como uma plataforma para desenvolvimento de software e oferece todo o suporte tecnológico e ferramental para desenvolvimento de sistemas, como o Java e suas tecnologias (Zambon e Sekler, 2007). 


\subsection{METODOLOGIA ADOTADA}

Para o monitoramento do gás, foi desenvolvido um sistema on-line em tempo real para aquisição dos dados necessários para coletar os dois parâmetros especificados. A supervisão e controle em tempo real da quantidade de gás contida nos compartimentos são feitos com auxilio de sensores eletrônicos de densidade (pressão e temperatura). O controle através de sensores eletrônicos de densidade se mostrou ser adequado, principalmente por oferecer grande sensibilidade. Desta forma, o processamento digital permite o acompanhamento de pequenas variações na quantidade de gás, em caso de perda por vazamento. A visualização dos dados em modo gráfico possibilita análises de tendências e/ou periodicidade de ocorrência de outros eventos associados ao comportamento do gás em longos períodos de tempo.

A instalação da subestação blindada da Eletropaulo, onde o sistema foi desenvolvido, foi construída a partir de um projeto mais antigo. Os bays possuem compartimentos com pressão diferenciada, onde os disjuntores operam em pressão maior que o restante dos equipamentos. Durante o seu ciclo de operação do disjuntor, o $\mathrm{SF}_{6}$ circula entre compartimentos de alta e baixa pressão causando uma variação de pressão e densidade nestes compartimentos sem que isto signifique anormalidade. Isso é um fator que gera dificuldade de se realizar um controle de densidade de gás. Desta forma, se torna difícil o simples monitoramento de densidade em cada compartimento ou o estabelecimento de níveis de alarme para perdas de gás apenas pela variação de densidade. Porém, se considerada a soma das massas de gás contidas em todos os compartimentos do bay, esta deve permanecer constante. As massas de gás deverão ser obtidas a partir de todos os sensores de densidade do bay do sistema de monitoramento. Os dados coletados e armazenados no banco de dados servirão de base para o calculo da massa do bay, que segue a seguinte ponderação: 
MassaTotal $=($ densidade $1+$ densidade $2+$ densidade 3$) *$ volumeBay

Quando se considera a instalação de um sistema de monitoramento em uma subestação antiga e que não tem em seu projeto original interfaces para equipamentos de aquisição e transmissão dos dados, devem-se incluir elementos que se adaptam. Desta forma, foi necessária a especificação e construção de adaptadores para conexão dos transdutores a serem utilizados no sistema de monitoramento. Além disso, se fez necessário a instalação de elementos para alimentação dos transdutores e comunicação de dados. Isso significa que toda a estrutura necessária para inclusão destes novos elementos, incluindo o hardware para coleta e transmissão dos dados deve ser agregada à subestação.

Em função do reconhecimento das condições de campo, das análises de custo benefício e da disponibilidade financeira do projeto, o monitoramento online foi desenvolvido para fazer a aquisição dos valores de duas grandezas básicas:

- Densidade do gás $\mathrm{SF}_{6}$;

- Ponto de orvalho do gás.

Para coleta destas informações foi necessária a instalação de uma unidade de cada sensor (um par) em cada compartimento a ser monitorado, sendo um específico para densidade e outro específico para ponto de orvalho. São monitorados três bays e as duas barras da subestação. Em cada bay foram instalados sensores em três compartimentos distintos, enquanto que nas barras foram instalados em apenas um ponto. Uma vez disponíveis pelos módulos de aquisição, estas informações passam por um tratamento em software dedicado para validação e armazenamento. Estando armazenadas na base de dados estas duas grandezas poderão ser utilizadas para se observar um potencial comprometimento 
dos compartimentos em função de possíveis contaminações por umidade e, consequentemente, permitirão avaliações do dielétrico da subestação.

Os valores de densidade obtidos com sensores eletrônicos ao longo do tempo poderão indicar eventuais diminuições na massa de gás nos compartimentos monitorados, portanto será possível a identificação de perdas de gás. Este método proposto melhora a sensibilidade em relação ao método atual utilizando pressostatos eletromecânicos.

Os valores de ponto de orvalho do $\mathrm{SF}_{6}$, obtidos de forma online permitem aumentar os intervalos desta verificação por instrumental externo, reduzindo assim a perda e emissão de $\mathrm{SF}_{6}$ para atmosfera. Entende-se que isso gera também um ganho ambiental, pois ao se realizar a medição de gás com este tipo de equipamento normalmente há liberação de gás para a atmosfera, mesmo que em pequenas quantidades. Considera-se também que o aumento do intervalo entre medições com instrumental externo reduz os custos diretos envolvendo programação e recursos humanos para esta atividade. 


\section{RESULTADOS}

\subsection{REQUISITOS DO SISTEMA DE MONITORAMENTO}

Para o monitoramento do estado do gás $\mathrm{SF}_{6}$ foram definidos alguns requisitos para a elaboração da sua arquitetura. Primeiramente, optou-se por equipamentos de comunicação e aquisição de dados de baixo custo. Como há necessidade de aquisição de dados de muitos pontos, os equipamentos especificados devem atender também ao requisito de custo. Foi definida a utilização dos protocolos padrão MODBUS/TCP e TCP/IP (para aquisição e comunicação, respectivamente) por facilitarem a instalação e comunicação além de diminuir o custo do projeto.

Foi definido que seriam monitorados dois parâmetros principais, a densidade do gás e o ponto de orvalho. O objetivo de se monitorar a densidade do gás nos compartimentos é a detecção de vazamentos. Este parâmetro permite observar a diminuição da massa de gás até os níveis críticos de isolamento. Esta informação se torna importante, uma vez que quando a quantidade de gás no compartimento não for mais suficiente para manter o isolamento mínimo para operação segura deve-se determinar o impedimento de utilização do equipamento. O segundo parâmetro citado a ser monitorado tem o objetivo de fornecer indicativos da qualidade do gás e por meio dele se deseja observar a umidade interna com auxilio de sensor de ponto de orvalho. A umidade $\left(\mathrm{H}_{2} \mathrm{O}\right)$ contida no $\mathrm{SF}_{6}$ pode afetar o desempenho do equipamento sob dois aspectos:

- redução da capacidade dielétrica do gás;

- rompimento completo do dielétrico, provocado pela eventual condensação de umidade sobre superfícies isolantes. 
Considerando estas necessidades, os sensores especificados devem atender os requisitos de exatidão alta, pois permitem observar pequenas variações.

\subsection{ARQUITETURA DO SISTEMA DE MONITORAMENTO}

Antes de definir a solução que seria adotada no projeto foi feito estudo para a supervisão completa da subestação. Neste cenário, foi considerado o monitoramento de todos os compartimentos da subestação, a supervisão dos sinais de abertura e fechamento dos disjuntores e dos sinais de operação dos compressores. Considerando a forma como a subestação Paula Souza é compartimentada, seria necessária a instalação de três sensores de densidade de gás e três sensores de ponto de orvalho em cada bay, além de dois sensores em cada barra. O monitoramento de todos os dados, tanto dos sensores, quanto os demais sinais devem ser feitos através de módulos de aquisição de dados. $\mathrm{O}$ módulo tem a função de realizar as leituras dos sinais e disponibilizar os dados no protocolo de comunicação MODBUS. Eles devem ser conectados a uma rede Ethernet por meio de um concentrador com interface para fibra ótica que é conectada ao servidor do sistema, distante aproximadamente $100 \mathrm{~m}$. Os dados são coletados continuamente pelo servidor e armazenados em um banco de dados histórico para consultas posteriores. O desenho da arquitetura computacional para esta solução é apresentado na figura 5. Os equipamentos especificados também visam a otimização de custos. 


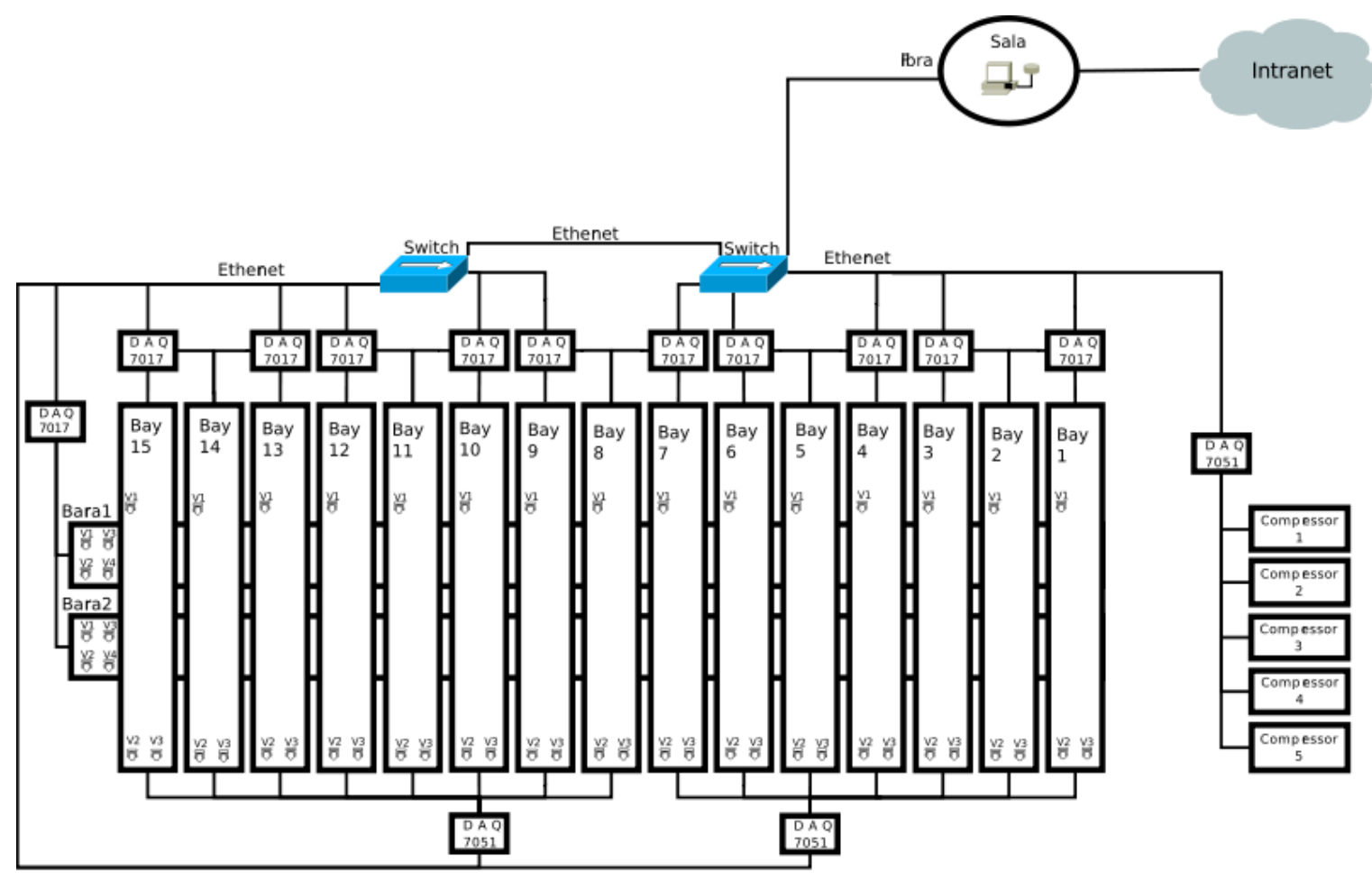

Figura 5: Arquitetura completa do sistema de monitoramento

Devido a restrições de recursos para instalação do projeto completo, foi elaborada uma versão reduzida e adequada aos recursos disponíveis. O sistema que foi efetivamente instalado contempla o monitoramento parcial da subestação, mas é suficiente para avaliar a aplicabilidade da proposta. Portanto, foi definido que seriam monitorados três bays (lado a lado), incluindo os sinais de abertura e fechamento dos respectivos disjuntores, e as duas barras da subestação. A arquitetura do sistema de monitoramento segue o mesmo modelo apresentado na figura 5, apenas se considera que um número menor de bays são monitorados e também são utilizados menos equipamentos para aquisição e comunicação de dados. A arquitetura simplificada do projeto instalado pode ser visualizada na figura 6. 


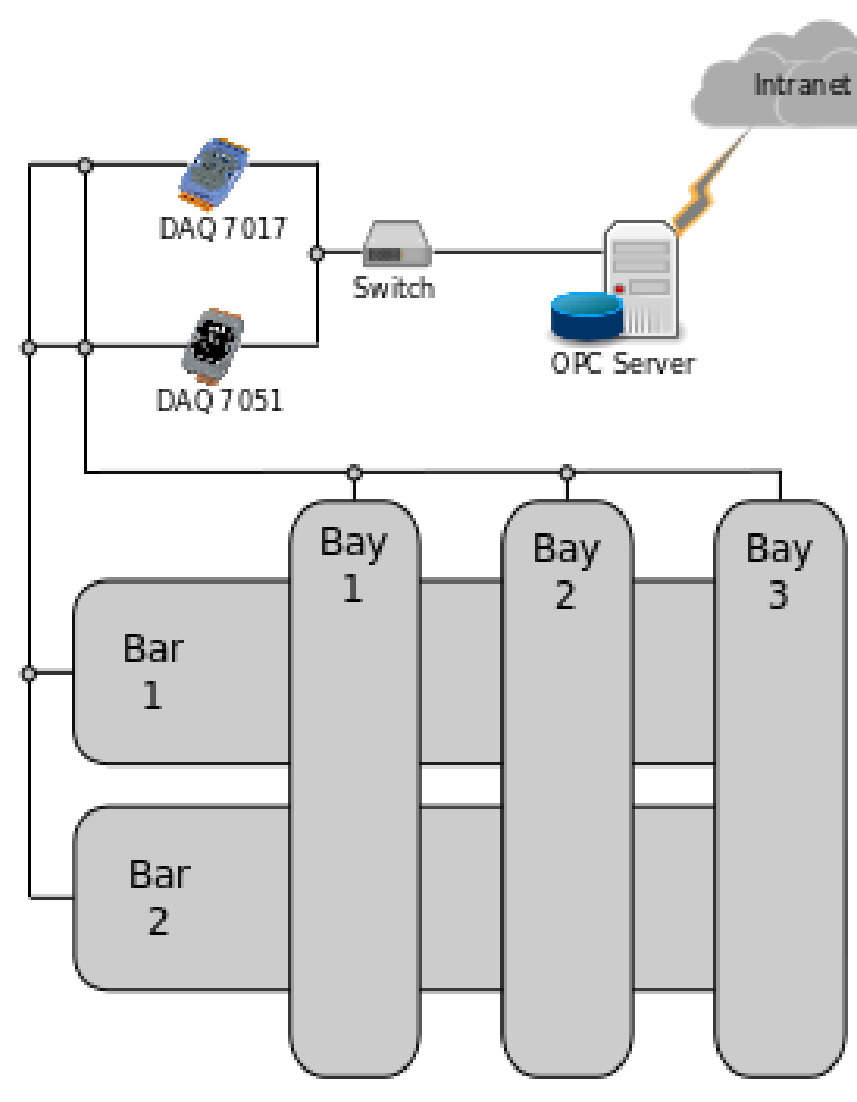

Figura 6: Arquitetura do sistema de monitoramento (instalado)

É importante ressaltar que o sistema de monitoramento ideal é aquele que inclui todos os bays da subestação, desta forma poder-se-ia ter uma visão completa do comportamento do gás durante a operação dos equipamentos, bem como a quantidade de gás em todos os compartimentos da subestação. 


\subsection{ARQUITETURA DE SOFTWARE DO SISTEMA DE MONITORAMENTO}

Foi desenvolvido um sistema para aquisição remota de dados. O sistema tem uma interface com o usuário baseado na plataforma Web. O hardware local usado no sistema de aquisição de dados é composto de um micro computador, para comunicação com o painel onde estão os equipamentos de aquisição de dados dos sensores. A plataforma básica inclui o sistema operacional Windows 7 juntamente com o servidor Apache, com módulo TomCat para suporte a Java JSP, servidor OPC e Oracle como sistema de gerenciamento de banco de dados. A comunicação local com o painel de monitoramento é feita com o protocolo MODBUS por meio do servidor OPC. A arquitetura de aquisição de dados do sistema é representada na figura 7 . 


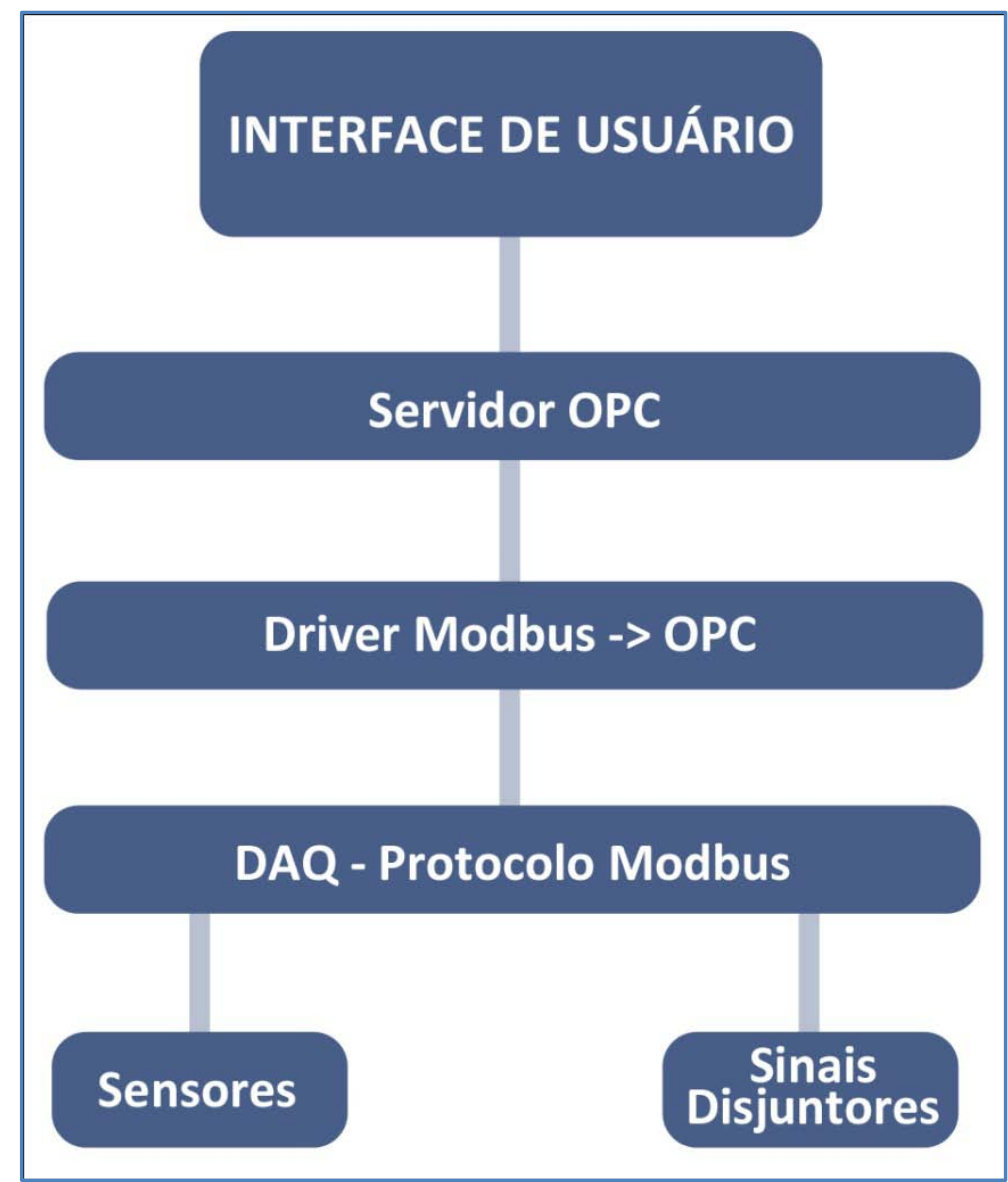

Figura 7: Arquitetura de aquisição de dados

\subsection{ADAPTAÇÕES PARA CONEXÃO DOS SENSORES}

Para que possam ser instalados os sensores na subestação foi necessário agregar adaptadores para a conexão dos sensores em cada um dos pontos a serem monitorados. São utilizados três pontos distintos em cada bay, além de um ponto em cada barra da subestação. Os adaptadores foram instalados nas válvulas utilizadas para preenchimento de gás. Para a construção dos adaptadores foram utilizados válvulas e acopladores padronizados pelo fabricante Dilo ${ }^{\circledR}$. Foram construídos três adaptadores distintos, com configurações diferentes. Isso foi 
necessário devido aos espaços disponíveis em cada ponto a ser instalado na subestação e também de forma a facilitar o acesso ao ponto de preenchimento de gás. Como os adaptadores foram instalados em pontos que eram utilizados para preenchimento de gás foi necessário manter o ponto, desta forma os adaptadores permitem a conexão de dois sensores e ainda possui uma terceira saída para manutenção. Para instalação dos sensores nas barras, foi construído um adaptador que fosse compatível com o espaço disponível e também facilitasse a instalação de um manômetro já existente.

\subsection{INSTALAÇÃO}

A criação e instalação da estrutura para o sistema de aquisição de dados pode ser dividida em duas etapas, uma relativa a definição e instalação dos equipamentos e demais estruturas de hardware para o funcionamento do sistema de monitoramento. A segunda etapa trata do desenvolvimento de software bem como a disponibilização e configuração da estrutura computacional.

Inicialmente, foram definidos os componentes e equipamentos necessários para que o sistema de monitoramento seguisse a metodologia. A partir desta definição foram feitas as instalações da estrutura para alimentação e comunicação de dados dos sensores. Para as atividades de instalação foram seguidos os procedimentos da empresa para a garantia de não vazamento de gás. Para tanto, os sensores foram montados nos conectores e foram feitos ensaios de estanqueidade para garantir a sua hermeticidade. Além disso, antes da instalação efetiva na subestação, as peças foram submetidas a um equipamento para criar vácuo. Após os procedimentos de segurança, os sensores e adaptadores foram instalados na subestação. Nas figuras 8, 9 e 10 são demonstradas as peças instaladas na subestação. Na figura 10 também é possível observar a fixação 
adotada para o ponto do compartimento do disjuntor. Esta fixação foi necessária para manter a sustentação da peça na subestação. Para os demais pontos não foi necessário a adoção de suporte adicional.

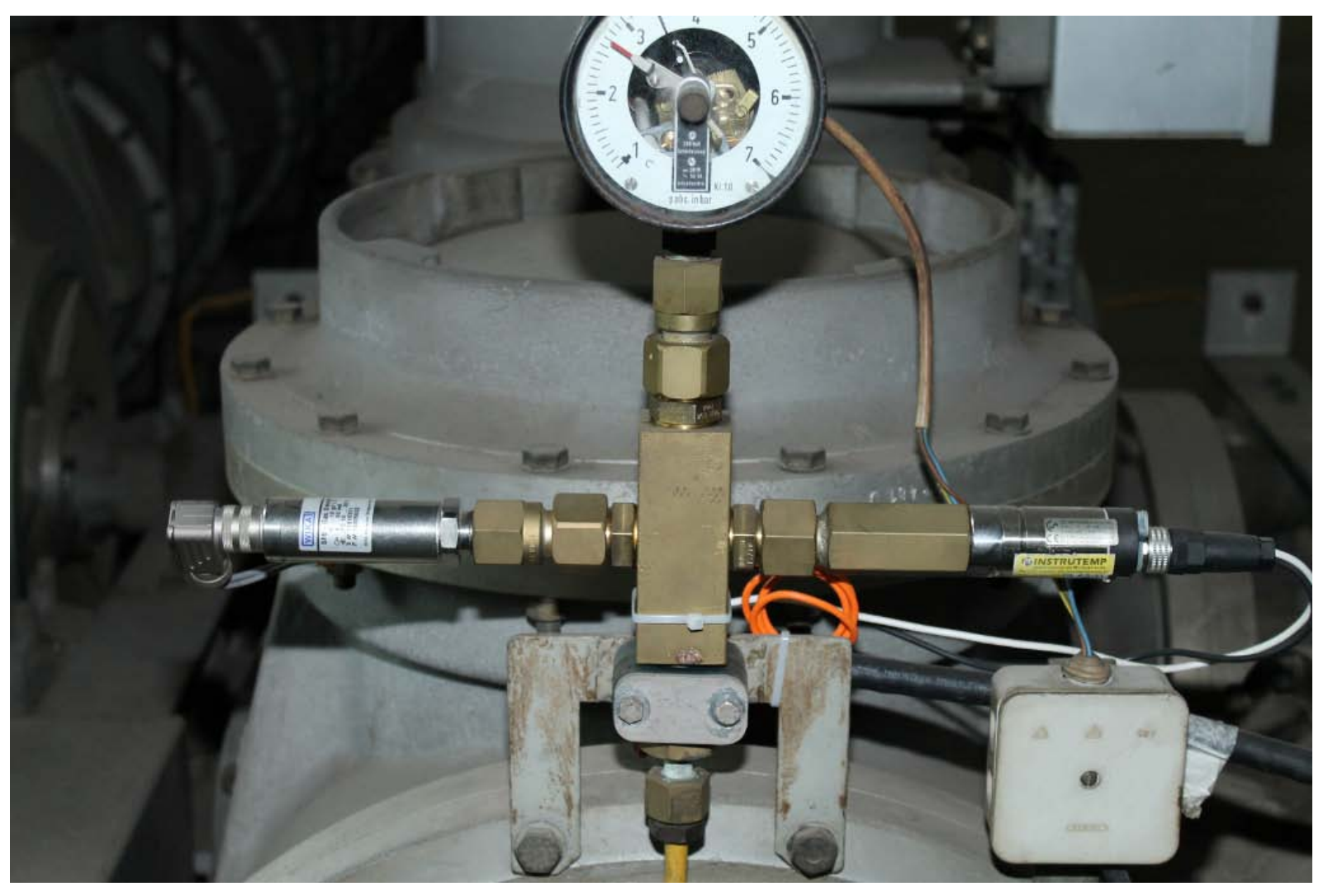

Figura 8: Sensores instalados (barra 2) 


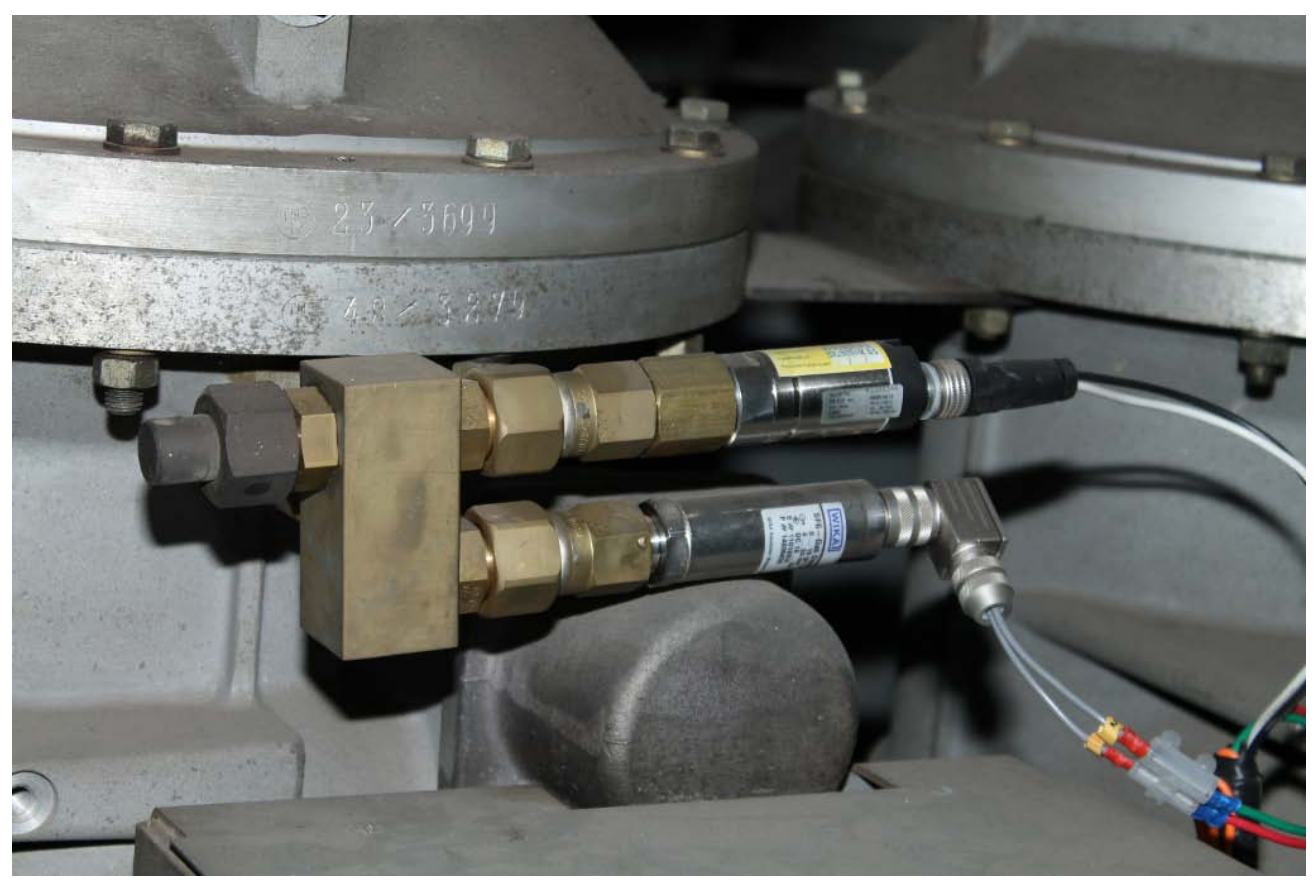

Figura 9: Sensores instalados (ponto central do bay)

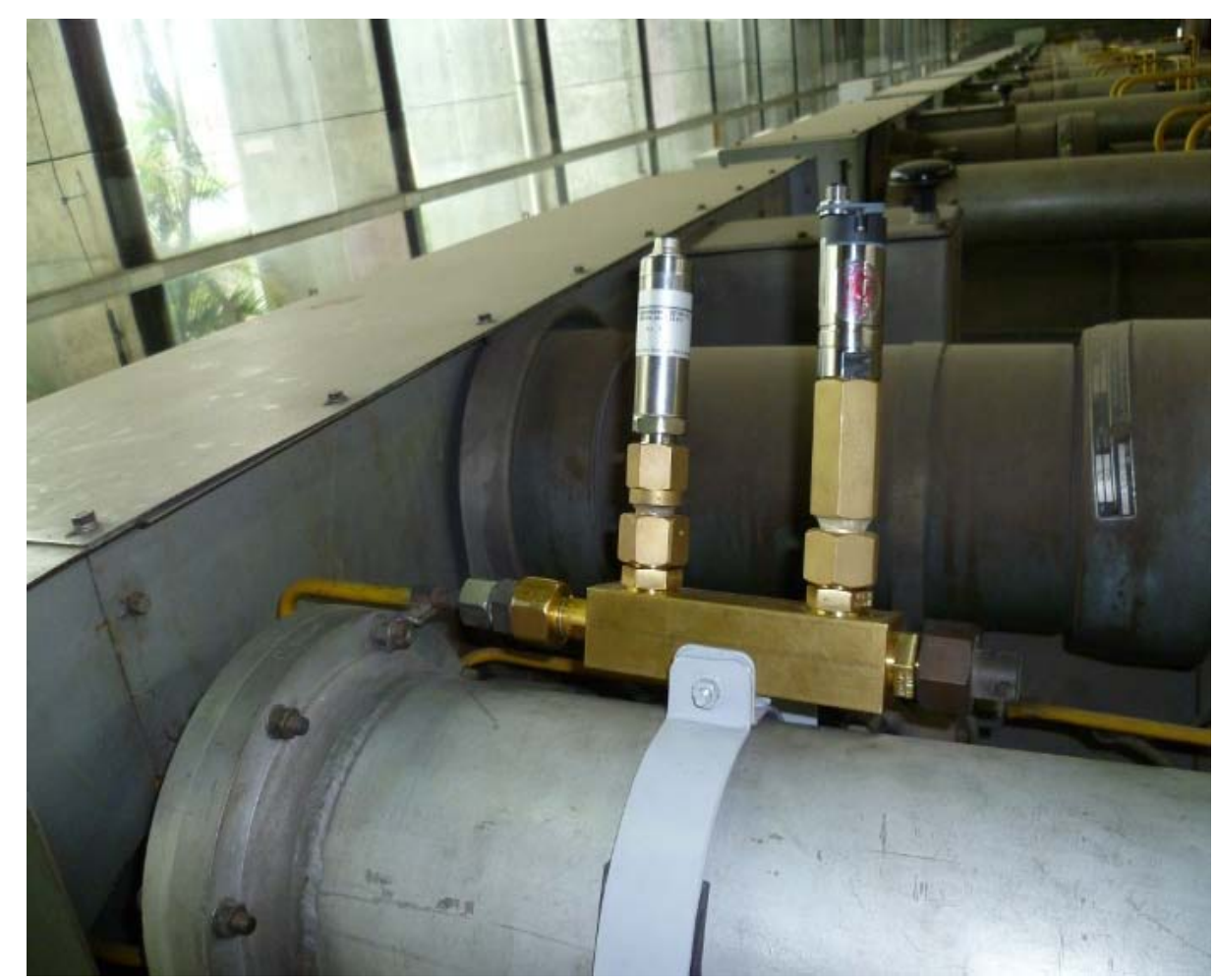

Figura 10: Sensores instalados (disjuntor) 
Após a instalação dos sensores, foram feitos os conectores para a sua alimentação e comunicação. Os sensores foram ligados ao painel de monitoramento e organizados de forma que os seus sinais pudessem ser lidos pelos módulos de aquisição de dados. Cada sensor foi conectado a uma porta do módulo analógico. Finalmente, foi feita a conexão da fibra ótica e instalado o servidor em um painel na sala de comando da subestação.

O suporte de software para o sistema também pode ser visto de duas formas distintas, o desenvolvimento do sistema de aquisição e a estrutura de suporte. Para que o sistema pudesse ser implantado foi necessária a instalação do banco de dados Oracle, servidor Apache com módulo TomCat e servidor OPC. Além disso, foi necessária a configuração das variáveis analógicas e digitais no servidor OPC para que pudessem ser requisitados os dados de campo. O restante do software componente do sistema foi desenvolvido especificamente para esta solução de monitoramento. Uma das peças importantes de software desenvolvido foi o sistema que faz a gravação dos dados do servidor OPC no banco de dados. Para esta função foi criado um software que faz a leitura das variáveis do servidor $O P C$ e as grava no banco de dados. A partir dele são determinados os intervalos de tempo entre as leituras que serão gravadas no banco de dados, independente do tempo de varredura configurado no OPC. Outra parte do desenvolvimento do software foi a criação da interface de usuário. A partir dela o operador poderá acompanhar as variações de comportamento nos bays monitorados e também fazer gráficos a partir de dados históricos armazenados no banco. É importante ressaltar que os dados visualizados representam os valores que já foram gravados na base de dados, a interface trabalha com a recuperação de dados do banco e não dos últimos valores lidos instantaneamente pelos sensores. Isso representa uma vantagem, uma vez que os dados apresentados para o usuário já foram validados pela estrutura de aquisição de dados. 
O sistema de interface com o usuário foi desenvolvido e dividido em duas funcionalidades, a visualização dos dados mais recentes dos pontos monitorados e a recuperação de dados históricos para geração de gráficos. As telas do sistema foram organizadas com links para cada um dos três bays, as duas barras, vazamentos (onde se podem visualizar as massas calculadas para os bays e barras) e também links com telas pré configuradas para a geração de gráficos relativos a esta mesma estrutura citada. Na figura 11, pode-se observar a organização dos links de acesso às funções do sistema. A tela representada por esta figura também demonstra as informações relativas ao bay 1. A tela mostra o estado do disjuntor do bay, este dado é recuperado do banco de dados a partir do dado mais recente lido do módulo digital. Podem-se observar também os dados lidos dos três pontos distintos com sensores na subestação. As localizações dos pontos foram chamadas de: disjuntor, seccionadora e entrada de cabos. Estes nomes fazem referência ao local onde o sensor foi instalado. Além disso, podem-se observar os dados de todos os sensores instalados e a sua data e hora de aquisição. As telas para os bays $2 \mathrm{e}$ 3 são idênticas a esta tela referenciada, tendo apenas como diferença os dados relativos ao bay em particular. 


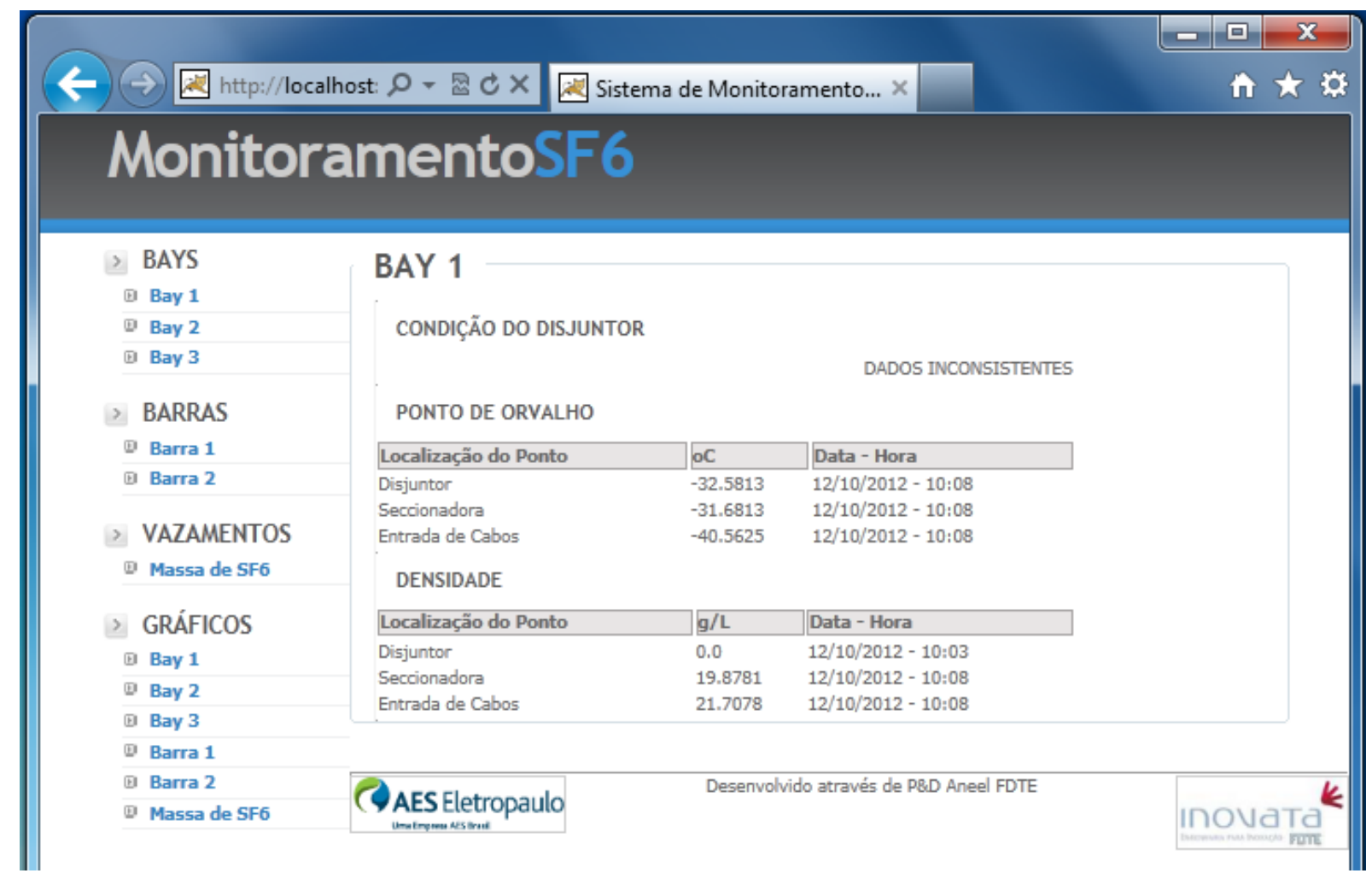

Figura 11: Tela monitoramento Bay 1

A tela de monitoramento das barras é similar as telas desenvolvidas para o monitoramento dos bays. Podem-se observar nesta tela os dados relativos aos sensores instalados na barra, conforme representação na figura 12. Cada barra possui um par de sensores instalados. 


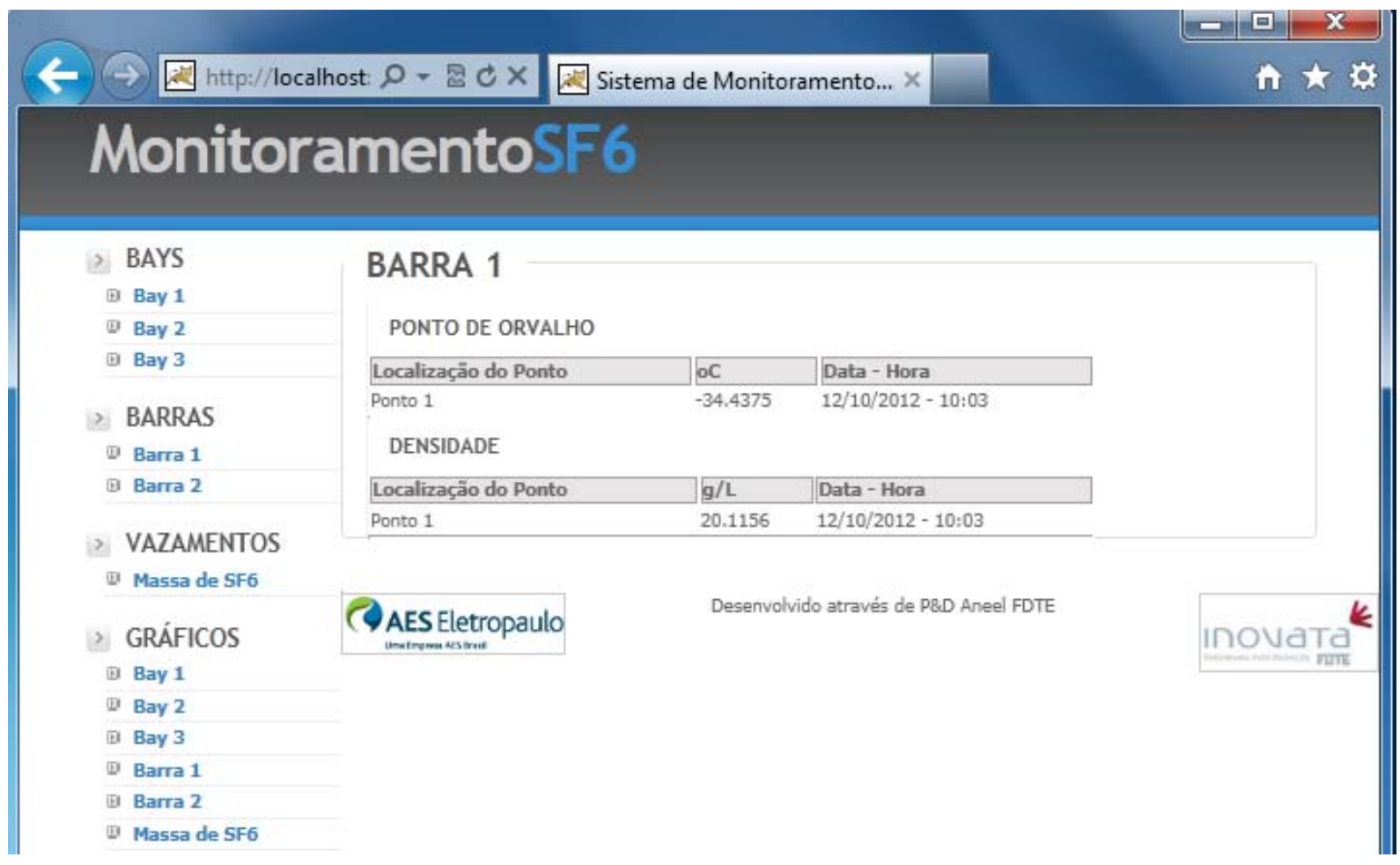

Figura 12: Tela monitoramento Barra 1

O monitoramento de vazamentos pode ser feito através da tela do sistema desenvolvida para esta finalidade. Nesta tela o usuário visualiza os dados calculados da massa total de cada bay e de cada barra de forma individualizada. Segundo a metodologia definida para o projeto, a massa de cada bay deve permanecer constante mesmo que haja movimentação de gás entre os compartimentos durante a operação da subestação. A figura 13 demonstra a tela onde são apresentados os valores de massa atual, calculada a partir dos dados dos sensores. Além disso, foi criada uma tabela onde podem ser comparados os valores atuais com valores conhecidos e pré-determinados. Os valores de referência são definidos pelo usuário ou operador do sistema. Há ainda uma tela para configuração 
e ajuste dos valores, onde podem ser feitas alterações e atualizações dos valores de referência sempre que necessário.

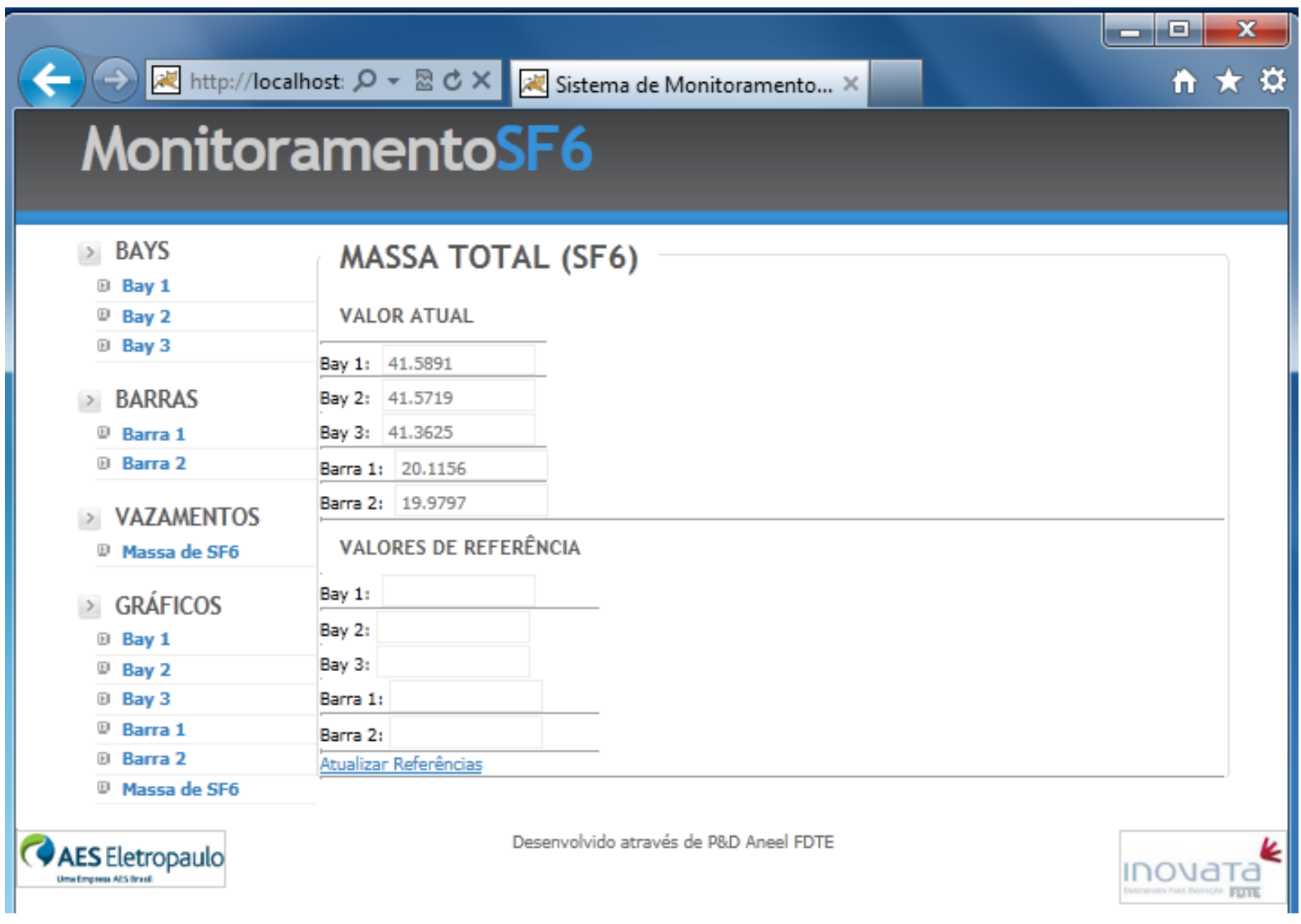

Figura 13: Tela monitoramento de vazamentos

Uma forma alternativa de visualização dos dados lidos em campo é na forma de gráfico, portanto foram criadas telas para acesso histórico aos dados armazenados no banco de dados. Os dados podem ser recuperados a partir de botões de acesso rápido com períodos pré configurados ou também gerar um 
gráfico a partir de um intervalo de data especificado pelo usuário para um sensor específico. A figura 14 apresenta a tela de geração de gráficos para o bay 1, nela existem botões representando os pontos monitorados e a partir deles é possível gerar um gráfico com os dados coletados no dia atual. Além disso, o usuário pode determinar o intervalo de datas e a variável que deseja visualizar os dados históricos para gerar um gráfico personalizado. As telas para os demais bays e as barras seguem uma interface correspondente a esta detalhada.

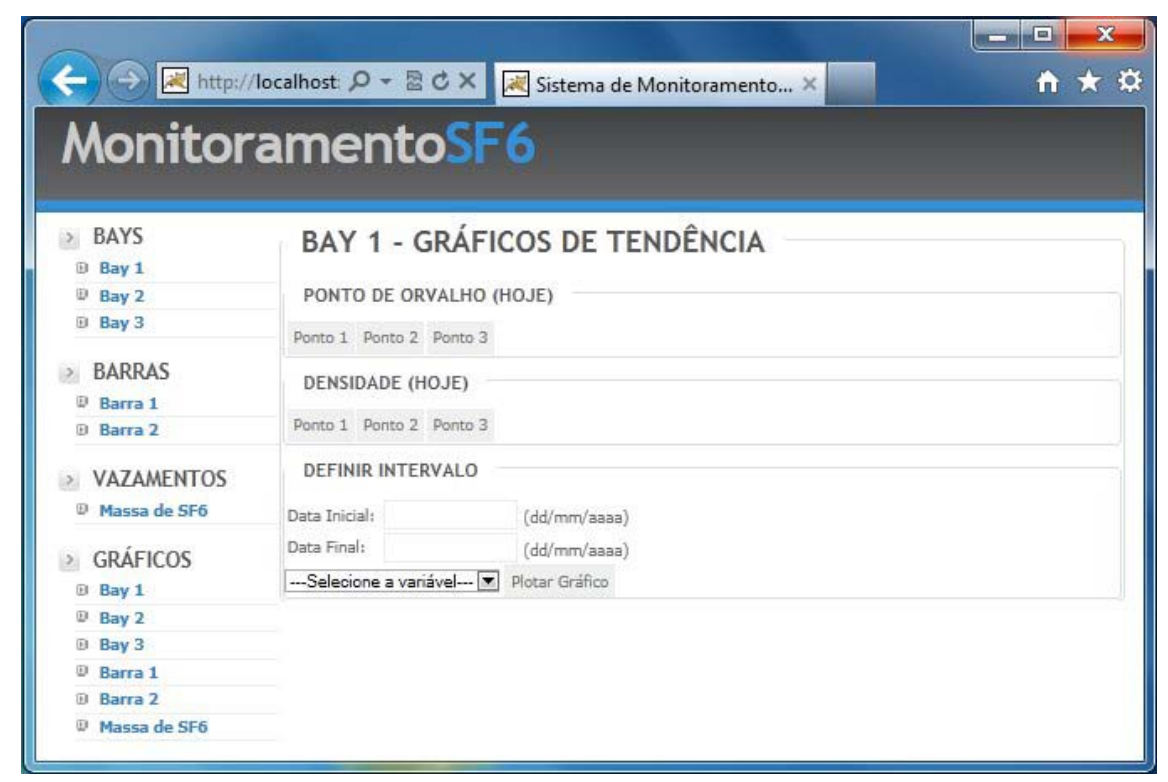

Figura 14: Tela para criação de gráficos Bay 1

Para verificações de vazamentos e análise da massa de gás nos compartimento, foi criada uma tela para geração de gráficos da massa nos bays e barras. Da mesma forma que as demais telas para gráficos, foram incluídos botões para geração instantânea de gráficos com períodos de tempo pré-determinados. Desta forma podem ser gerados facilmente gráficos relativos a um dia, uma semana, 
uma quinzena e um mês. Além disso, também é possível definir intervalos diferentes para os gráficos. A figura 15 apresenta a tela de usuário para geração de dados gráficos.

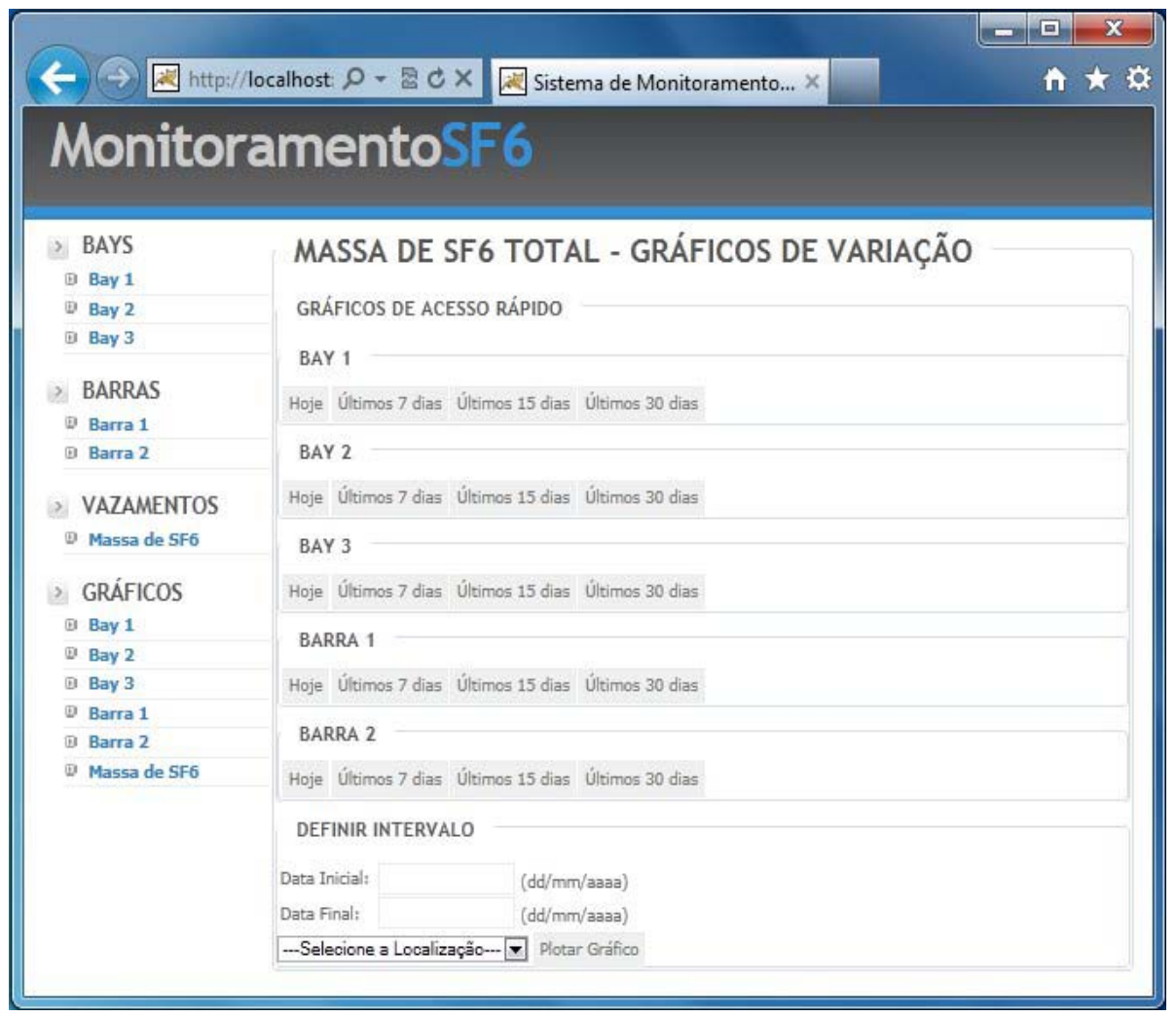

Figura 15: Tela para gráficos de massa (vazamentos)

\subsection{ANÁLISE DE DADOS}

Foi realizada uma análise dos dados com objetivo de observar o comportamento dos parâmetros monitorados. Os dados analisados se apresentaram extremamente estáveis, com variações muito pequenas, o que 
confirma a estabilidade do gás no equipamento. Foram analisados dados de 5 dias consecutivos (07/10/2012 a 11/10/2012), sendo um deles do fim de semana.

Para a geração de dados suficientes para garantir uma análise detalhada, o sistema foi configurado para obter dados a cada 1 minuto. A partir do volume de dados coletados, foi calculada a média horária e desvio padrão para os dados de cada sensor. Ao se verificar a variabilidade baixa dos dados, pode-se considerar que o volume coletado é estatisticamente suficiente para se ter um comportamento diário dos parâmetros monitorados.

Os resultados de todos os sensores foram muito similares, ou seja, o comportamento de todos os compartimentos monitorados é praticamente o mesmo. As variações observadas são muito pequenas a ponto de serem insignificantes para algum eventual comprometimento da operação do equipamento. Entretanto, é possível atribuir um comportamento constante aos valores, isso significa que a partir de comparações históricas é possível verificar se há alguma tendência que possa comprometer a qualidade do gás ou há diminuição de quantidade.

A tabela 1 apresenta os dados de ponto de orvalho (PO), em ${ }^{0} \mathrm{C}$, da barra 2. Aos dados obtidos, a cada minuto, foi calculada da média de cada hora e o seu desvio padrão correspondente. Pode-se observar que a variação dos dados de todas as médias é próximo a zero, pois o desvio padrão (DP) da média indica a baixa variabilidade. Os dados dos demais sensores de ponto de orvalho apresentaram valores equivalentes, portanto pode-se afirmar que o comportamento dos dados apresentados na tabela referente ao ponto de orvalho da barra 2 é equivalente aos demais sensores. 
Tabela 1: Dados relativos a ponto de orvalho da barra 2

\begin{tabular}{|r|l|l|l|l|l|l|l|l|l|l|}
\hline & Dia 7 & & Dia 8 & & Dia 9 & & Dia 10 & & Dia 11 & \\
\hline Hora & PO & DP & PO & DP & PO & DP & PO & DP & PO & DP \\
\hline 0 & $-33,64$ & 0,02 & $-32,96$ & 0,07 & $-33,46$ & 0,09 & $-33,96$ & 0,06 & $-32,07$ & 0,08 \\
\hline 1 & $-33,73$ & 0,03 & $-33,18$ & 0,06 & $-33,76$ & 0,09 & $-34,17$ & 0,07 & $-32,33$ & 0,07 \\
\hline 2 & $-33,82$ & 0,03 & $-33,39$ & 0,06 & $-34,00$ & 0,06 & $-34,35$ & 0,04 & $-32,55$ & 0,07 \\
\hline 3 & $-33,92$ & 0,03 & $-33,59$ & 0,06 & $-34,21$ & 0,05 & $-34,48$ & 0,04 & $-32,78$ & 0,07 \\
\hline 4 & $-34,00$ & 0,02 & $-33,76$ & 0,05 & $-34,37$ & 0,04 & $-34,60$ & 0,04 & $-32,99$ & 0,06 \\
\hline 5 & $-34,07$ & 0,03 & $-33,88$ & 0,03 & $-34,53$ & 0,05 & $-34,75$ & 0,04 & $-33,18$ & 0,06 \\
\hline 6 & $-34,15$ & 0,03 & $-33,96$ & 0,01 & $-34,62$ & 0,01 & $-34,86$ & 0,02 & $-33,33$ & 0,03 \\
\hline 7 & $-34,22$ & 0,02 & $-33,94$ & 0,02 & $-34,55$ & 0,04 & $-34,85$ & 0,04 & $-33,35$ & 0,03 \\
\hline 8 & $-34,14$ & 0,07 & $-33,79$ & 0,07 & $-34,33$ & 0,09 & $-34,62$ & 0,10 & $-33,15$ & 0,09 \\
\hline 9 & $-33,86$ & 0,10 & $-33,36$ & 0,21 & $-33,92$ & 0,13 & $-34,21$ & 0,14 & $-32,77$ & 0,13 \\
\hline 10 & $-33,49$ & 0,15 & $-32,76$ & 0,18 & $-33,36$ & 0,23 & $-33,59$ & 0,22 & $-32,24$ & 0,19 \\
\hline 11 & $-32,80$ & 0,28 & $-32,18$ & 0,22 & $-32,52$ & 0,26 & $-32,90$ & 0,20 & $-31,54$ & 0,21 \\
\hline 12 & $-32,18$ & 0,14 & $-31,25$ & 0,29 & $-31,68$ & 0,17 & $-32,25$ & 0,16 & $-30,89$ & 0,16 \\
\hline 13 & $-31,51$ & 0,11 & $-30,73$ & 0,04 & $-31,30$ & 0,07 & $-31,61$ & 0,14 & $-30,41$ & 0,11 \\
\hline 14 & $-31,06$ & 0,16 & $-30,43$ & 0,15 & $-31,06$ & 0,07 & $-31,28$ & 0,09 & $-30,06$ & 0,11 \\
\hline 15 & $-30,62$ & 0,11 & $-29,71$ & 0,18 & $-31,05$ & 0,04 & $-30,91$ & 0,12 & $-29,48$ & 0,18 \\
\hline 16 & $-30,36$ & 0,03 & $-29,49$ & 0,04 & $-31,39$ & 0,13 & $-30,62$ & 0,07 & $-29,12$ & 0,05 \\
\hline 17 & $-30,47$ & 0,11 & $-30,27$ & 0,40 & $-31,84$ & 0,17 & $-30,42$ & 0,04 & $-28,94$ & 0,05 \\
\hline 18 & $-30,95$ & 0,14 & $-31,34$ & 0,23 & $-32,35$ & 0,10 & $-30,40$ & 0,02 & $-29,48$ & 0,28 \\
\hline 19 & $-31,48$ & 0,18 & $-31,99$ & 0,16 & $-32,63$ & 0,08 & $-30,57$ & 0,09 & $-30,37$ & 0,22 \\
\hline 20 & $-31,97$ & 0,11 & $-32,45$ & 0,11 & $-32,90$ & 0,07 & $-30,89$ & 0,09 & $-31,01$ & 0,17 \\
\hline 21 & $-32,32$ & 0,09 & $-32,77$ & 0,09 & $-33,18$ & 0,10 & $-31,22$ & 0,09 & $-31,41$ & 0,06 \\
\hline 22 & $-32,56$ & 0,06 & $-33,03$ & 0,07 & $-33,51$ & 0,09 & $-31,49$ & 0,08 & $-31,62$ & 0,06 \\
\hline 23 & $-32,75$ & 0,05 & $-33,24$ & 0,05 & $-33,76$ & 0,06 & $-31,78$ & 0,09 & $-31,87$ & 0,08 \\
\hline
\end{tabular}

A partir dos dados compilados, foram gerados gráficos de outros pontos de medição. A figura 16 apresenta os dados de ponto de orvalho da barra 2. Pode-se observar uma pequena variação em função do horário, visto que aproximadamente a partir das 10h da manhã o valor cresce e após as 22h retorna ao seu valor anterior. Esta variação, apesar de ser praticamente insignificante, pode ser explicada pelo aumento da temperatura ambiente durante o dia e sua diminuição a noite. As 
figuras 16 a 23 representam graficamente outros pontos de medição, que também seguem o mesmo padrão de comportamento.

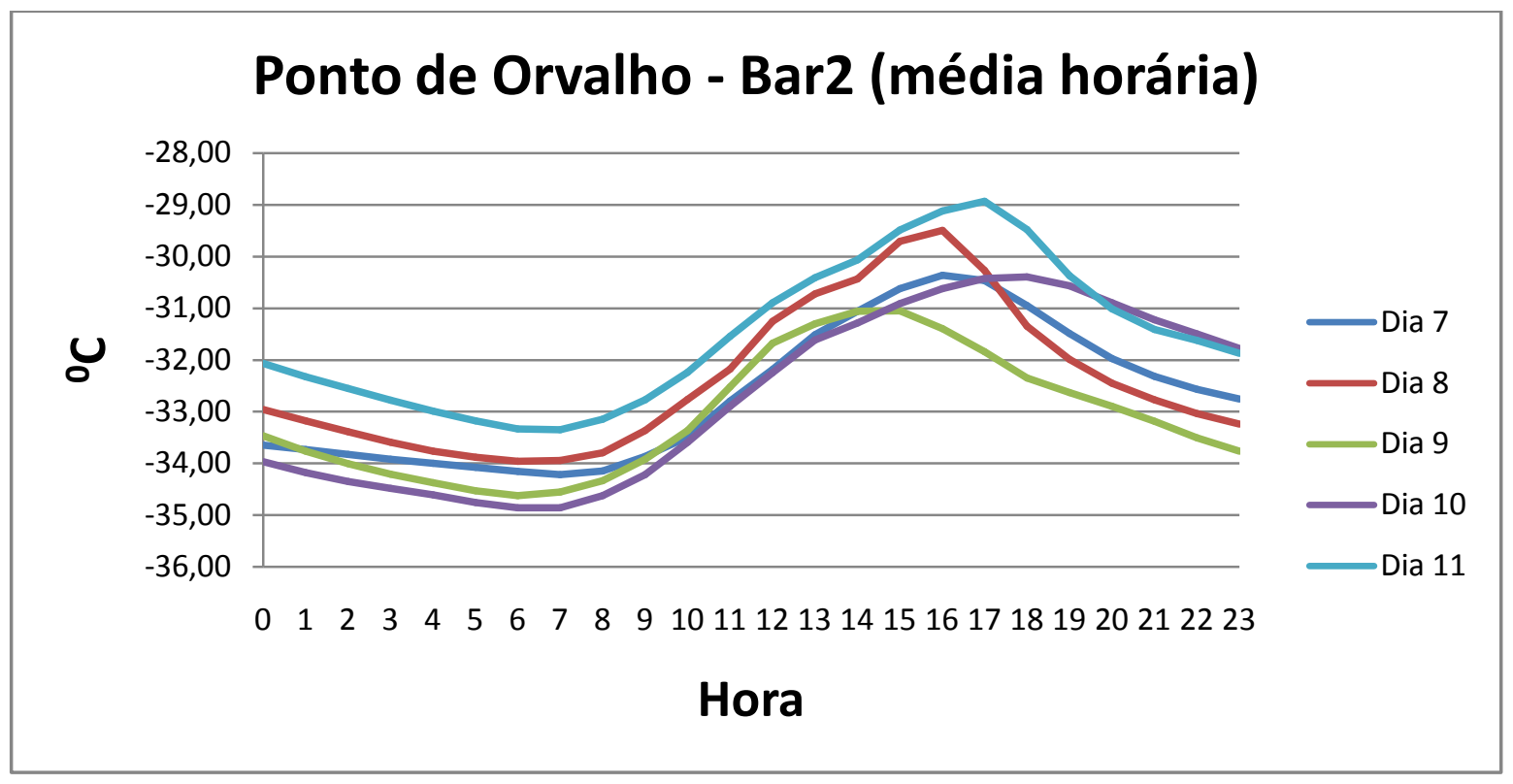

Figura 16: Dados de ponto de orvalho Barra 2 (média horária)

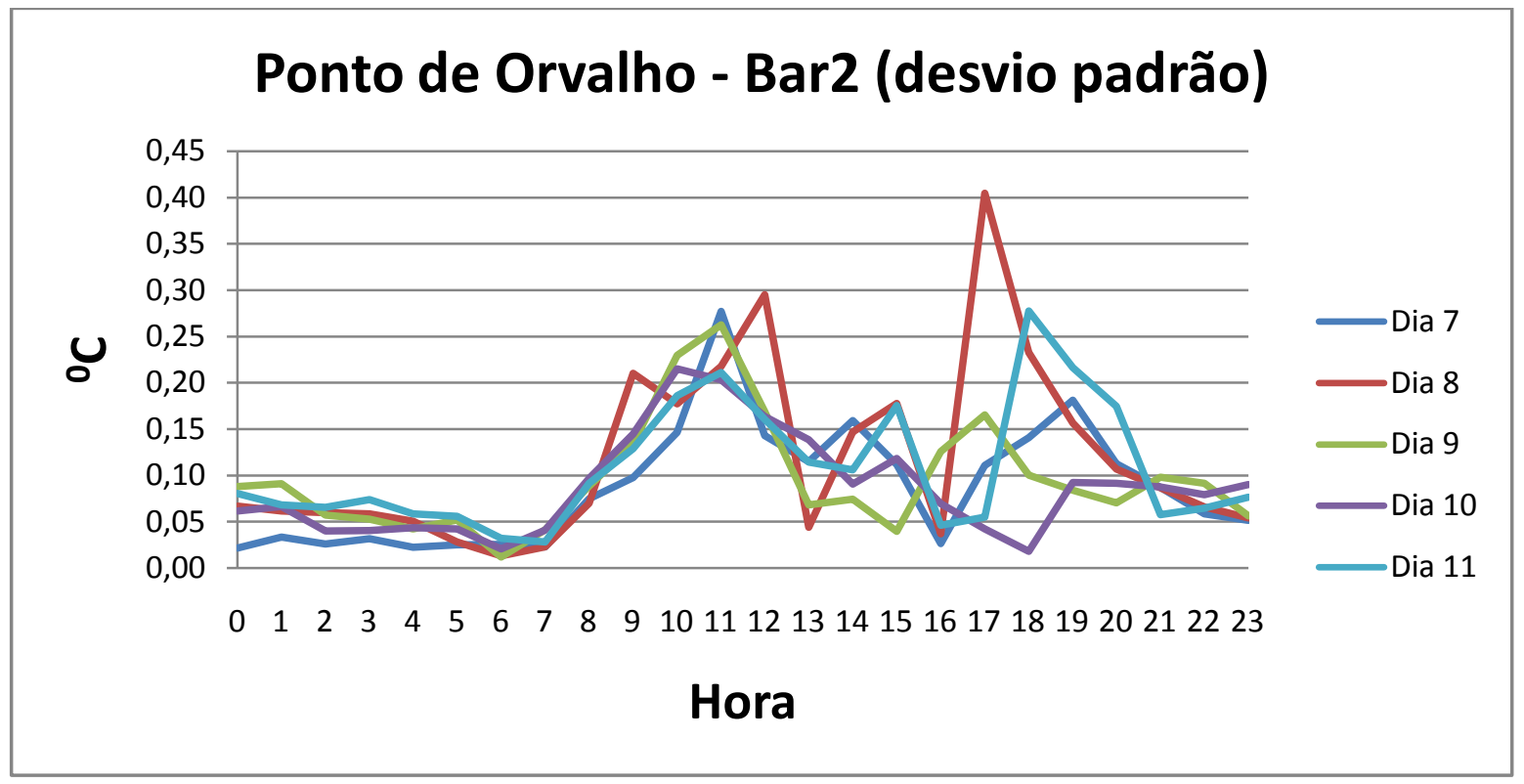

Figura 17: Dados de ponto de orvalho Barra 2 (desvio padrão) 


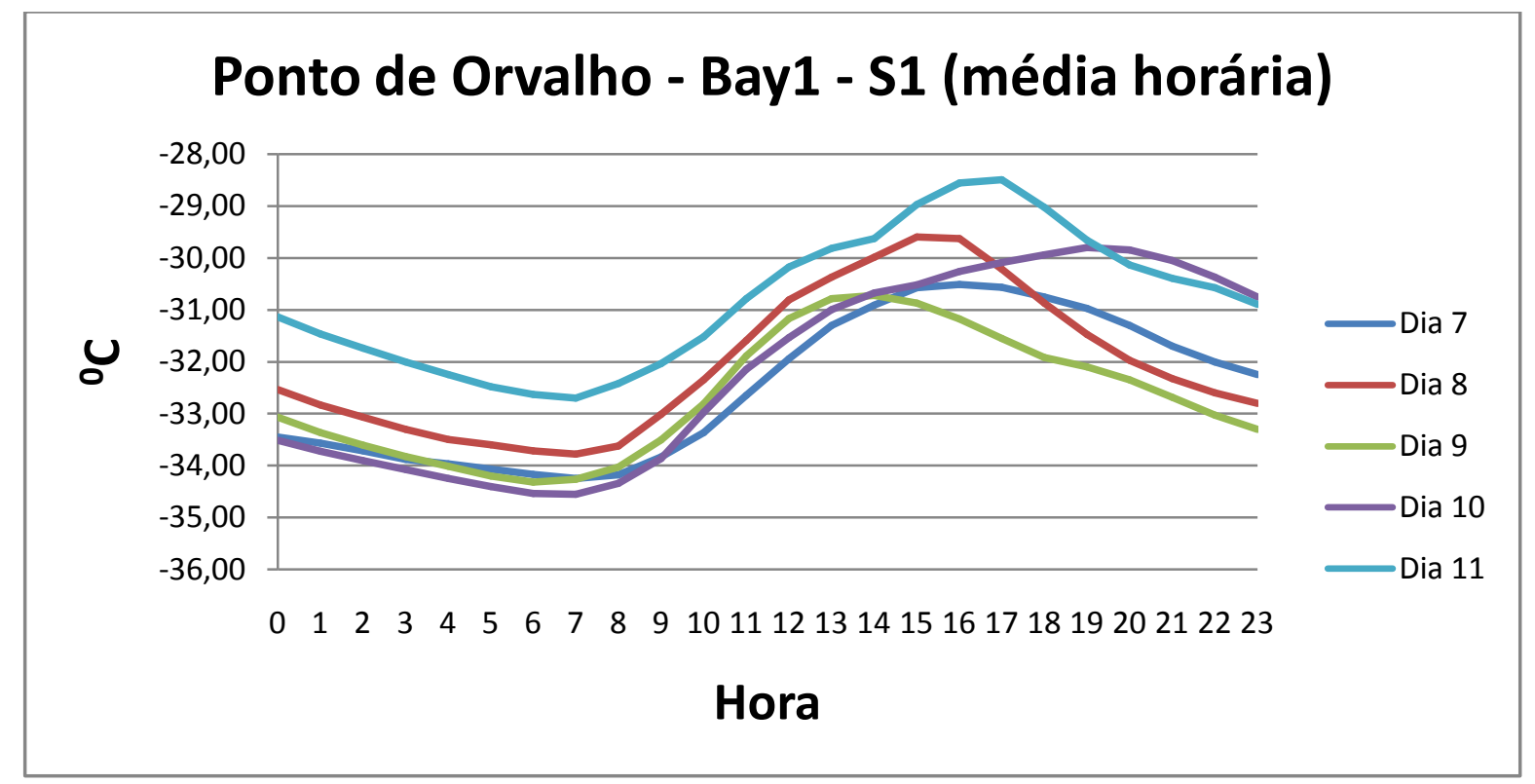

Figura 18: Dados de ponto de orvalho Bay 1 - Sensor 1 (média horária)

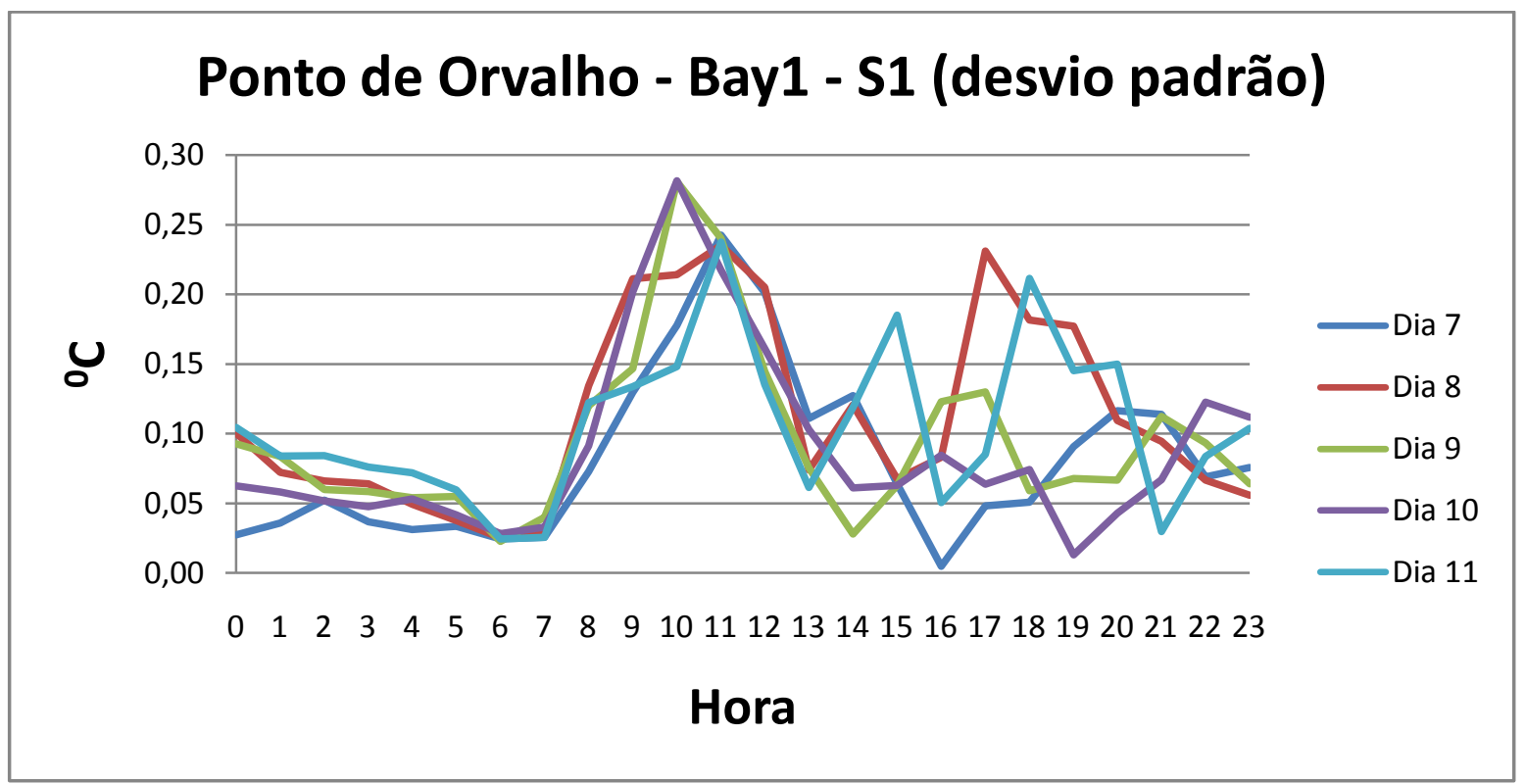

Figura 19: Dados de ponto de orvalho Bay 1 - Sensor 1 (desvio padrão) 


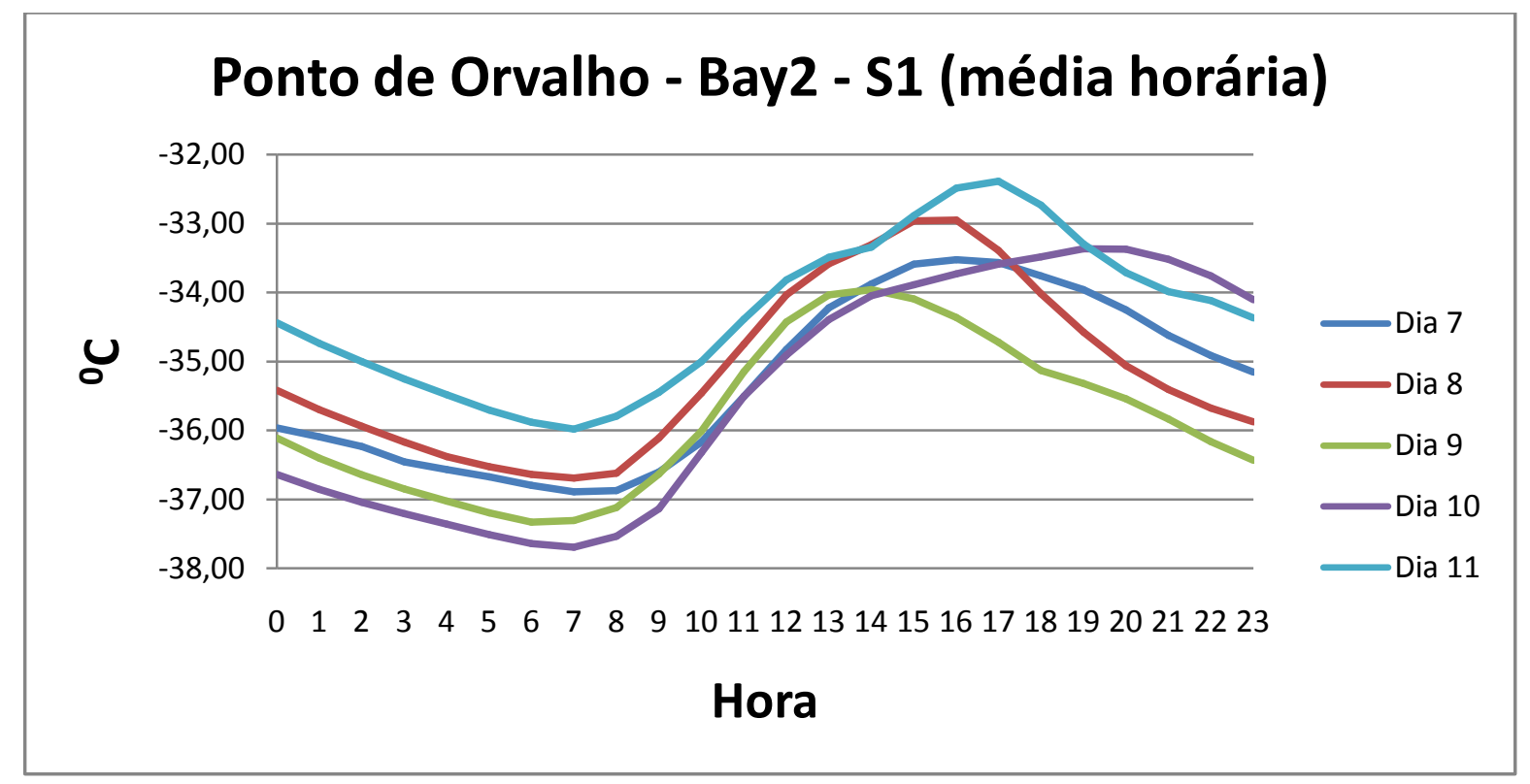

Figura 20: Dados de ponto de orvalho bay 2 - sensor 1 (média horária)

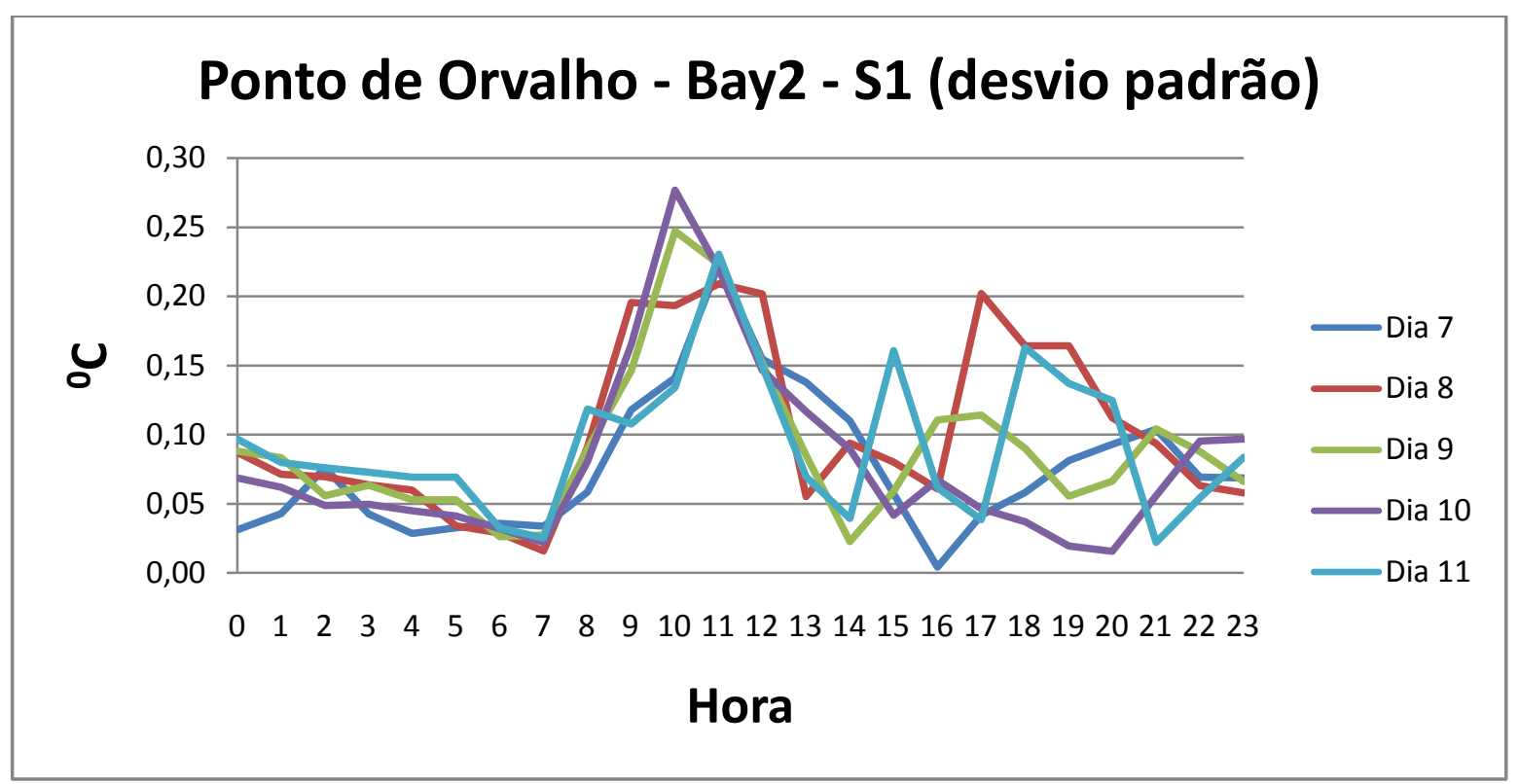

Figura 21: Dados de ponto de orvalho bay 2 - sensor 1 (desvio padrão) 


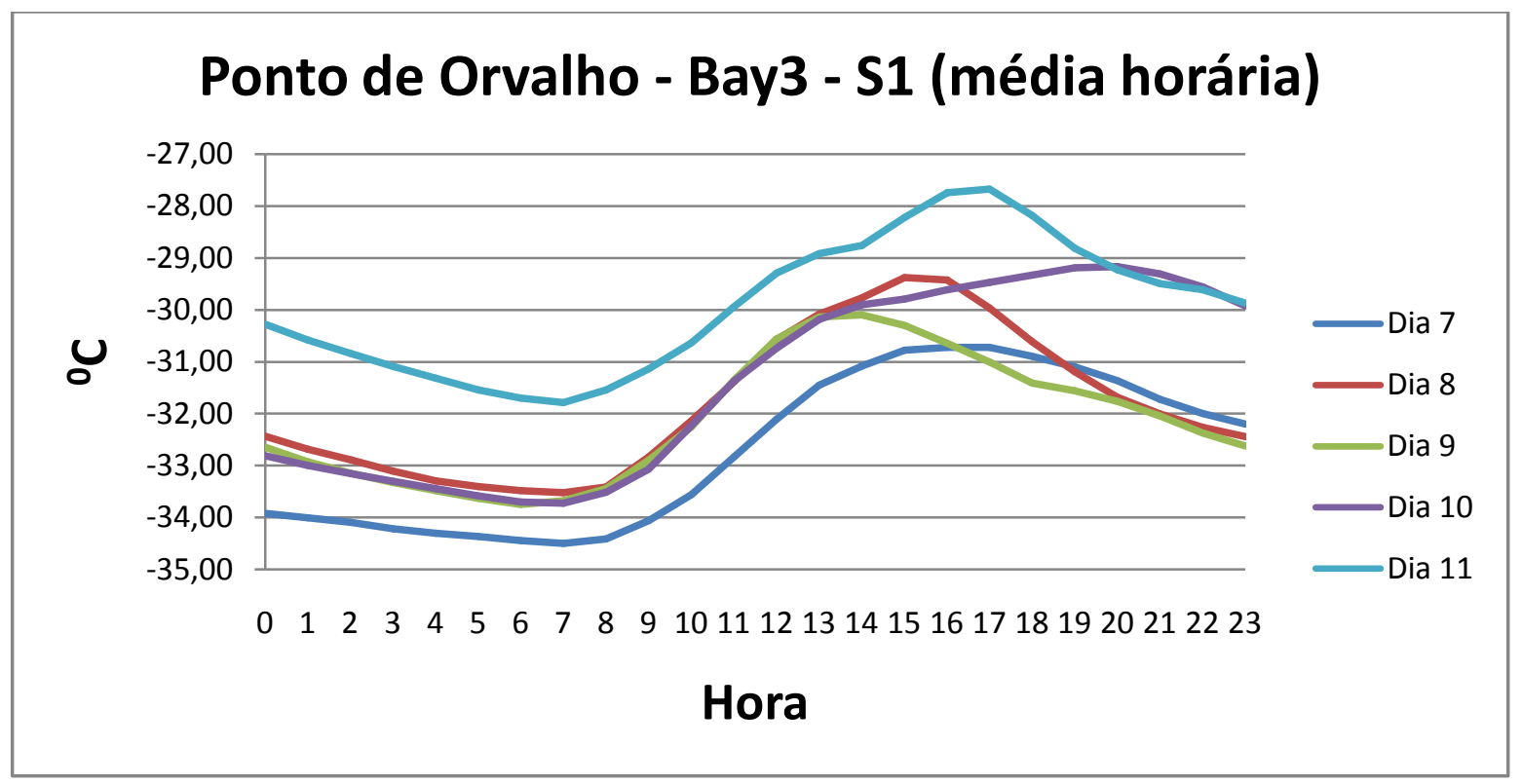

Figura 22: Dados de ponto de orvalho bay 3 - sensor 1 (média horária)

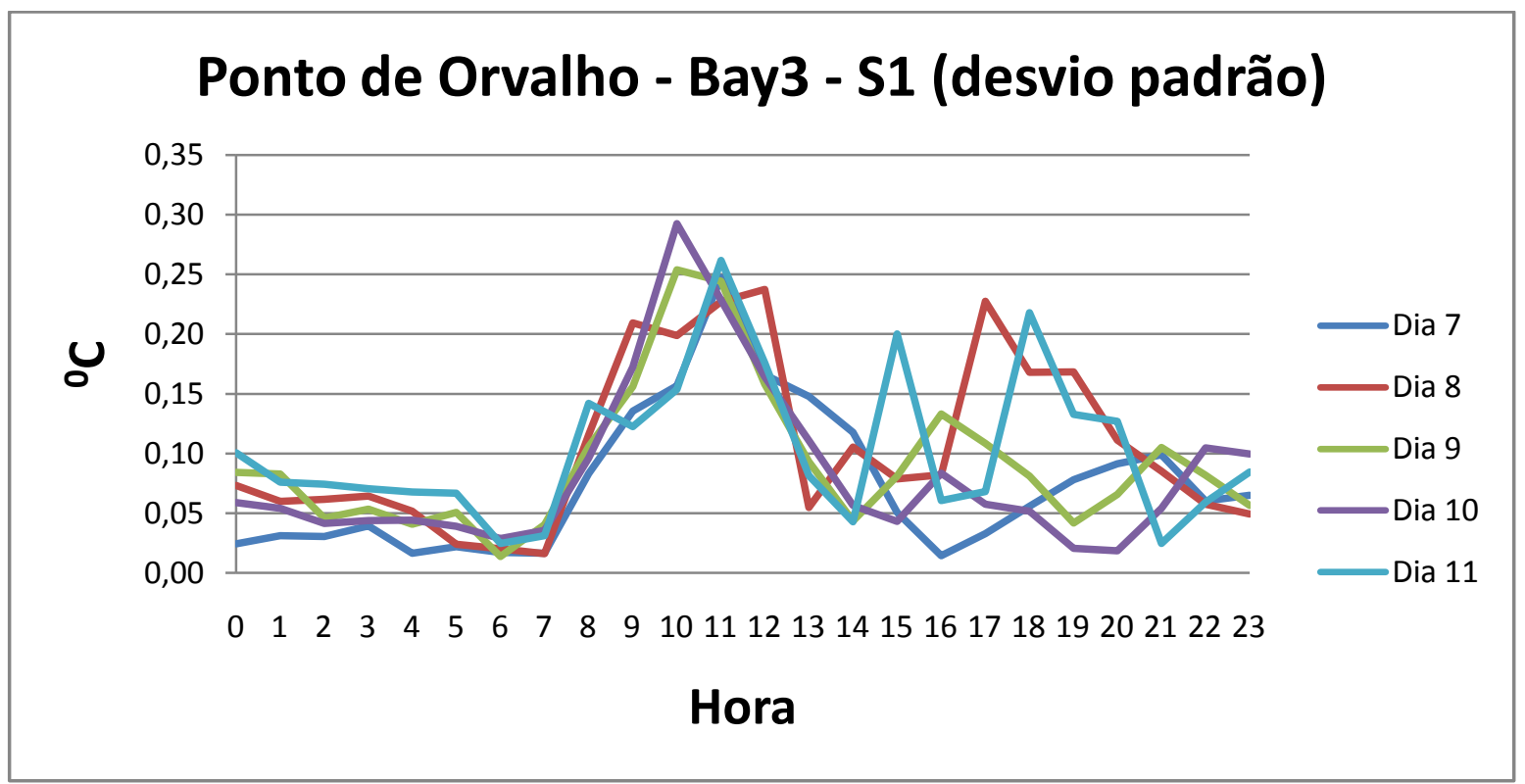

Figura 23: Dados de ponto de orvalho bay 3 - sensor 1 (desvio padrão) 
Foi realizada uma compilação adicional dos dados, onde foi calculada a média de $24 \mathrm{~h}$ dos pontos medidos. Durante o dia todo é possível observar uma variação um pouco maior dos dados, entretanto ainda assim a variação é baixa. A tabela 2 apresenta as médias diárias do sensor de ponto de orvalho da barra 2. Os demais dados dos sensores devido a semelhança de comportamento seguem o mesmo padrão diário ao apresentado na tabela 2 e consequentemente a sua representação gráfica apresentada nas figuras 24 e 25.

Tabela 2: Dados de ponto de orvalho da barra 2 (médias diárias)

\begin{tabular}{|l|r|r|}
\hline & \multicolumn{1}{|l|}{ PO } & \multicolumn{1}{l|}{ DP } \\
\hline Dia 7 & $-32,67$ & 1,31 \\
\hline Dia 8 & $-32,39$ & 1,39 \\
\hline Dia 9 & $-33,09$ & 1,18 \\
\hline Dia 10 & $-32,70$ & 1,68 \\
\hline Dia 11 & $-31,54$ & 1,39 \\
\hline
\end{tabular}

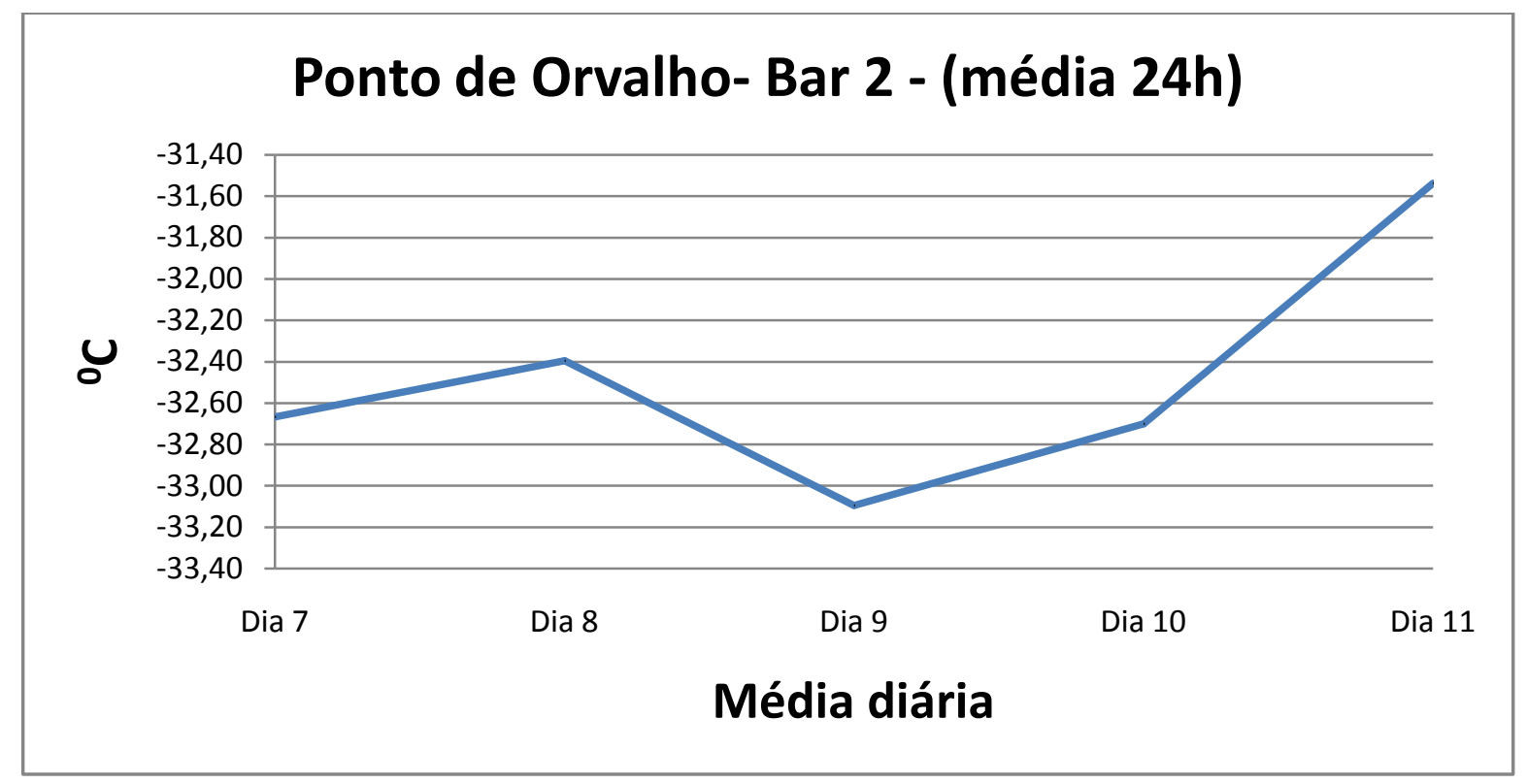

Figura 24: Dados de ponto de orvalho barra 2 (média de 24h) 


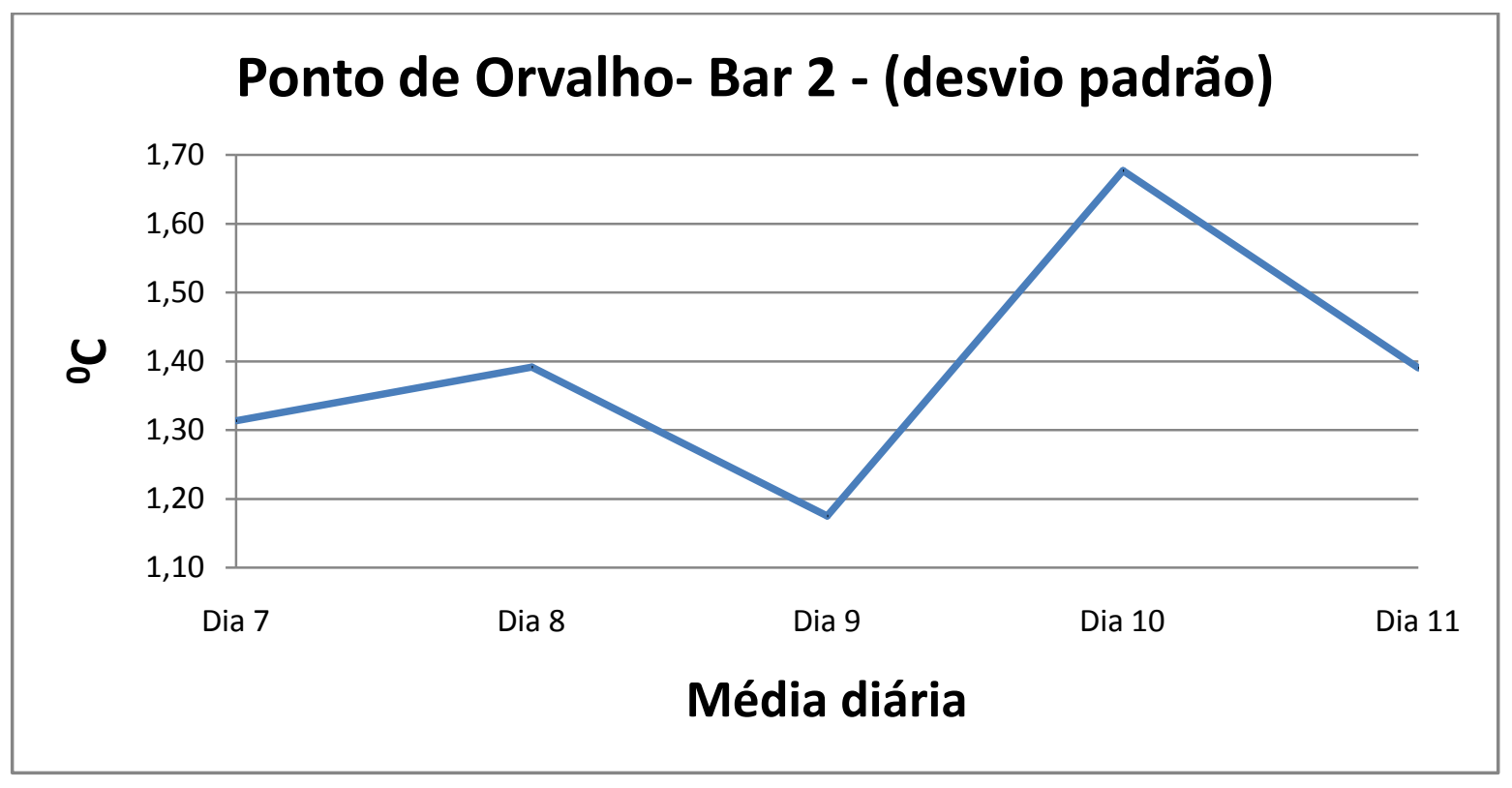

Figura 25: Dados de ponto de orvalho barra 2 (desvio padrão)

Os dados obtidos de densidade seguiram o mesmo procedimento citado acima e relativos a ponto de orvalho. O parâmetro densidade é relativo a quantidade de gás existente em determinado compartimento. Os sensores instalados são dotados de um sistema de correção em relação à temperatura. Neste caso os dados não sofrem variação durante o dia. Para todos os compartimentos monitorados o desvio padrão muito próximo de zero para quase todas as médias. A tabela 3 apresenta os dados coletados na barra 2, onde DENS representa a média das densidades (em g/L) e DP representa o desvio padrão da média. 
Tabela 3: Dados de densidade da barra 2

\begin{tabular}{|r|l|l|l|l|l|l|l|l|l|l|}
\hline & Dia 07 & & Dia 08 & & Dia 09 & & Dia 10 & & Dia 11 & \\
\hline Hora & DENS & DP & DENS & DP & DENS & DP & DENS & DP & DENS & DP \\
\hline 0 & 20,15 & 0,00 & 20,12 & 0,00 & 20,14 & 0,00 & 20,16 & 0,00 & 19,96 & 0,00 \\
\hline 1 & 20,14 & 0,00 & 20,13 & 0,00 & 20,15 & 0,00 & 20,16 & 0,00 & 19,98 & 0,00 \\
\hline 2 & 20,13 & 0,00 & 20,13 & 0,00 & 20,15 & 0,00 & 20,15 & 0,00 & 19,98 & 0,00 \\
\hline 3 & 20,13 & 0,00 & 20,13 & 0,00 & 20,15 & 0,00 & 20,15 & 0,00 & 19,99 & 0,00 \\
\hline 4 & 20,13 & 0,00 & 20,13 & 0,00 & 20,15 & 0,00 & 20,15 & 0,00 & 20,00 & 0,00 \\
\hline 5 & 20,13 & 0,00 & 20,13 & 0,00 & 20,15 & 0,00 & 20,15 & 0,00 & 20,00 & 0,00 \\
\hline 6 & 20,12 & 0,00 & 20,13 & 0,00 & 20,15 & 0,00 & 20,15 & 0,00 & 20,00 & 0,00 \\
\hline 7 & 20,12 & 0,00 & 20,11 & 0,00 & 20,14 & 0,00 & 20,14 & 0,01 & 19,99 & 0,01 \\
\hline 8 & 20,11 & 0,01 & 20,09 & 0,01 & 20,12 & 0,01 & 20,11 & 0,01 & 19,96 & 0,01 \\
\hline 9 & 20,09 & 0,01 & 20,05 & 0,02 & 20,09 & 0,01 & 20,09 & 0,01 & 19,93 & 0,01 \\
\hline 10 & 20,06 & 0,01 & 20,01 & 0,01 & 20,08 & 0,07 & 20,06 & 0,01 & 19,89 & 0,01 \\
\hline 11 & 20,02 & 0,02 & 19,97 & 0,01 & 20,08 & 0,07 & 20,03 & 0,01 & 19,85 & 0,01 \\
\hline 12 & 19,99 & 0,01 & 19,92 & 0,01 & 20,08 & 0,07 & 20,02 & 0,04 & 19,82 & 0,01 \\
\hline 13 & 19,95 & 0,00 & 19,91 & 0,01 & 20,08 & 0,07 & 19,98 & 0,00 & 19,81 & 0,00 \\
\hline 14 & 19,94 & 0,01 & 19,90 & 0,01 & 20,09 & 0,07 & 19,99 & 0,00 & 19,80 & 0,01 \\
\hline 15 & 19,92 & 0,00 & 19,87 & 0,00 & 20,02 & 0,01 & 19,99 & 0,00 & 19,78 & 0,01 \\
\hline 16 & 19,92 & 0,01 & 19,89 & 0,01 & 20,07 & 0,01 & 19,99 & 0,00 & 19,78 & 0,00 \\
\hline 17 & 19,95 & 0,02 & 19,98 & 0,04 & 20,12 & 0,02 & 19,99 & 0,00 & 19,78 & 0,01 \\
\hline 18 & 20,00 & 0,01 & 20,06 & 0,02 & 20,09 & 0,07 & 20,00 & 0,00 & 19,85 & 0,03 \\
\hline 19 & 20,05 & 0,02 & 20,10 & 0,01 & 20,15 & 0,00 & 20,03 & 0,01 & 19,92 & 0,01 \\
\hline 20 & 20,09 & 0,01 & 20,12 & 0,01 & 20,15 & 0,00 & 20,05 & 0,01 & 19,96 & 0,01 \\
\hline 21 & 20,11 & 0,01 & 20,13 & 0,00 & 20,16 & 0,00 & 20,07 & 0,01 & 19,97 & 0,00 \\
\hline 22 & 20,11 & 0,00 & 20,13 & 0,00 & 20,17 & 0,00 & 20,08 & 0,00 & 19,97 & 0,00 \\
\hline 23 & 20,11 & 0,00 & 20,13 & 0,00 & 20,17 & 0,00 & 20,09 & 0,00 & 19,98 & 0,00 \\
\hline
\end{tabular}

As figuras 26 a 33 apresentam, graficamente, os dados compilados de cinco dias relativos à densidade. Observam-se variações insignificantes na densidade, tanto para os compartimentos representados pelas figuras quanto para os demais monitorados. Portanto, não há comportamento diferenciado entre os diferentes compartimentos. 


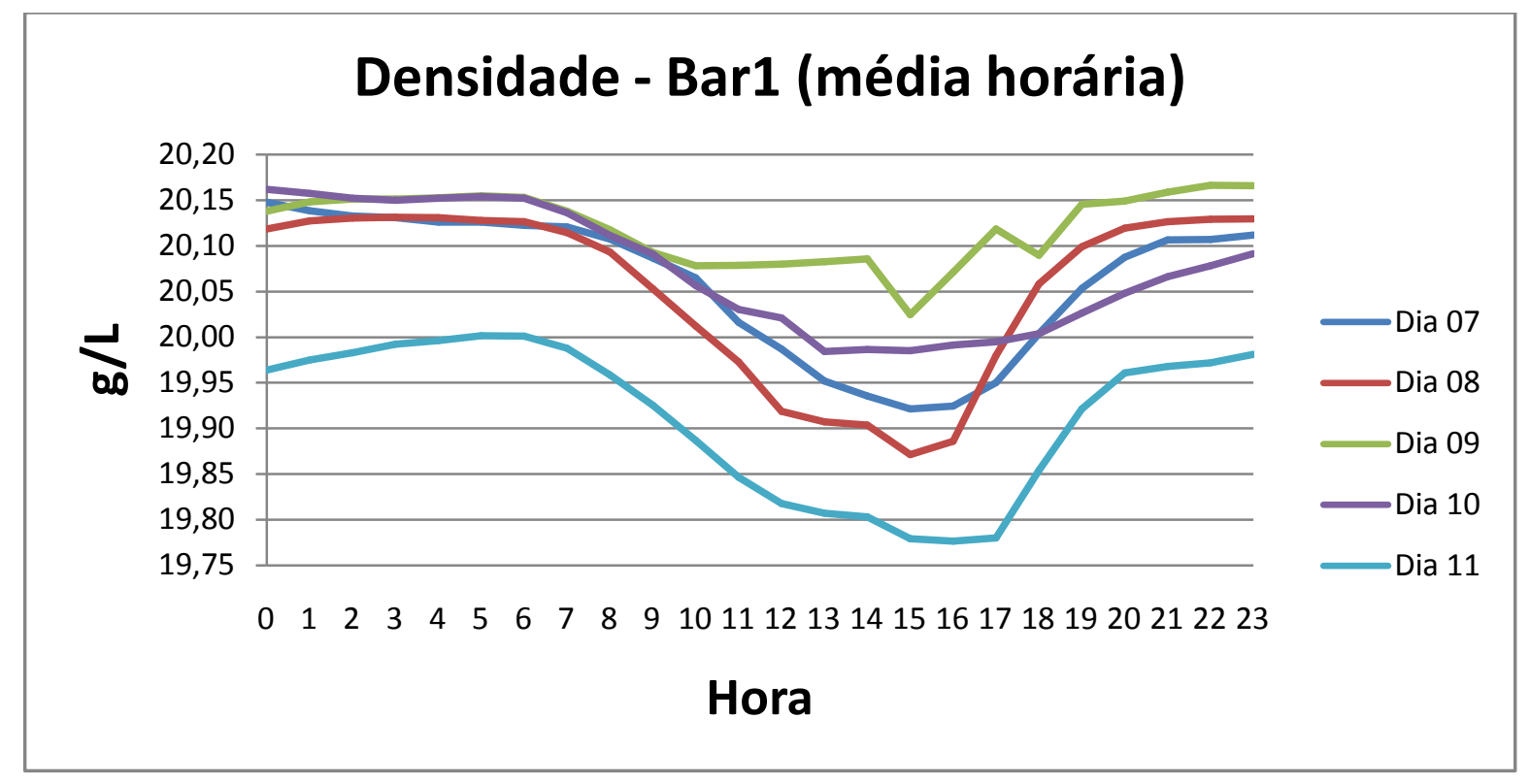

Figura 26: Dados de densidade barra 1 (média horária)

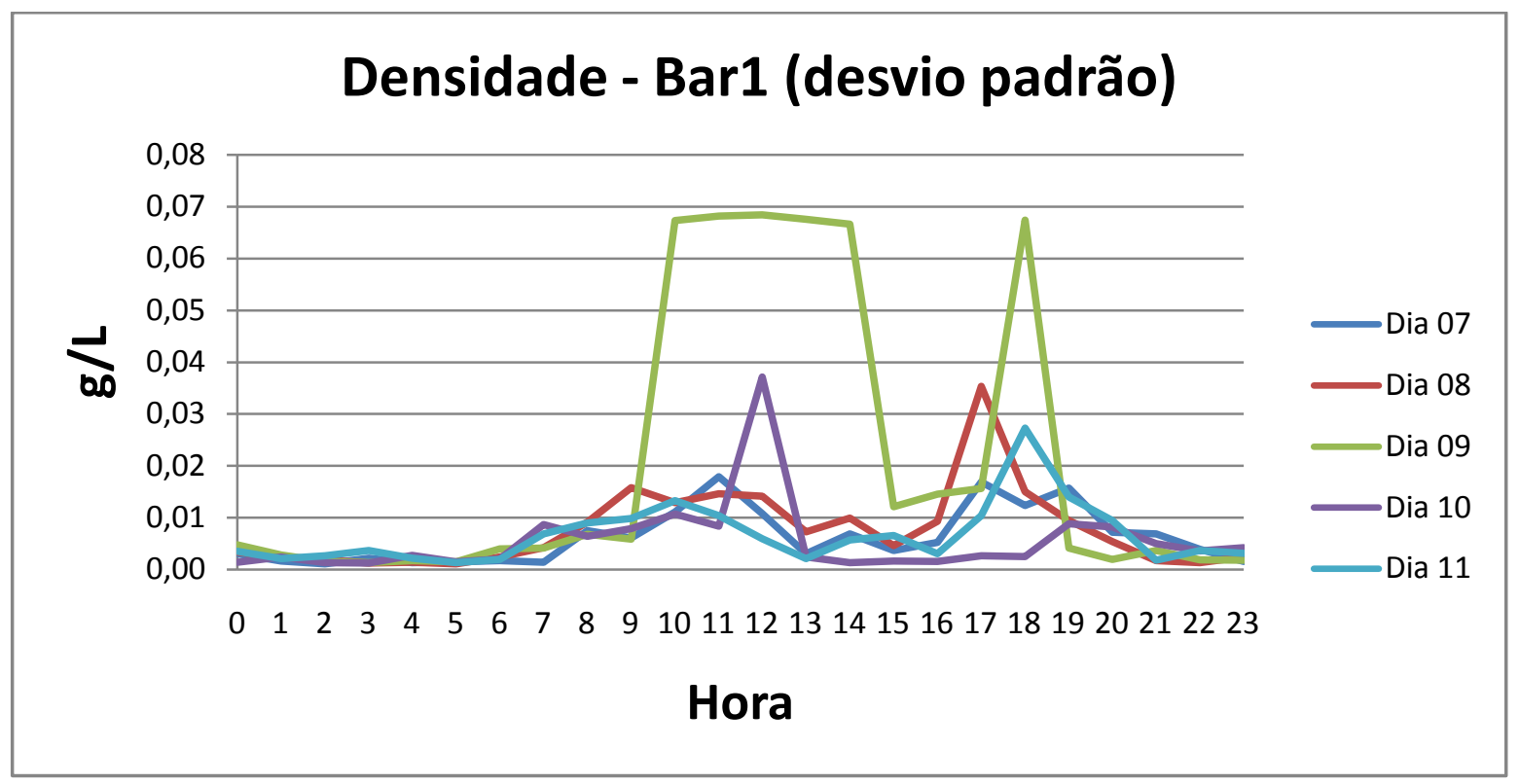

Figura 27: Dados de densidade barra 1 (desvio padrão) 


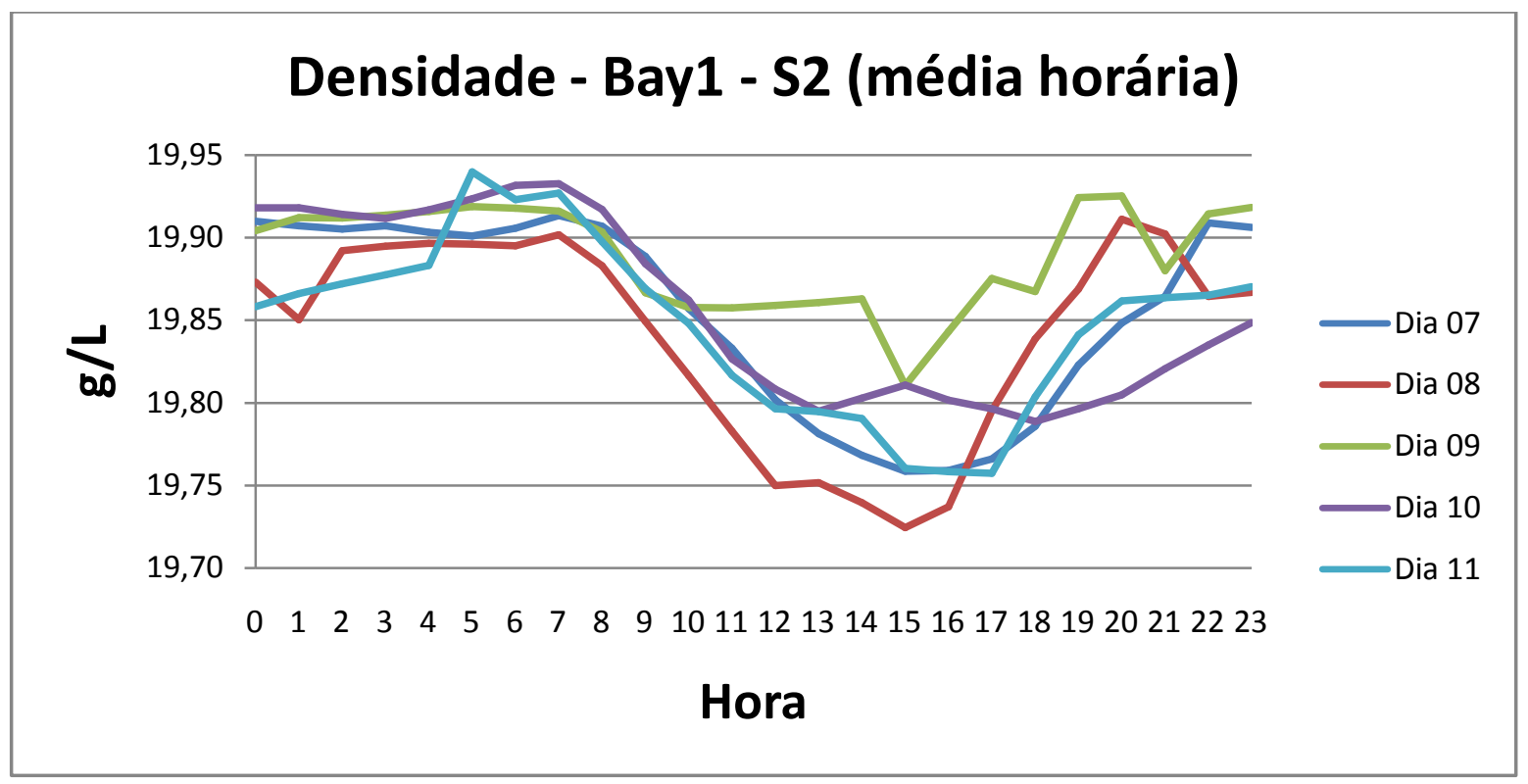

Figura 28: Dados de densidade bay 1 - sensor 2 (média horária)

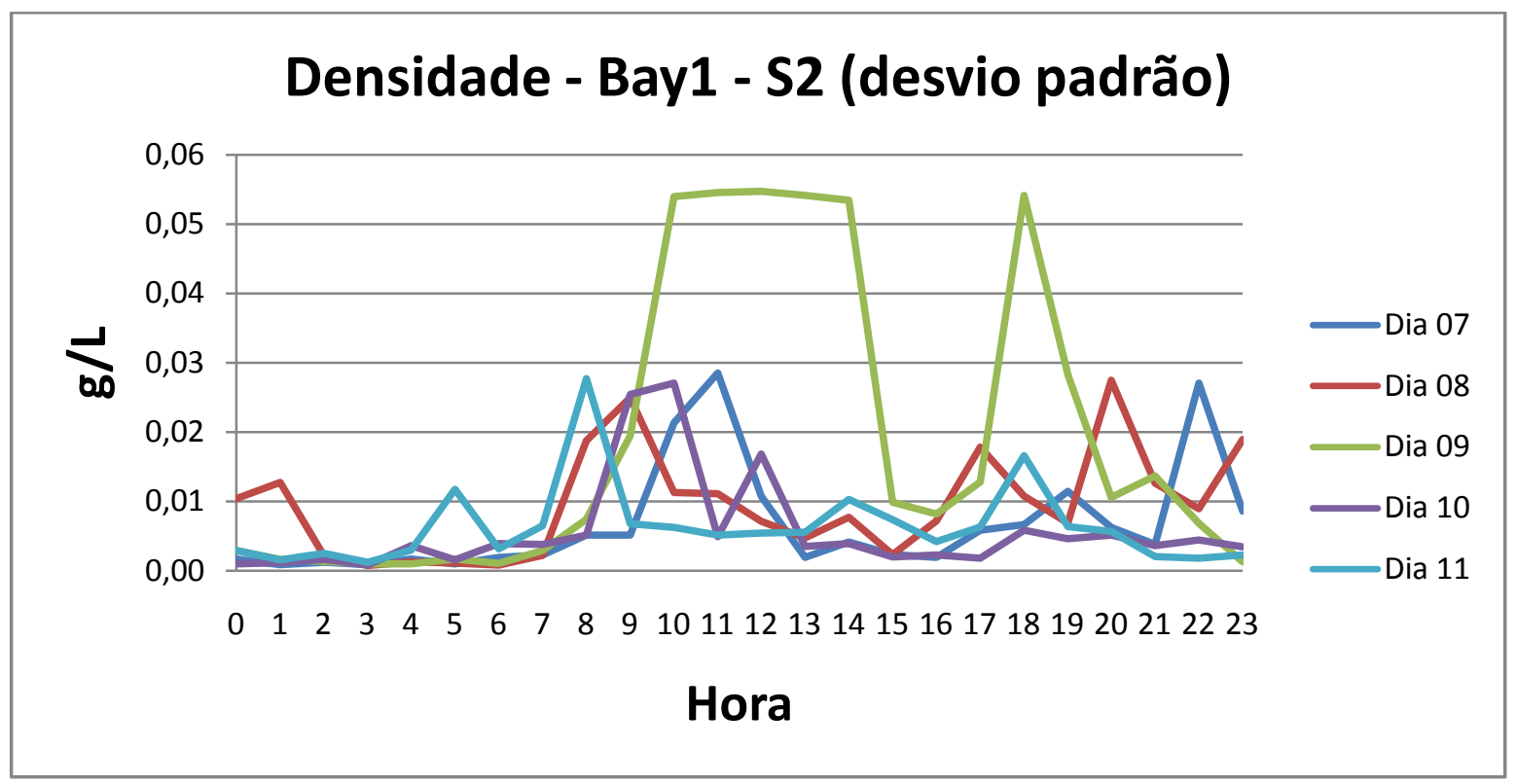

Figura 29: Dados de densidade bay 1 - sensor 2 (desvio padrão) 


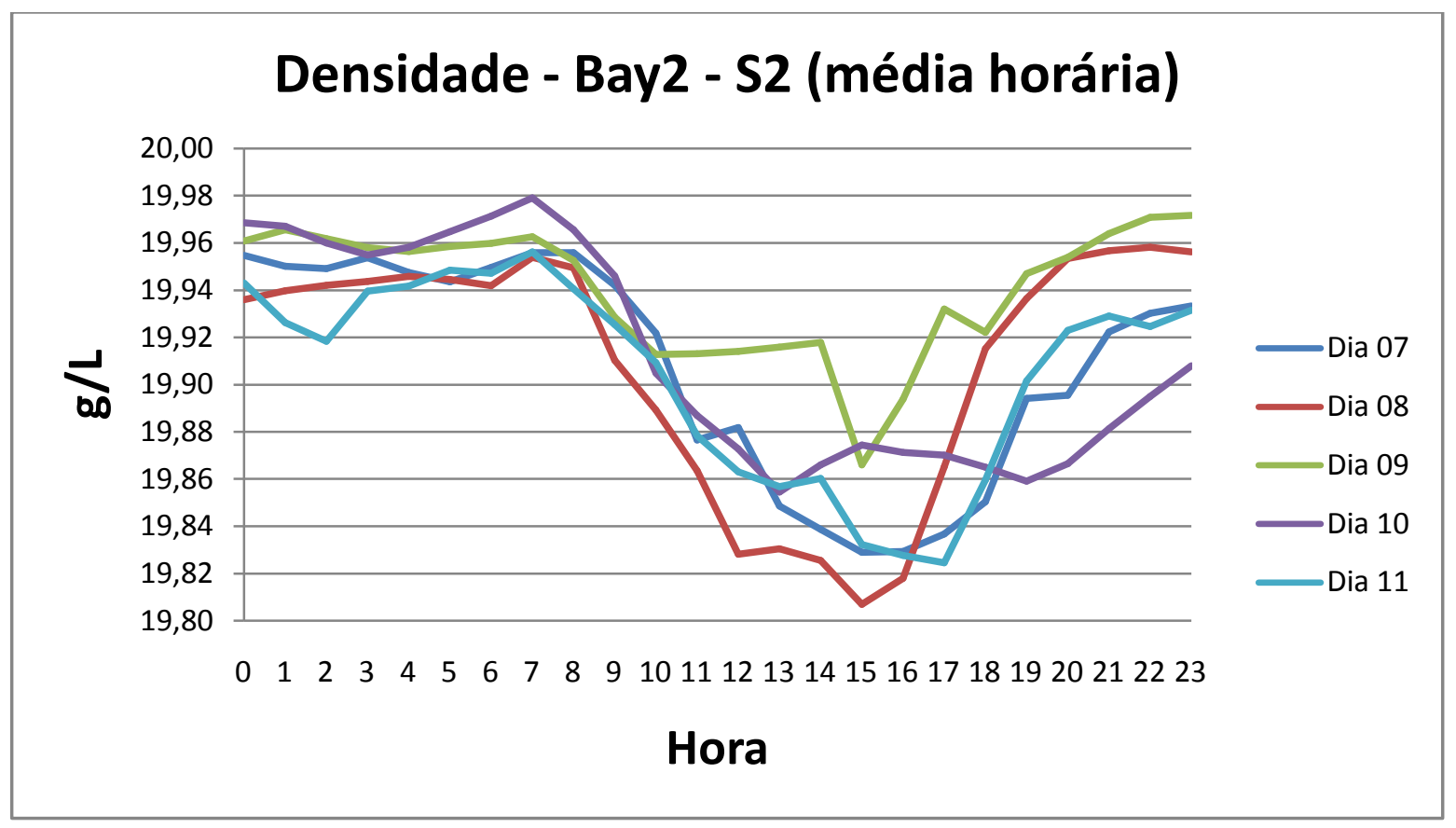

Figura 30: Dados de densidade bay 2 - sensor 2 (média horária)

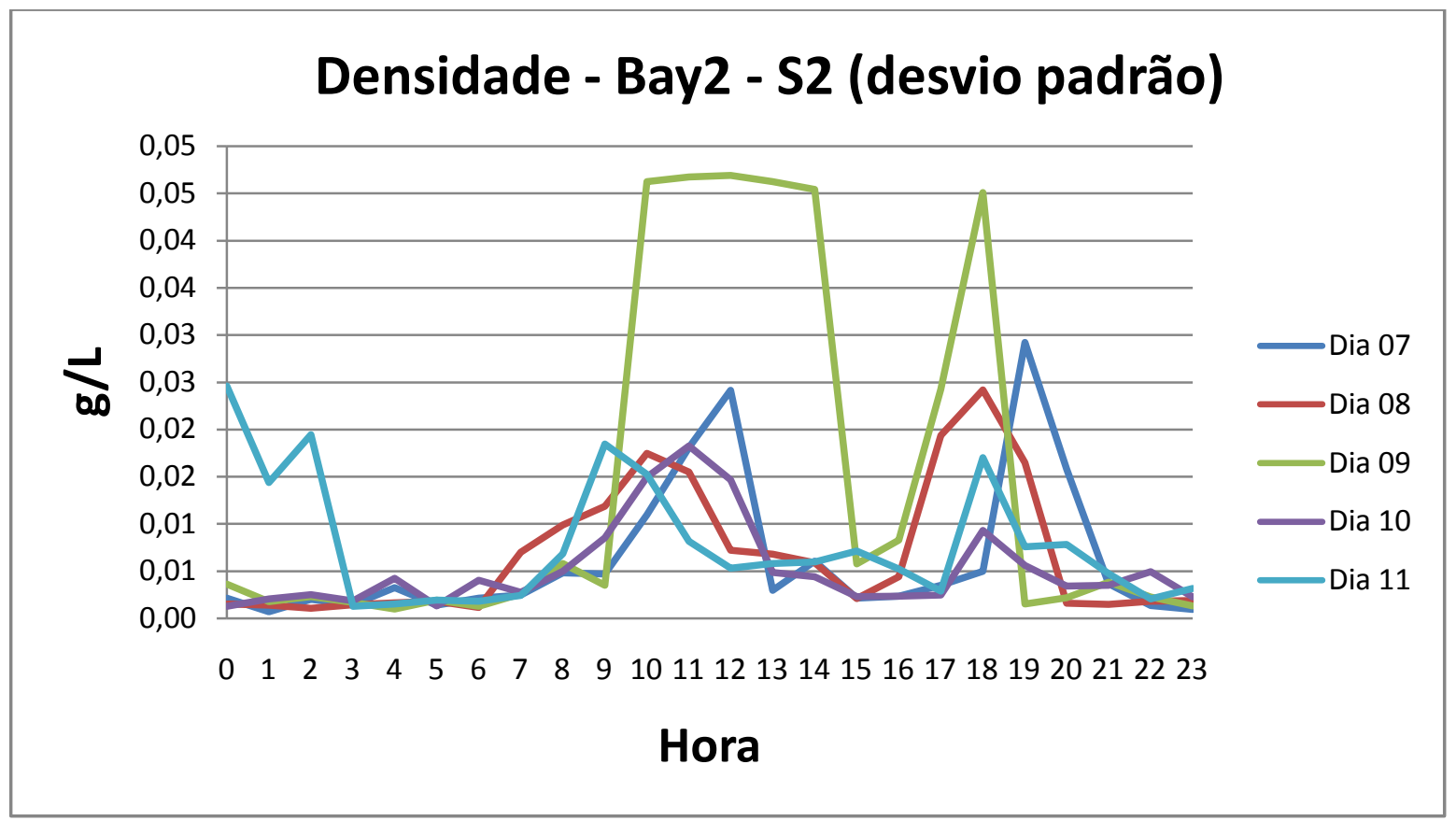

Figura 31: Dados de densidade bay 2 - sensor 2 (desvio padrão) 


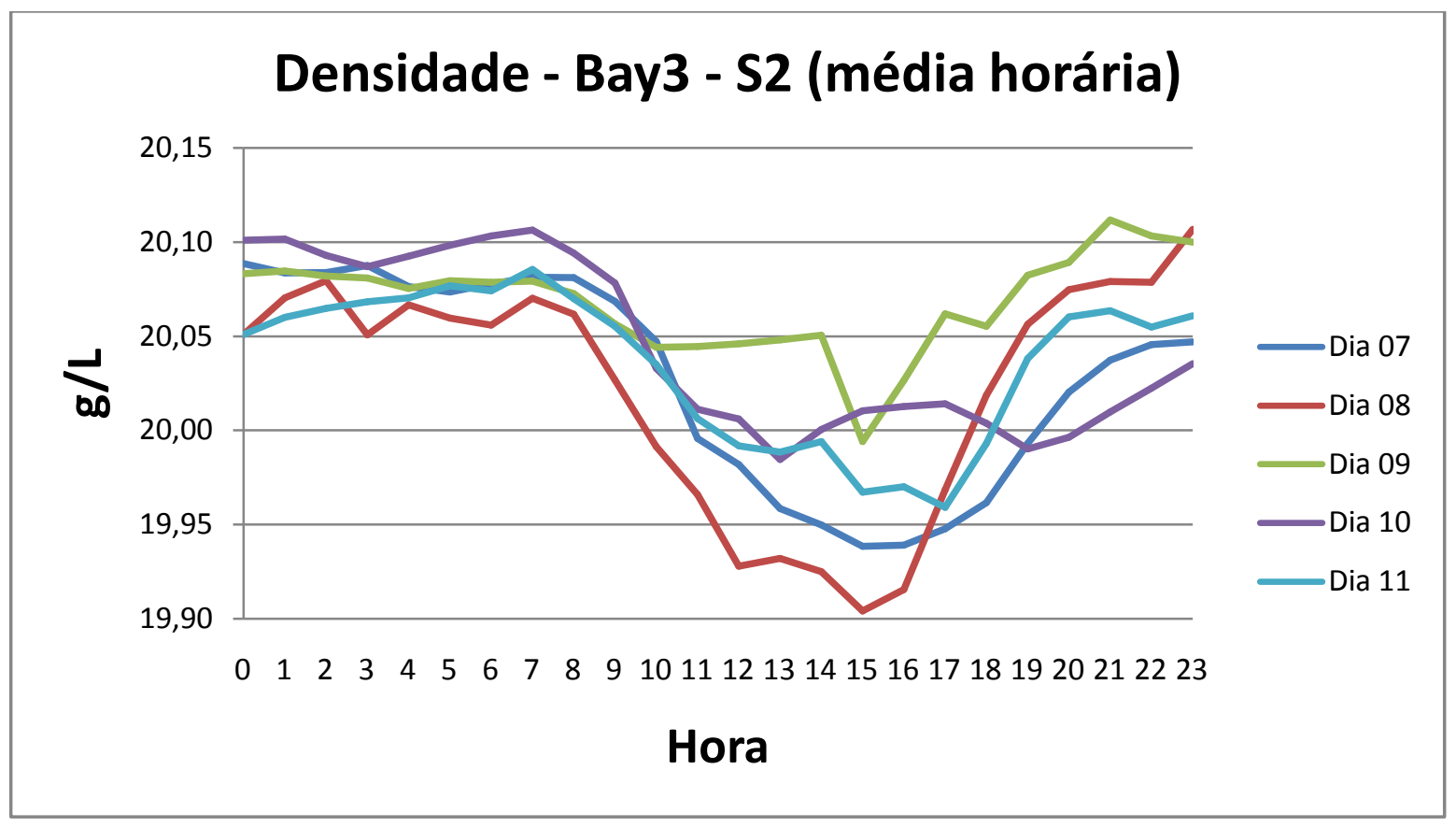

Figura 32: Dados de densidade bay 3 - sensor 2 (média horária)

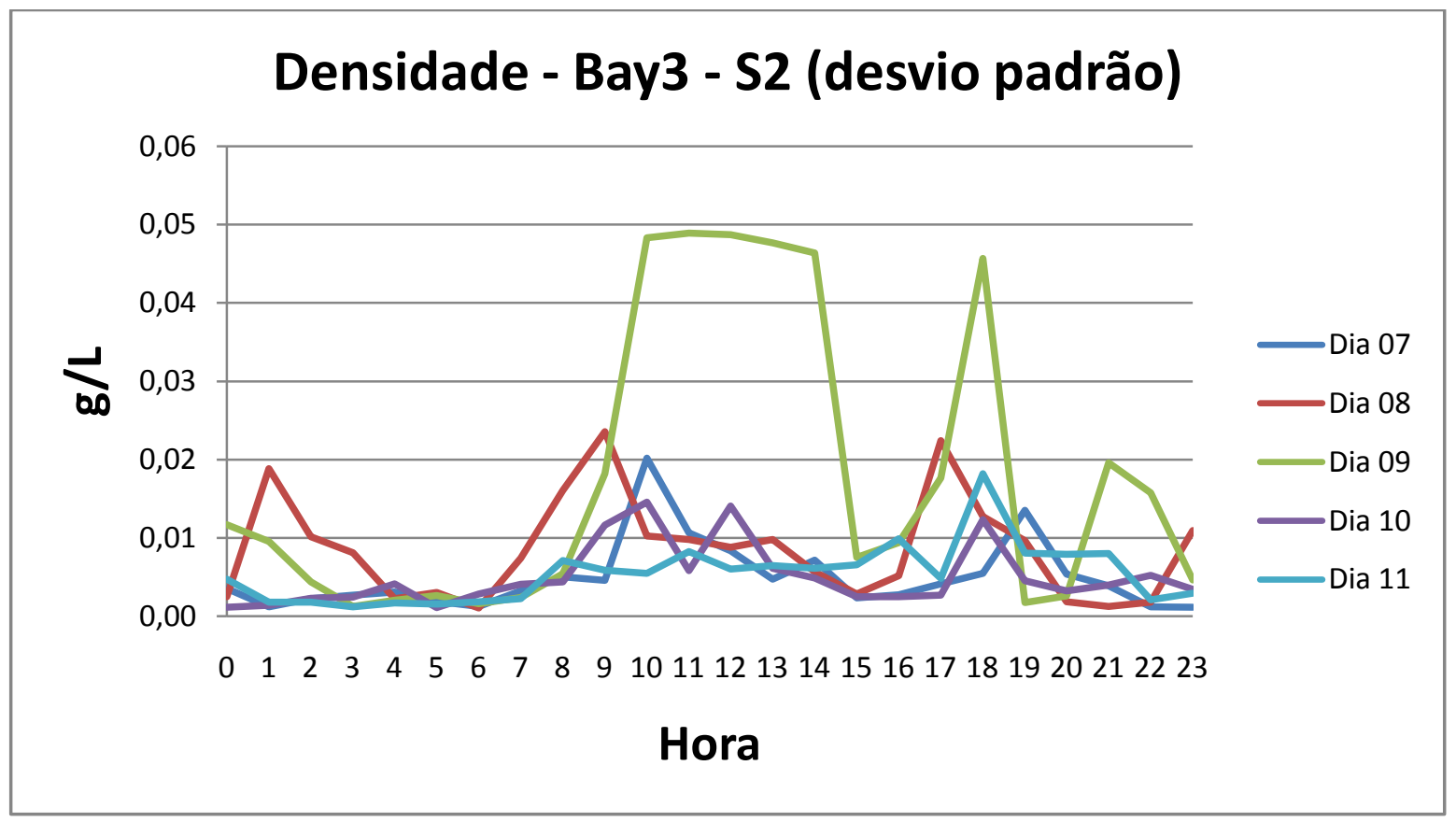

Figura 33: Dados de densidade bay 3 - sensor 2 (desvio padrão) 
Para os dados de densidade também foi analisado a média diária de $24 \mathrm{~h}$. Neste caso fica bastante evidente a variação quase a zero. Ao se observar o desvio padrão de todos os dias pode-se concluir que a variação é nula. Isso significa que a massa de $\mathrm{SF}_{6}$ se manteve estável, ou seja, não há vazamentos. A tabela apresenta os dados da barra 2 compilados, enquanto as figuras 34 e 35 apresentam os valores de forma gráfica.

Tabela 4: Dados de densidade da barra 2 (médias diárias)

\begin{tabular}{|l|r|r|}
\hline & \multicolumn{1}{|l|}{ DENS } & \multicolumn{1}{l|}{ DP } \\
\hline Dia 7 & 19,93 & 0,09 \\
\hline Dia 8 & 19,93 & 0,10 \\
\hline Dia 9 & 19,95 & 0,08 \\
\hline Dia 10 & 19,92 & 0,09 \\
\hline Dia 11 & 19,91 & 0,08 \\
\hline
\end{tabular}

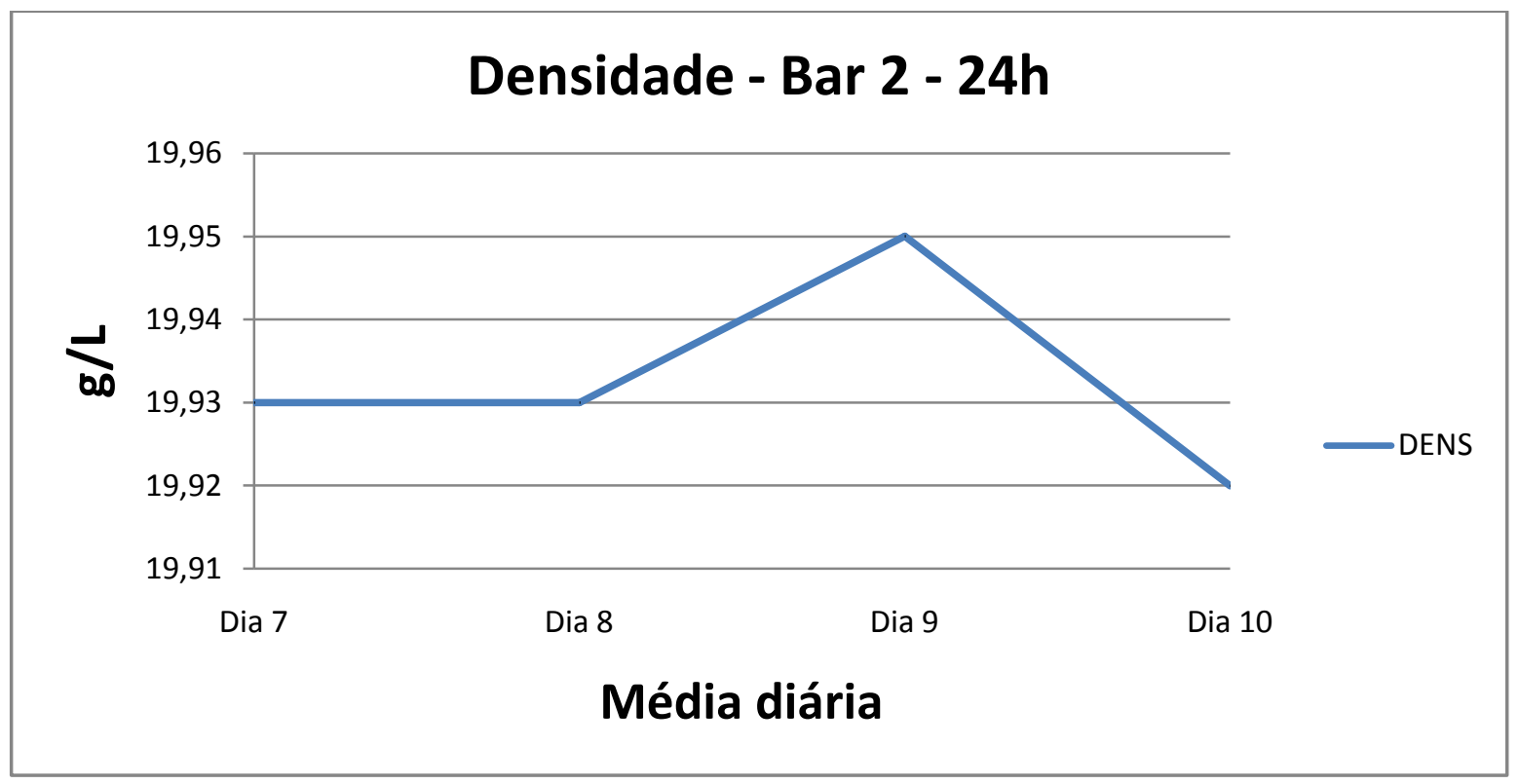

Figura 34: Dados de densidade barra 2 (média de 24h) 


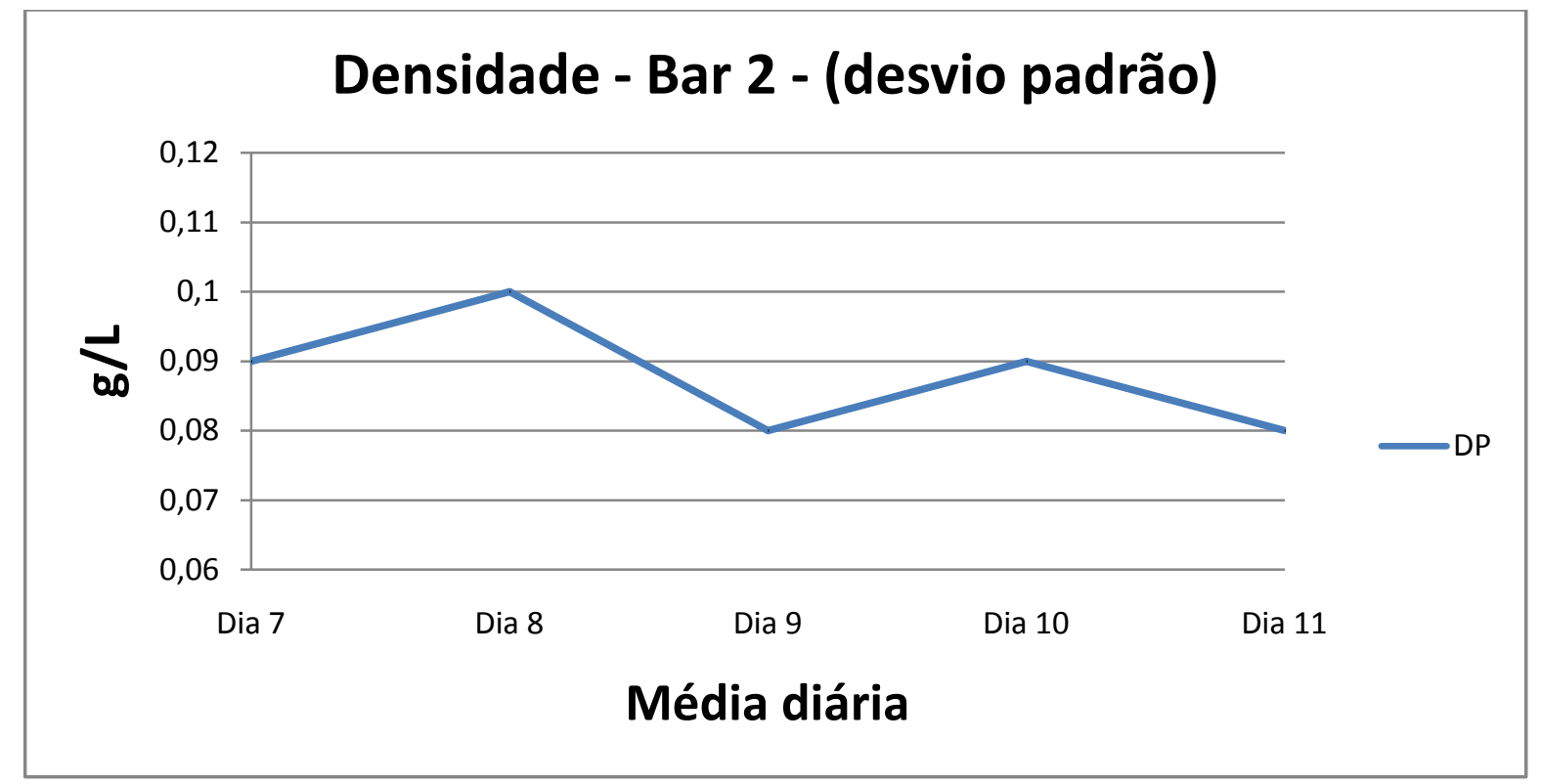

Figura 35: Dados de densidade barra 2 (desvio padrão)

O sistema foi configurado inicialmente para obter dados a cada 1 minuto para que se pudesse analisar o comportamento padrão dos valores medidos. A análise destes dados demonstrou a estabilidade e variabilidade quase nula dos valores. Após esta coleta inicial o sistema foi configurado para realizar aquisições a cada 15 minutos. Espera-se pouca variabilidade no longo prazo também, entretanto, a partir da coleta contínua e armazenamento histórico dos dados serão realizadas novas observações e análises de períodos longos. 


\section{DISCUSSÃo}

O presente trabalho pode ter os seus objetivos delimitados de duas formas: (1) criar uma estrutura de aquisição de dados de uma subestação blindada, para auxiliar a manutenção; (2) oferecer suporte computacional e informativo para a operação segura da subestação, com intuito de mantê-la funcionando além de sua vida útil.

A subestação da AES Eletropaulo, que recebeu o sistema desenvolvido neste trabalho não possuía qualquer sistema de controle automatizado relacionado ao gás. O controle de quantidade de gás é feito por meio de observação humana nos pressostatos eletromecânicos instalados em alguns pontos da subestação. O sistema instalado oferece benefício imediato quando se considera a observação de quantidade de gás. O que antes demandava o envio de um técnico para observar a pressão dos compartimentos, pode ser feito por meio de acesso ao sistema através da rede de computadores da empresa. Um segundo benefício oferecido pelo sistema é a observação de pequenos vazamentos. Devido a sensibilidade dos sensores é possível observar alguns dados históricos para se comprovar uma diminuição pequena na quantidade de gás. Este tipo de observação certamente não seria percebido pelo técnico durante uma verificação rotineira, pois a precisão dos pressostatos é muito menor em relação aos sensores. O controle de qualidade do gás é realizado com auxílio de um equipamento que faz a análise do gás por meio de amostras retiradas dos compartimentos. Este tipo de análise é bastante eficiente para se ter informação da qualidade do gás, incluindo teores contaminantes e nível de pureza do $\mathrm{SF}_{6}$. Porém a análise desta forma demanda equipe especializada para retirada de amostras de todos os compartimentos. O procedimento pode ter alto custo se considerada as horas de trabalho da equipe. Além disso, o procedimento de retirada de amostra causa liberação de $\mathrm{SF}_{6}$ para a atmosfera, mesmo que seja em quantidades muito pequenas. 
O sistema resultante deste trabalho oferece melhorias no processo de controle de qualidade do gás. O parâmetro de ponto de orvalho pode ser verificado online, sem retirada de amostras. Este não é o único parâmetro a ser medido para se ter dados de confiabilidade do gás, entretanto como se trata de um dos parâmetros importantes, o sistema faz com que menos intervenções sejam necessárias. Além disso, o fato de se poder observar a evolução ao longo do tempo, o sistema pode indicar uma tendência de comportamento negativo em algum compartimento. Isso faria com que uma verificação por amostras possam ser feitas de forma antecipada a alguma possível ocorrência de defeitos. Portanto o resultado do trabalho pode ser atribuído a melhorias no processo de manutenção da subestação.

A metodologia adotada por este trabalho pode ser resumida ao processo de instalação de sensores para ler dados do gás, tratar as informações e gravar em uma base de dados. Ao se comparar a outras metodologias que foram expostas na revisão da literatura deste texto, a proposta neste trabalho se apresenta como uma alternativa eficiente. Quando se considera subestações blindadas antigas, como a de Paula Souza da AES Eletropaulo que operam com dupla pressão, a proposta deste trabalho é única com relação a controle de densidade do gás, pois não há menção de trabalhos que levaram em consideração este projeto antigo. Portanto a metodologia de verificação de vazamentos, por meio do cálculo de massa de gás no bay, proposto por este trabalho oferece a sua contribuição para a área de pesquisa relacionada a monitoramento de subestações blindadas.

O custo benefício de equipamentos e recursos sempre foi um fator determinante para as escolhas de hardware para o sistema. A idéia de se ter um sistema simples e de baixo custo teve o objetivo de favorecer a aceitação e replicação da estrutura para a subestação toda. Seguindo esta premissa, o sistema pode ser ampliado para o restante da subestação apenas com a adição de mais sensores e módulos de aquisição. O restante da estrutura pode receber novos sensores sem custo adicional, necessitando apenas de inclusão de novos pontos e 
alguma reconfiguração. A escolha do protocolo MODBUS também se justifica pela mesma premissa de custo dos módulos de aquisição. O sistema poderia ser direcionado para o padrão IEC 61850, que está se tornando padrão de comunicação em subestação, mas os equipamentos para aquisição de dados são extremamente caros em relação aos utilizados, podendo chegar a ordem de 5 vezes maior. Por outro lado, os ganhos imediatos com a melhoria do processo de manutenção justificam a decisão. Futuramente, a migração para este protocolo pode ser estudado, ou ainda, uma simples adaptação de software pode ser adotada a partir dos dados já coletados.

O sistema desenvolvido está conectado a rede da concessionária, entretanto está isolado. Como ainda demanda estudos de confiabilidade será mantido isolado, entretanto futuramente poderia ser integrado ao sistema de controle da AES Eletropaulo. Desta forma, os dados coletados sobre as condições do gás da subestação poderiam ser aproveitados de forma ampliada, ou seja, o controle poderia ser feito por operadores da subestação e não apenas pela equipe especializada.

A partir da colaboração dada por este trabalho, outras iniciativas de pesquisas podem surgir e novos trabalhos podem ser sugeridos ou realizados na mesma linha ou complementares ao trabalho realizado. Uma das sugestões de novos trabalhos que podem ser realizados com os dados coletados pelo sistema é um estudo detalhado do comportamento do gás ao longo do tempo ou de períodos. Pouco se sabe a respeito da sua evolução ao longo do tempo, se há degradação, se há influencia de outros fatores ou se a sua estabilidade natural pode ser atestada. Outra linha de trabalho poderia ser a expansão da arquitetura para toda a subestação, com isso poderiam ser feitas ponderações mais completas para uma subestação inteira, ou seja, considerar o gás como parte de uma estrutura maior. Desta forma, poderiam ser feitas comparações de diferentes comportamentos para diferentes partes da subestação, podendo assim fazer algumas conclusões a respeito dos efeitos que podem gerar degradação. Outra fonte rica para novos 
trabalhos está relacionada ao desenvolvimento de sensores ou transdutores. Para este trabalho foram adotados sensores comerciais, entretanto poderiam ser desenvolvidos sensores de características similares que poderiam oferecer um custo mais atrativo. Além disso, outros parâmetros poderiam ser explorados, como por exemplo, o desenvolvimento de sensores para medir gases resultantes da degradação do $\mathrm{SF}_{6}$. 


\section{CONCLUSÕES}

Mesmo considerando que a instalação do sistema foi feita apenas parcialmente na subestação, ressaltando que esta questão está relacionada a custos, pode-se concluir que o sistema desenvolvido atende plenamente o objetivo de fornecer subsídios para a extensão de vida útil da subestação. Os dados fornecidos em tempo real fornecem informações importantes sobre o estado atual da subestação, enquanto a base de dados histórica pode fornecer indicativos de tendências para tomadas de decisão. O formato modular do sistema permite que novas funcionalidades sejam agregadas ao software, tais como inclusão de tratamentos diferenciados para os dados ou agregação de limites para as grandezas. Além disso, o sistema é escalável, de forma que outros bays podem ser adicionados ao sistema ou ainda outros tipos de sensores podem ser agregados ao sistema de aquisição.

O controle vazamentos de gás se tornou muito mais eficiente e mais refinado. Enquanto a verificação manual poderia não perceber vazamentos de pequena proporção o sistema garante precisão e maior autonomia de verificação. Certamente a ampliação do sistema para a subestação completa é necessária, além de estudos mais detalhados do comportamento do gás no longo prazo. 


\section{REFERÊNCIAS}

BIASSE, J.-M.; OTEGUI, E.; TILWITZ-VON KEISER, B. Benefits of proper SF6 handling to reduce SF6 emissions for sustainable Electricity Transmission and Distribution. In: 2010 China International Conference on Electricity Distribution (CICED). Anais (CICED). set. 2010.

BOLIN, P.; KOCH, H. Gas insulated substation GIS. In: Transmission and Distribution Conference and Exposition, 2008. T \#x00026;D. IEEE/PES. Anais abr. 2008.

CHRISTOPHOROU, L. G.; OLTHOFF, J. K.; BRUNT, R. J. VAN. Sulfur hexafluoride and the electric power industry. IEEE Electrical Insulation Magazine, v. 13, n. 5, p. $20-24$, out. 1997.

ETTER, M.; KOCH, H. Sulfur hexafluoride SF6. In: 2008 IEEE Power and Energy Society General Meeting - Conversion and Delivery of Electrical Energy in the 21st Century. Anais jul. 2008.

GRABER, L. Improving the accuracy of SF6 leakage detection for high voltage switchgear. IEEE Transactions on Dielectrics and Electrical Insulation, v. 18, n. 6, p. 1835 -1846, dez. 2011.

GREENWALD, R.; STACKOWIAK, R.; STERN, J. Oracle Essentials: Oracle Database 11g. 4. ed. [s.I.] O'Reilly Media, 2007.

HASE, Y. Handbook of Power System Engineering. [s.I.] Wiley, 2007.

HILLERS, T.; BEIERL, O. Control, monitoring and diagnostics for high voltage GIS. In: GIS (Gas-Insulated Switchgear) at Transmission and Distribution Voltages, IEE Colloquium on (Digest No.1995/203). Anais nov. 1995. 
IEEE Guide for Gas-Insulated Substations. IEEE Std C37.122.1-1993, p. i, 1994.

IEEE Guide for Sulphur Hexafluoride (SF6) Gas Handling for High-Voltage (over 1000 Vac) Equipment. IEEE Std C37.122.3-2011, p. 1 -69, 2012.

INTERNATIONAL COUNCIL ON LARGE ELECTRIC SYSTEMS (CIGRE). SF6 Recycling Guide.Task Force 23.10.01, v. 117, 1997.

INTERNATIONAL COUNCIL ON LARGE ELECTRIC SYSTEMS (CIGRE). SF6 Tightness Guide. [S.I: s.n.], 2010. v. 430.

JABIRI, Z. N.; SHARAFI, D. Reducing SF6 emission from HV circuit breakers - A life cycle approach. In: Power and Energy Engineering Conference (APPEEC), 2010 Asia-Pacific. Anais mar. 2010.

KUMAR, G. V. N.; AMARNATH, J.; SINGH, B. P. Behavior of metallic particles in a single phase gas insulated system with dielectric coated electrodes. In: International Conference on Condition Monitoring and Diagnosis, 2008. CMD 2008. Anais abr. 2008.

MAHNKE, W.; LEITNER, S.-H.; DAMM, M. OPC Unified Architecture. [s.I.] Springer, 2009.

MCDONALD, J. D. (ED.). Electric Power Substations Engineering. 2. ed. [s.I.] CRC Press, 2007.

OGIBOSKI, L. et al. Real time system to monitor SF6 leakage and quality of gas in a gas insulated substation. In: PowerTech, 2011 IEEE Trondheim. Anais jun. 2011. 
OGIBOSKI, L. et al.Sistema de monitoramento de tempo real para prevenção de vazamentos e qualidade do SF6 em uma subestação isolada a gás. In: IV CITENEL - Congresso de Inovação Tecnológica em Energia Elétrica, 2011, Fortaleza-CE. IV CITENEL - Anais 2011.

OGIBOSKI, L. et al. Development and installation of a data acquisition and monitoring system to gas insulated substation. In: 2012 13th International Conference on Optimization of Electrical and Electronic Equipment (OPTIM). Anais maio. 2012.

O'CONNELL, P.et al. SF6 in the electric industry, Status 2000. Electra, n. 200, p. 16$25,2002$.

PITTOCK, A. B. Climate change: the science, impacts and solutions. 2. ed. [s.I.] Routledge, 2009.

TSAI, W.-T. The decomposition products of sulfur hexafluoride (SF6): Reviews of environmental and health risk analysis. Journal of Fluorine Chemistry, v. 128, n. 11, p. 1345-1352, nov. 2007.

$\mathrm{XU}$, Y. et al. Study on Detection of SF6 Gas Leakage Based on Photoacoustic Spectrometry. In: International Conference on Measuring Technology and Mechatronics Automation, 2009. ICMTMA '09. Anais ICMTMA '09. abr. 2009.

YUANYUAN, W. et al. Study on SF6 gas decomposition products of typical GIS defect models by infrared detection. In: 2011 1st International Conference on Electric Power Equipment - Switching Technology (ICEPE-ST). Anais out. 2011.

ZAMBON, G.; SEKLER, M. Beginning JSP, JSF and Tomcat Web Development: From Novice to Professional. [s.l.] Apress, 2007. 
ZHENGZHENG, T. et al. A new method for SF6 gas leakage detection. In: 2010 5th International Conference on Computer Science and Education (ICCSE). Anais ago. 2010. 